\title{
Surveillance of Vaccination Coverage Among Adult Populations - United States, 2014
}

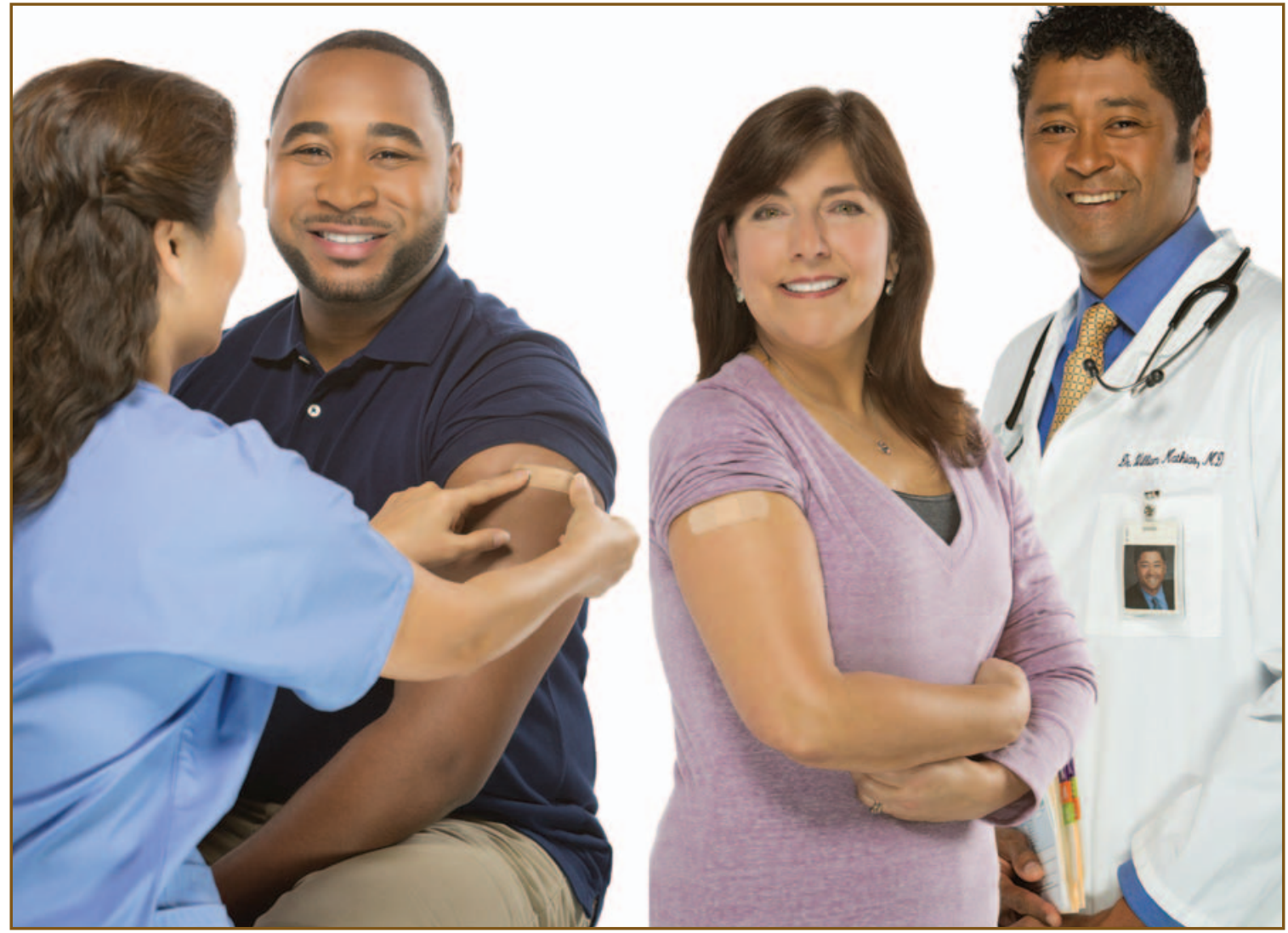




\section{CONTENTS}

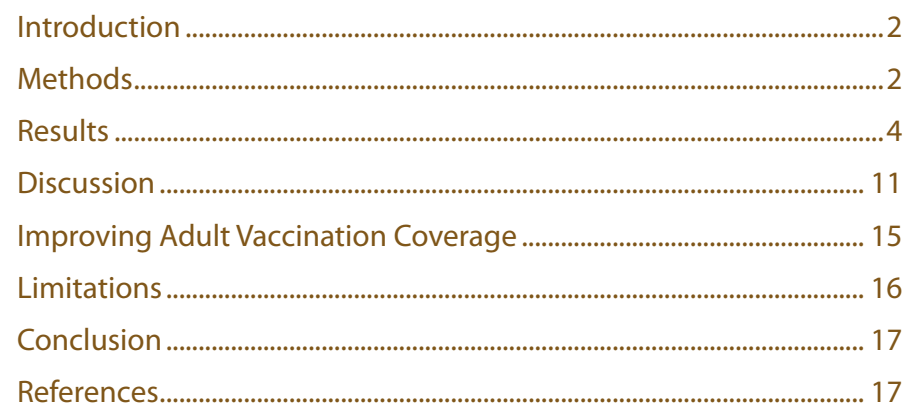

Front cover photo: The composite photograph on the cover shows two health care providers with patients who have received vaccination.

The MMWR series of publications is published by the Center for Surveillance, Epidemiology, and Laboratory Services, Centers for Disease Control and Prevention (CDC), U.S. Department of Health and Human Services, Atlanta, GA 30329-4027.

Suggested citation: [Author names; first three, then et al., if more than six.] [Title]. MMWR Surveill Summ 2016;65(No. SS-\#):[inclusive page numbers].

\section{Centers for Disease Control and Prevention}

Thomas R. Frieden, MD, MPH, Director

Harold W. Jaffe, MD, MA, Associate Director for Science

Joanne Cono, MD, ScM, Director, Office of Science Quality

Chesley L. Richards, MD, MPH, Deputy Director for Public Health Scientific Services

Michael F. Iademarco, MD, MPH, Director, Center for Surveillance, Epidemiology, and Laboratory Services

\section{MMWR Editorial and Production Staff (Serials)}

Sonja A. Rasmussen, MD, MS, Editor-in-Chief

Charlotte K. Kent, $\mathrm{PhD}$, MPH, Executive Editor

Christine G. Casey, MD, Editor

Teresa F. Rutledge, Managing Editor

David C. Johnson, Lead Technical Writer-Editor

Jeffrey D. Sokolow, MA, Project Editor

Timothy F. Jones, MD, Chairman

Matthew L. Boulton, MD, MPH

Virginia A. Caine, MD

Katherine Lyon Daniel, $\mathrm{PhD}$

Jonathan E. Fielding, MD, MPH, MBA

David W. Fleming, MD
Martha F. Boyd, Lead Visual Information Specialist Maureen A. Leahy, Julia C. Martinroe, Stephen R. Spriggs, Moua Yang, Tong Yang, Visual Information Specialists Quang M. Doan, MBA, Phyllis H. King, Teresa C. Moreland, Terraye M. Starr, Information Technology Specialists

MMWR Editorial Board

William E. Halperin, MD, DrPH, MPH

Jeff Niederdeppe, $\mathrm{PhD}$

King K. Holmes, MD, PhD

Robin Ikeda, MD, MPH

Rima F. Khabbaz, MD

Phyllis Meadows, PhD, MSN, RN

Jewel Mullen, MD, MPH, MPA
Patricia Quinlisk, MD, MPH

Patrick L. Remington, MD, MPH Carlos Roig, MS, MA

William L. Roper, MD, MPH

William Schaffner, MD 


\title{
Surveillance of Vaccination Coverage Among Adult Populations - United States, 2014
}

\author{
Walter W. Williams, $\mathrm{MD}^{1}$ \\ Peng-Jun $\mathrm{Lu}, \mathrm{MD}, \mathrm{PhD}^{1}$ \\ Alissa O'Halloran, $\mathrm{MSPH}^{1}$ \\ David K. Kim, $\mathrm{MD}^{1}$ \\ Lisa A. Grohskopf, $\mathrm{MD}^{2}$ \\ Tamara Pilishvili, $\mathrm{MPH}^{3}$ \\ Tami H. Skoff, MS 3 \\ Noele P. Nelson, MD, $\mathrm{PhD}^{4}$ \\ Rafael Harpaz, MD 5 \\ Lauri E. Markowitz, $\mathrm{MD}^{6}$ \\ Alfonso Rodriguez-Lainz, PhD, $\mathrm{DVM}^{7}$ \\ Carolyn B. Bridges, $\mathrm{MD}^{1}$ \\ ${ }^{1}$ Immunization Services Division, National Center for Immunization and Respiratory Diseases, CDC \\ ${ }^{2}$ Influenza Division, National Center for Immunization and Respiratory Diseases, CDC \\ ${ }^{3}$ Division of Bacterial Diseases, National Center for Immunization and Respiratory Diseases, CDC \\ ${ }^{4}$ Division of Viral Hepatitis, National Center for HIVIAIDS, Viral Hepatitis, STD, and TB Prevention, CDC \\ ${ }^{5}$ Division of Viral Diseases, National Center for Immunization and Respiratory Diseases, CDC \\ ${ }^{6}$ Division of Sexually Transmitted Disease Prevention, National Center for HIVIAIDS, Viral Hepatitis, STD, and TB Prevention, CDC \\ ${ }^{7}$ Division of Global Migration and Quarantine, National Center for Emerging and Zoonotic Infectious Diseases, CDC
}

\begin{abstract}
Problem/Condition: Overall, the prevalence of illness attributable to vaccine-preventable diseases is greater among adults than among children. Adults are recommended to receive vaccinations based on their age, underlying medical conditions, lifestyle, prior vaccinations, and other considerations. Updated vaccination recommendations from CDC are published annually in the U.S. Adult Immunization Schedule. Despite longstanding recommendations for use of many vaccines, vaccination coverage among U.S. adults is low.
\end{abstract}

Reporting Period: August 2013-June 2014 (for influenza vaccination) and January-December 2014 (for pneumococcal, tetanus and diphtheria [Td] and tetanus and diphtheria with acellular pertussis [Tdap], hepatitis A, hepatitis B, herpes zoster, and human papillomavirus [HPV] vaccination).

Description of System: The National Health Interview Survey (NHIS) is a continuous, cross-sectional national household survey of the noninstitutionalized U.S. civilian population. In-person interviews are conducted throughout the year in a probability sample of households, and NHIS data are compiled and released annually. The survey objective is to monitor the health of the U.S. population and provide estimates of health indicators, health care use and access, and health-related behaviors.

Results: Compared with data from the 2013 NHIS, increases in vaccination coverage occurred for Tdap vaccine among adults aged $\geq 19$ years (a 2.9 percentage point increase to $20.1 \%$ ) and herpes zoster vaccine among adults aged $\geq 60$ years (a 3.6 percentage point increase to $27.9 \%$ ). Aside from these modest improvements, vaccination coverage among adults in 2014 was similar to estimates from 2013 (for influenza coverage, similar to the 2012-13 season). Influenza vaccination coverage among adults aged $\geq 19$ years was $43.2 \%$. Pneumococcal vaccination coverage among high-risk persons aged $19-64$ years was $20.3 \%$ and among adults aged $\geq 65$ years was $61.3 \%$. Td vaccination coverage among adults aged $\geq 19$ years was $62.2 \%$. Hepatitis A vaccination coverage among adults aged $\geq 19$ years was $9.0 \%$. Hepatitis B vaccination coverage among adults aged $\geq 19$ years was $24.5 \%$. HPV vaccination coverage among adults aged $19-26$ years was $40.2 \%$ for females and $8.2 \%$ for males. Racial/ethnic differences in coverage persisted for all seven vaccines, with higher coverage generally for whites compared with most other groups. Adults without health insurance were significantly less likely than those with health insurance to report receipt of influenza vaccine (aged $\geq 19$ years), pneumococcal vaccine (aged 19-64 years with high-risk conditions and aged $\geq 65$ years), Td vaccine (aged $\geq 19$ years), Tdap vaccine (aged $\geq 19$ years and 19-64 years), hepatitis A vaccine (aged $\geq 19$ years overall and among travelers), hepatitis B vaccine (aged $\geq 19$ years, $19-49$ years, and $19-59$ years with diabetes),

Corresponding author: Walter W. Williams, Immunization Services Division, National Center for Immunization and Respiratory Diseases, CDC. Telephone: 404-718-8734; E-mail: www1@cdc.gov. herpes zoster vaccine (aged $\geq 60$ years and 60-64 years), and HPV vaccine (females aged 19-26 years and males aged 19-26 years). Adults who reported having a usual place for 
health care generally were more likely to receive recommended vaccinations than those who did not have a usual place for health care, regardless of whether they had health insurance. Vaccination coverage was significantly higher among those reporting one or more physician contacts in the past year compared with those who had not visited a physician in the past year, regardless of whether they had health insurance. Even among adults who had health insurance and $\geq 10$ physician contacts within the past year, $23.8 \%-88.8 \%$ reported not having received vaccinations that were recommended either for all persons or for those with some specific indication. Overall, vaccination coverage among U.S.-born respondents was significantly higher than that of foreign-born respondents with few exceptions (influenza vaccination [adults aged 19-49 years], hepatitis A vaccination [adults aged $\geq 19$ years], hepatitis B vaccination [adults with diabetes aged $\geq 60$ years], and HPV vaccination [males aged 19-26 years]).

Interpretation: Overall, increases in adult vaccination coverage are needed. Although modest gains occurred in Tdap vaccination coverage among adults aged $\geq 19$ years and herpes zoster vaccination coverage among adults aged $\geq 60$ years, coverage for other vaccines and risk groups did not improve, and racial/ethnic disparities persisted for routinely recommended adult vaccines. Coverage for all vaccines for adults remained low, and missed opportunities to vaccinate adults continued. Although having health insurance coverage and a usual place for health care are associated with higher vaccination coverage, these factors alone do not assure optimal adult vaccination coverage.

Public Health Actions: Assessing associations with vaccination is important for understanding factors that contribute to low coverage rates and to disparities in vaccination, and for implementing strategies to improve vaccination coverage. Practices that have been demonstrated to improve vaccination coverage should be used. These practices include assessment of patients' vaccination indications by health care providers and routine recommendation and offer of needed vaccines to adults, implementation of reminder-recall systems, use of standing-order programs for vaccination, and assessment of practice-level vaccination rates with feedback to staff members. For vaccination to be improved among those least likely to be up-to-date on recommended adult vaccines, efforts also are needed to identify adults who do not have a regular provider or insurance and who report fewer health care visits.

\section{Introduction}

Overall, the prevalence of illness attributable to vaccinepreventable diseases is greater among adults aged $\geq 19$ years than among children aged $\leq 12$ years $(1-4)$. The prevalence of illness among older persons is especially high. For example, in recent years, an estimated $50 \%-70 \%$ of the average 226,000 annual influenza-related hospitalizations, $80 \%-90 \%$ of the 3,000-49,000 influenza-related deaths (data available at http:// www.cdc.gov/flu/about/disease/65over.htm), and approximately half of the 13,500 cases of invasive pneumococcal disease (IPD) in the United States occurred among persons aged $\geq 65$ years (1-3). The lifetime risk for herpes zoster (also known as shingles) is approximately $30 \%$, with the risk increasing with age (4). Vaccinations are recommended throughout a person's lifetime to prevent vaccine-preventable diseases and their sequelae. However, adult vaccination coverage remains low for most routinely recommended vaccines (5) and below Healthy People 2020 targets (https://www.healthypeople.gov/2020/topics-objectives/topic/ immunization-and-infectious-diseases/objectives).

Many factors contribute to low adult vaccination rates, including limited public awareness about adult vaccinations, misinformation about vaccines, lack of vaccine requirements for adults, gaps in incorporation of routine vaccine needs assessment and recommendations for adults during health care visits, the cost of stocking vaccines and providing vaccination services, inadequate and/or inconsistent payment for vaccines and vaccine administration, complexities in how adult vaccinations are paid for by private as well as public insurers, lack of health insurance and limited funding for programs to vaccinate uninsured adults, and acute medical care taking precedence over preventive services (6-14). In October 2015, the Advisory Committee on Immunization Practices (ACIP) approved the adult immunization schedule for 2016 (15). With the exception of influenza vaccination, which is recommended for all adults each year, other adult vaccinations are recommended for specific populations based on a person's age, health conditions, behavioral risk factors (e.g., injection drug use), occupation, travel, and other indications (15).

This report represents the first comprehensive release of adult vaccination coverage data to include assessment of associations with expanded data on demographic characteristics of respondents including access to health care. These findings can be used by public health practitioners, adult vaccination providers, and the general public to better understand factors that contribute to low vaccination and modify strategies and interventions to improve vaccination coverage.

\section{Methods}

To assess vaccination coverage among adults aged $\geq 19$ years for selected vaccines and factors associated with vaccination, CDC analyzed data from the 2014 National Health Interview Survey (NHIS); for influenza coverage, data from the 2013 NHIS (August-December) also were used. This report 
highlights results of that analysis for influenza, pneumococcal, tetanus toxoid-containing (tetanus and diphtheria vaccine [Td] or tetanus and diphtheria with acellular pertussis vaccine [Tdap]), hepatitis $A$, hepatitis $B$, herpes zoster (shingles), and human papillomavirus (HPV) vaccines by selected demographic and access-to-care characteristics (e.g., age, race/ethnicity, vaccination indication, health insurance status, contacts with physicians, nativity and citizenship). Estimates of influenza vaccination coverage using 2014-15 season data from other sources have been published (16-18). The attributes, strengths, and limitations of each of these data sources have been described (19). Proportions were estimated of adults aged $\geq 19$ years who received selected vaccinations during 2010-2014. Additional information on NHIS methods is available at http://www.cdc.gov/nchs/nhis/methods.htm.

\section{Data Source and Collection}

NHIS collects information about the health and health care of the noninstitutionalized U.S. civilian population using nationally representative samples. Face-to-face interviews are conducted by the U.S. Census Bureau for CDC's National Center for Health Statistics. Questions about receipt of vaccinations recommended for adults are asked of one randomly selected adult within each family in the household. Respondents were asked if they had received an influenza shot or nasal spray in the past 12 months and if so, in which month and year. Respondents were asked if they had ever had a pneumonia shot. The proportion of pneumococcal vaccination by type of vaccine (23-valent pneumococcal polysaccharide vaccine or 13 -valent pneumococcal conjugate vaccine) was not measured. The presence of selected high-risk conditions as defined by ACIP for pneumococcal disease (Box) (15) was determined by responses to questions in NHIS. Respondents were asked if they had received a tetanus shot in the past 10 years. Respondents who had received a tetanus shot in the past 10 years were asked if their most recent shot was received in 2005 or later. Respondents who had received a tetanus shot since 2005 were asked if they were told that their most recent tetanus shot included the pertussis or whooping cough vaccine. Respondents were asked if they had ever received the hepatitis A vaccine, and if yes, how many doses were received. Respondents were asked if they had ever received the hepatitis B vaccine, and if yes, whether they had received $\geq 3$ doses or $<3$ doses. For hepatitis A and hepatitis B vaccination, data were collected on selected respondent characteristics that increase the risk for infection (travel to countries in which hepatitis A infections are endemic and having chronic liver disease, having diabetes, travel to countries in which hepatitis B infections are endemic, and having chronic liver disease, respectively). Respondents were asked if they had ever received a shingles vaccine and if they had ever received an HPV shot or cervical cancer vaccine, and if yes, age at the first dose.

Vaccination outcomes and demographic and other characteristics (e.g., health conditions, insurance status, and usual source and frequency of health care) are self-reported. Race/ethnicity was categorized as Hispanic or Latino, black, white, Asian, and "other." Persons identified as Hispanic or Latino might be of any race. Persons identified as black, white, Asian, or other race are non-Hispanic. "Other" includes American Indian/Alaska Native and multiple race. The five racial/ethnic categories are mutually exclusive. Adults were classified as health care personnel (HCP) if they reported that they currently volunteer or work in a hospital, medical clinic, doctor's office, dentist's office, nursing home, or some other health care facility including part-time and unpaid work in a health care facility as well as professional nursing care provided in the home. Adults were considered insured if they reported having public health insurance coverage (Medicare, Medicaid, military health care [TRICARE/VA/CHAMP-VA], Indian Health Service, state-sponsored health plan, or other government program insurance) or private health insurance coverage. Respondents were asked if there is a place to which they usually go when sick or need advice on their health. Respondents answering "yes" were defined as having a usual place for health care.

BOX. Selected high-risk conditions for pneumococcal disease as defined by the Advisory Committee on Immunization Practices

Adults were considered at high risk for pneumococcal disease or its complications if they

- had ever been told by a doctor or other health professional that they had diabetes, emphysema, chronic obstructive pulmonary disease, coronary heart disease, angina, heart attack, or other heart condition;

- had a diagnosis of cancer during the previous 12 months (excluding nonmelanoma skin cancer);

- had ever been told by a doctor or other health professional that they had lymphoma, leukemia, or blood cancer;

- had been told by a doctor or other health professional that they had chronic bronchitis or weak or failing kidneys during the preceding 12 months;

- had an asthma episode or attack during the preceding 12 months; or

- were current smokers.

Source: CDC. Advisory Committee on Immunization Practices recommended immunization schedule for adults aged 19 years and older-United States, 2016. MMWR Morb Mortal Wkly Rep 2016. In press. 


\section{Analysis}

For the noninfluenza adult vaccination coverage estimates, the weighted proportion of respondents who reported receiving selected vaccinations was calculated. To better assess influenza vaccination coverage for the 2013-14 influenza season, CDC restricted reported coverage to persons who were interviewed during August 2013-June 2014 and vaccinated during July 2013-May 2014, using the Kaplan-Meier survival analysis procedure; 2013 NHIS data for August-December 2013 were used. Differences were measured as the simple difference between the 2012-13 and 2013-14 influenza seasons. Data for missing month and year $(3.1 \%)$ were imputed.

To assess adjusted vaccination coverage and adjusted prevalence ratios for each vaccine, CDC used logistic regression and predicted marginal modeling for selected comparisons (health insurance status). Estimates were adjusted for age, sex, race/ethnicity, marital status, education, employment status, poverty level, number of physician contacts in the past year, usual source of health care, self-reported health status, nativity, and region of residence. Income-to-poverty ratio variables are included in the NHIS public use data file (http://www. cdc.gov/nchs/nhis/nhis_2014_data_release.htm). Poverty thresholds were defined according to family size using weighted average Census poverty thresholds from 2012, the average Consumer Price Index from 2012, actual Consumer Price Index values for January-July 2013, and projected Consumer Price Index values for August-December 2013 (ftp://ftp.cdc. gov/pub/Health_Statistics/NCHS/Dataset_Documentation/ NHIS/2014/srvydesc.pd).

Weighted data were used to produce national vaccination coverage estimates. Point estimates and 95\% confidence intervals (CIs) were calculated by using statistical software to account for the complex sample design. $T$ tests were used for comparisons by race/ethnicity (with non-Hispanic white as the reference), for comparisons between 2014 and 2013, and comparisons of covariates to the reference group within each level of each characteristic (e.g., age group, health care personnel status, patient care status, access-to-care factors, nativity, years of residence in the United States, and citizenship status). For influenza vaccination, tests for linear trend were performed using a weighted linear regression on the seasonspecific estimates, using season number as the independent variable and weights as the inverse of the estimated variance of the estimated vaccination coverage. For vaccination with the other vaccines, tests for linear trend were performed in SUDAAN using the RATIO procedure. Statistical significance was defined as $\mathrm{p}<0.05$. Coverage estimates are not reported for small sample size $(\mathrm{n}<30)$ or relative standard error (standard error/estimates) $>0.3$.

\section{Results}

The final sample adult component response rate for the 2014 NHIS was $58.9 \%$. The total adult sample was 36,324 persons aged $\geq 19$ years. The final sample adult component response rates for estimating influenza vaccination coverage for the 2013-14 influenza season were $61.2 \%$ for 2013 and $58.9 \%$ for 2014, respectively. The total adult sample for influenza coverage estimation was 32,296 persons aged $\geq 19$ years.

\section{Influenza Vaccination Coverage}

Influenza vaccination coverage for the 2013-14 season among adults aged $\geq 19$ years was $43.2 \%$, similar to the NHIS estimate from the 2012-13 season (Table 1). Coverage among whites aged $\geq 19$ years was higher $(46.7 \%)$ than that for blacks (36.5\%), Hispanics (33.2\%) and those reporting other race (38.6\%). Influenza coverage was $31.5 \%$ among adults aged 19-49 years and $47.7 \%$ among adults aged 50-64 years. Coverage among adults aged $\geq 65$ years $(71.5 \%)$ was higher compared with younger age groups. Among HCP aged $\geq 19$ years, influenza vaccination coverage overall was $65.4 \%$, similar to the estimate for 2013 (Table 2). Among HCP aged $\geq 19$ years with and without direct patient care responsibilities, influenza vaccination coverage was $65.1 \%$ and $66.0 \%$, respectively, similar to 2013 estimates (Table 3). Coverage was $74.8 \%$ for Hispanic HCP aged $\geq 19$ years with direct patient care responsibilities, a 20.8 percentage point increase compared with the 2013 estimate. However, influenza vaccination coverage among HCP with direct patient care responsibilities was similar across all racial/ethnic groups (Table 3). During the 2009-10 through the 2013-14 influenza seasons, fewer than half of adults aged $\geq 19$ years were vaccinated (range: $37.2 \%-43.2 \%$ ) (Figures 1 and 2); $56.6 \%-67.3 \%$ of HCP reported influenza vaccination (Figure 2 ).

\section{Pneumococcal Vaccination Coverage}

Reported pneumococcal vaccination coverage (23-valent pneumococcal polysaccharide vaccine [PPSV23] and 13-valent pneumococcal conjugate vaccine [PCV13]) among adults aged 19-64 years at high risk was $20.3 \%$ overall, similar to the estimate from 2013 (Table 1). Coverage among whites aged 19-64 years at high risk was higher $(21.1 \%)$ compared with Hispanics (16.4\%) and Asians (14.6\%) but was not significantly different for blacks $(20.2 \%)$ and persons reporting other race (25.3\%) compared with whites. Among adults aged $\geq 65$ years, coverage was $61.3 \%$ overall, similar to the estimate for 2013 . Coverage among whites aged $\geq 65$ years $(64.7 \%)$ was higher compared with blacks (49.8\%), Hispanics (45.2\%), and Asians (47.7\%) (Table 1). During 2010-2014, pneumococcal 
vaccination coverage among adults aged 19-64 years at high risk and adults aged $\geq 65$ years ranged from $18.5 \%-21.2 \%$ to $59.7 \%-62.3 \%$, respectively (Figures 1 and 2 ).

\section{Tetanus Vaccination Coverage}

In 2014, the proportion of adults reporting having received any tetanus toxoid-containing vaccination during the past 10 years was $62.2 \%$ overall for adults aged $\geq 19$ years, $62.6 \%$ for adults aged $19-49$ years, $64.7 \%$ for adults aged $50-64$ years, and $57.7 \%$ for adults aged $\geq 65$ years (Table 1 ). The proportion of adults receiving tetanus vaccination during the past 10 years across all age groups did not change compared with 2013. Whites had higher coverage across all age groups compared with blacks, Hispanics, and Asians. During 2010 2014 , tetanus vaccination among adults aged $\geq 19$ years was unchanged at approximately $62 \%$ (Figures 1 and 3 ).

Among adults aged $\geq 19$ years for whom Tdap vaccination specifically could be assessed, overall reported coverage in the past 9 years was $20.1 \%$, a 2.9 percentage point increase compared with 2013 (Table 1). Tdap coverage for black (11.6\%), Hispanic (12.4\%), and Asian (15.5\%) adults aged $\geq 19$ years was lower compared with whites $(23.8 \%)$. Coverage among adults aged $\geq 19$ years who reported living with an infant

FIGURE 1. Estimated proportion of adults aged $\geq 19$ years who received selected vaccines, ${ }^{*}$ by age group and high-risk status ${ }^{\dagger}-$ National Health Interview Survey, United States, 2010-2014

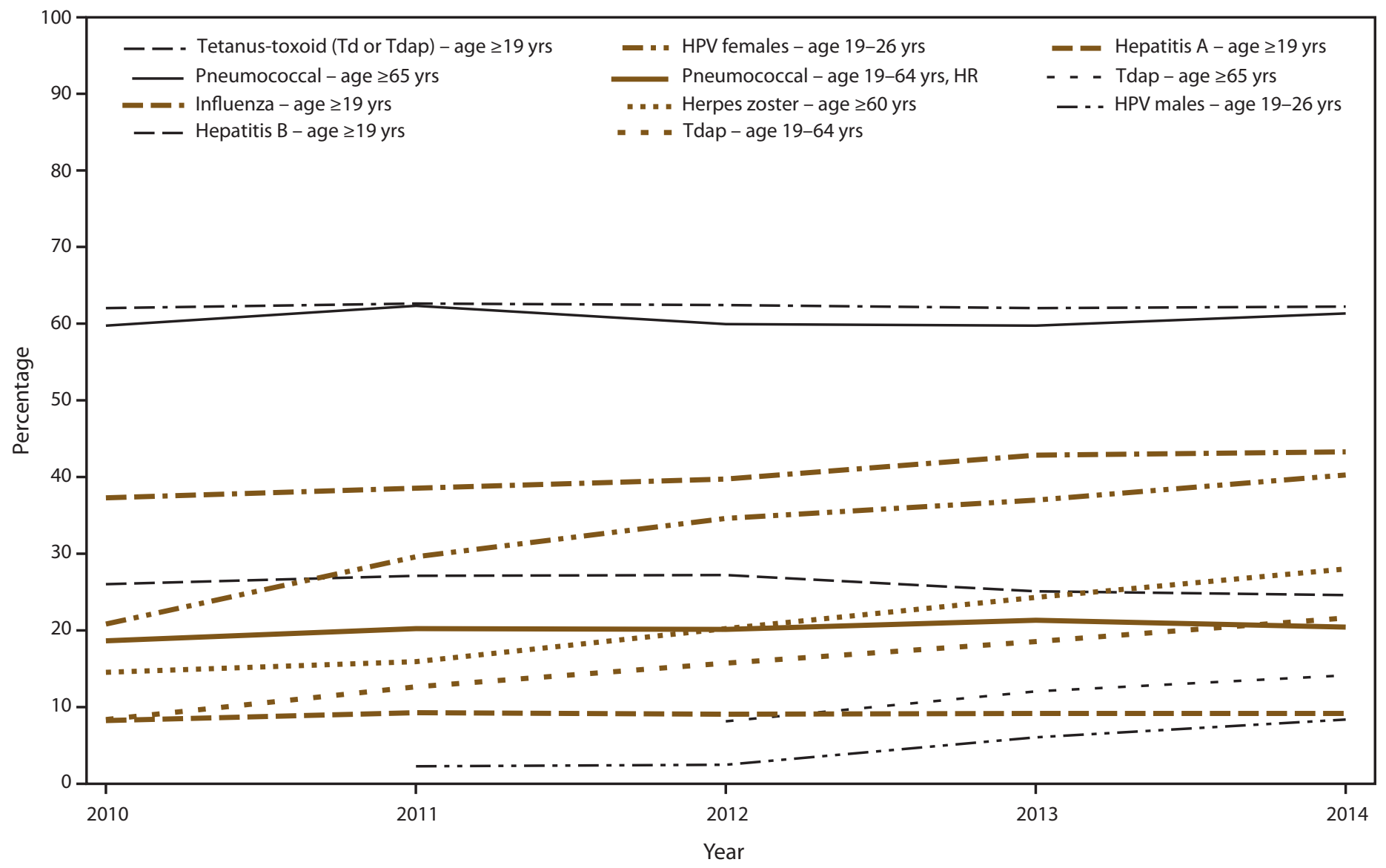

NOTE: Additional tables for this figure are available at http://stacks.cdc.gov/view/cdc/37407.

Abbreviations: $\mathrm{HPV}=$ human papillomavirus; $\mathrm{HR}=$ high risk; $\mathrm{Td}=$ tetanus-diphtheria toxoid; $\mathrm{Tdap}=$ tetanus, diphtheria, and acellular pertussis vaccine.

* Influenza vaccination coverage for 2010 is coverage from the 2009-10 season, 2011 is coverage from the 2010-11 season, 2012 is coverage from the $2011-12$ season, 2013 is coverage from the 2012-13 season, and 2014 is coverage from the 2013-14 season. Interviews from August through June of each season were used to estimate coverage from July through May using Kaplan Meier survival analysis. Tdap vaccination coverage data among adults aged $\geq 65$ years are available beginning in the NHIS 2012 survey. The 2010 HPV vaccination coverage estimate among males is suppressed due to relative standard error $>30 \%$.

† Adults were considered at high risk for pneumococcal disease if they had ever been told by a doctor or other health professional that they had diabetes, emphysema, chronic obstructive pulmonary disease (beginning in 2012), coronary heart disease, angina, heart attack, or other heart condition; had a diagnosis of cancer during the previous 12 months (excluding nonmelanoma skin cancer); had ever been told by a doctor or other health professional that they had lymphoma, leukemia, or blood cancer; had been told by a doctor or other health professional that they had chronic bronchitis or weak or failing kidneys during the preceding 12 months; had an asthma episode or attack during the preceding 12 months; or they were current smokers. 
FIGURE 2. Estimated proportion of adults* aged $\geq 19$ years who received influenza ${ }^{\dagger}$ and pneumococcal vaccines, by age group and high-risk status $^{\S}$ — National Health Interview Survey, United States, 2010-2014

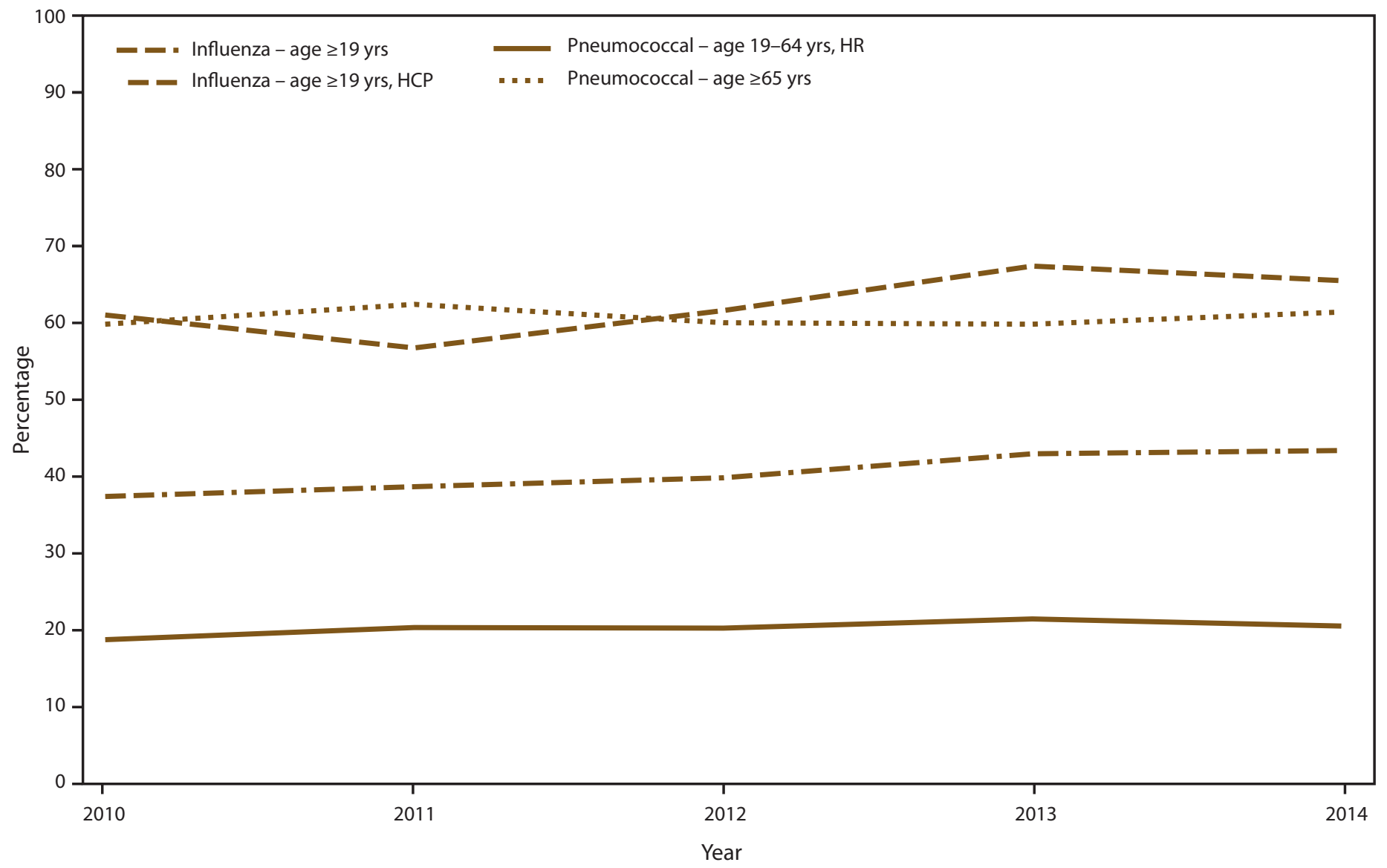

NOTE: Additional tables for this figure are available at http://stacks.cdc.gov/view/cdc/37407.

Abbreviations: $\mathrm{HCP}=$ health care personnel; $\mathrm{HR}=$ high risk.

* Adults were classified as health care personnel if they reported they currently volunteer or work in a hospital, medical clinic, doctor's office, dentist's office, nursing home or some other health-care facility including part-time and unpaid work in a health care facility as well as professional nursing care provided in the home.

† Influenza vaccination coverage for 2010 is coverage from the 2009-10 season, 2011 is coverage from the 2010-11 season, 2012 is coverage from the 2011-12 season, 2013 is coverage from the 2012-13 season, and 2014 is coverage from the 2013-14 season. Interviews from August through June of each season were used to estimate coverage from July through May using Kaplan Meier survival analysis.

$\S$ Adults were considered at high risk for pneumococcal disease if they had ever been told by a doctor or other health professional that they had diabetes, emphysema, chronic obstructive pulmonary disease (beginning in 2012), coronary heart disease, angina, heart attack, or other heart condition; had a diagnosis of cancer during the previous 12 months (excluding nonmelanoma skin cancer); had ever been told by a doctor or other health professional that they had lymphoma, leukemia, or blood cancer; had been told by a doctor or other health professional that they had chronic bronchitis or weak or failing kidneys during the preceding 12 months; had an asthma episode or attack during the preceding 12 months; or were current smokers.

aged $<1$ year* was $32.0 \%$, higher than the $19.6 \%$ coverage among adults aged $\geq 19$ years without household contact with an infant aged $<1$ year. During 2010-2014, Tdap vaccination coverage increased from $8.2 \%$ to $21.5 \%$ among adults aged 19-64 years, and during 2012-2014 increased from $8.0 \%$ to $14.0 \%$ among adults aged $\geq 65$ years (Figures 1 and 3 ).

Among 16,823 respondents who reported receiving a tetanus vaccination during 2005-2014, more than half (51.3\%)

\footnotetext{
${ }^{*}$ In 2006, a single dose of Tdap was recommended for adults who have or who anticipate having close contact with an infant aged $<1$ year (e.g., parents, grandparents, child care providers, and health care personnel) to reduce the risk for transmitting pertussis.
}

reported that they were not informed of the vaccination type, and $11.3 \%$ could not recall what type of tetanus vaccination they had received (Table 4). Of the remaining $37.4 \%$ of respondents who reported that they knew what type of tetanus vaccine they received, $70.1 \%$ reported receiving Tdap.

Overall Tdap vaccination of HCP aged $\geq 19$ years reported in 2014 was $42.1 \%$, similar to the estimate from 2013 (Table 2). White HCP had higher Tdap coverage (46.4\%) compared with black HCP (24.8\%) and Hispanic HCP (35.8\%). Among HCP aged $\geq 19$ years with direct patient care responsibilities, Tdap vaccination coverage was $47.5 \%$, similar to the 2013 estimate (Table 3). Black HCP with direct patient care responsibilities 
FIGURE 3. Estimated proportion of adults aged $\geq 19$ years who received a tetanus toxoid-containing vaccine (Td or Tdap) and proportion of those who received Tdap vaccine, by age group* — National Health Interview Survey, United States, 2010-2014

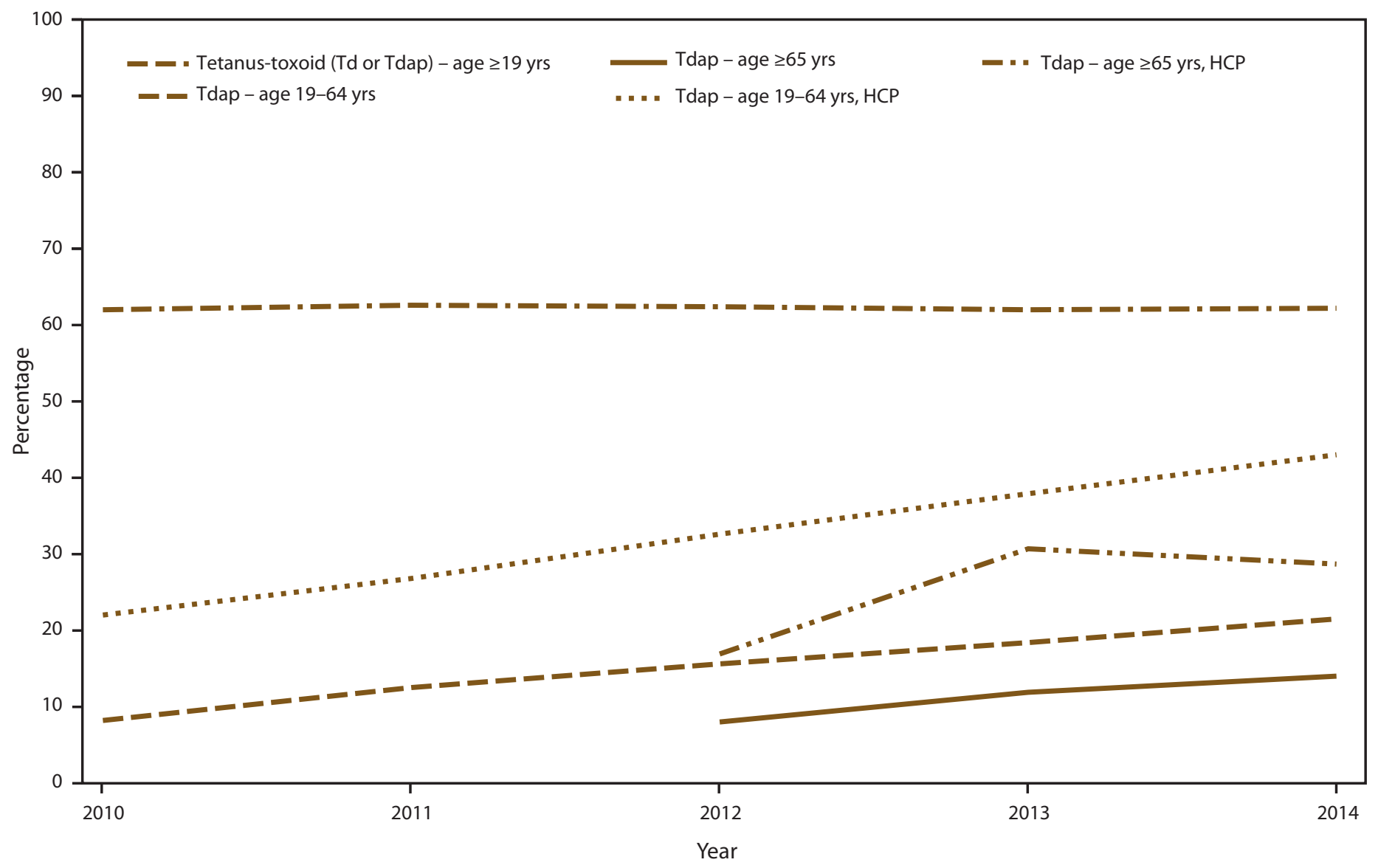

NOTE: Additional tables for this figure are available at http://stacks.cdc.gov/view/cdc/37407.

Abbreviations: $\mathrm{HCP}=$ health care personnel; $\mathrm{Td}=$ tetanus-diphtheria toxoid; $\mathrm{Tdap}=$ tetanus, diphtheria, and acellular pertussis vaccine.

* Tdap vaccination coverage data among adults aged $\geq 65$ years are available beginning in the NHIS 2012 survey.

had lower Tdap coverage (28.9\%) compared with white HCP (52.4\%), but coverage for HCP in the other racial/ethnic groups was similar to that for white HCP (Table 3). Tdap vaccination among HCP aged 19-64 years increased from $22.0 \%$ in 2010 to $43.0 \%$ in 2014 . Tdap vaccination among HCP aged $\geq 65$ years reported during 2012-2014 ranged from $16.9 \%$ to $30.7 \%$ (Figure 3 ). Among adults aged $\geq 19$ years who received a tetanus vaccination and reported that they knew what type of tetanus vaccine they received, HCP were more likely to report receipt of Tdap (80.6\%) than were non-HCP (68.0\%) (Table 4).

\section{Hepatitis A Vaccination Coverage}

In 2014, reported hepatitis A vaccination coverage ( $\geq 2$ doses) was $9.0 \%$ for adults aged $\geq 19$ years, $12.1 \%$ among adults aged $19-49$ years, and $5.5 \%$ among adults aged $\geq 50$ years, similar to the estimates for 2013 (Table 1). Among adults aged 19-49 years, coverage for Hispanics $(9.6 \%)$ was lower than that for whites $(12.7 \%)$. Vaccination coverage was higher among adults aged $\geq 19$ years who had traveled outside the United States since 1995 to a country in which hepatitis A is of high or intermediate endemicity (countries other than the countries of Europe, Japan, Australia, New Zealand, or Canada) than among respondents who did not travel outside the United States or had traveled only to countries in which the disease is of low endemicity $(16.0 \%$ versus $5.5 \%$, respectively). Vaccination coverage among adult travelers to countries with high or intermediate endemicity was similar to the estimate for 2013 (Table 1). Overall coverage among adults aged $\geq 19$ years with chronic liver conditions was $13.8 \%$, similar to the 2013 estimate. During 2010-2014 among adults aged $\geq 19$ years, hepatitis A vaccination among travelers to countries with high or intermediate endemicity, among nontravelers, and among persons with chronic liver conditions remained stable (range: $14.6 \%-16.2 \%, 5.1 \%-5.7 \%$, and $13.1 \%-14.9 \%$, respectively) (Figure 4 ). 


\section{Hepatitis B Vaccination Coverage}

Reported hepatitis B vaccination coverage ( $\geq 3$ doses) among adults was $24.5 \%$ for adults aged $\geq 19$ years, $32.2 \%$ among adults aged $19-49$ years, and $15.7 \%$ among adults aged $\geq 50$ years. Overall vaccination coverage among adults aged $\geq 19$ years was similar to the 2013 estimate (Table 1). Vaccination coverage was higher among adults aged $\geq 19$ years who had traveled outside the United States since 1995 to a country in which hepatitis B is of high or intermediate endemicity (countries other than the countries of Europe, Japan, Australia, New Zealand, or Canada) than among respondents who did not travel outside the United States or had traveled only to countries in which hepatitis B is of low endemicity (30.5\% versus $21.4 \%$, respectively). Among adults aged 19-49 years, vaccination coverage was lower for blacks (29.9\%) and Hispanics (20.2\%) compared with whites (36.3\%). Overall coverage among adults aged $\geq 19$ years with chronic liver conditions was $29.8 \%$, similar to the 2013 estimate. Vaccination coverage for persons with diabetes was $23.5 \%$ for those aged $19-59$ years and $13.5 \%$ for those aged $\geq 60$ years, similar to estimates for 2013 . Overall, hepatitis $\mathrm{B}$ vaccination coverage among $\mathrm{HCP}$ aged $\geq 19$ years was $60.7 \%$, similar to the estimate for 2013 . Black (51.4\%) and Hispanic HCP (51.1\%) had lower coverage compared with white HCP (63.0\%) (Table 2). Among HCP aged $\geq 19$ years with direct patient care responsibilities, hepatitis $\mathrm{B}$ vaccination coverage was $67.7 \%$, similar to the 2013 estimate (Table 3). Coverage for black HCP aged $\geq 19$ years with direct patient care responsibilities was lower (56.6\%) than that for white HCP with direct patient care responsibilities (70.9\%) (Table 3). During 2010-2014, among adults aged $\geq 19$ years, hepatitis $\mathrm{B}$ vaccination coverage among travelers to areas of high or intermediate endemicity, nontravelers, persons

FIGURE 4. Estimated proportion of adults aged $\geq 19$ years who received hepatitis $A$ and hepatitis $B$ vaccines, by age group and high-risk status — National Health Interview Survey, United States, 2010-2014

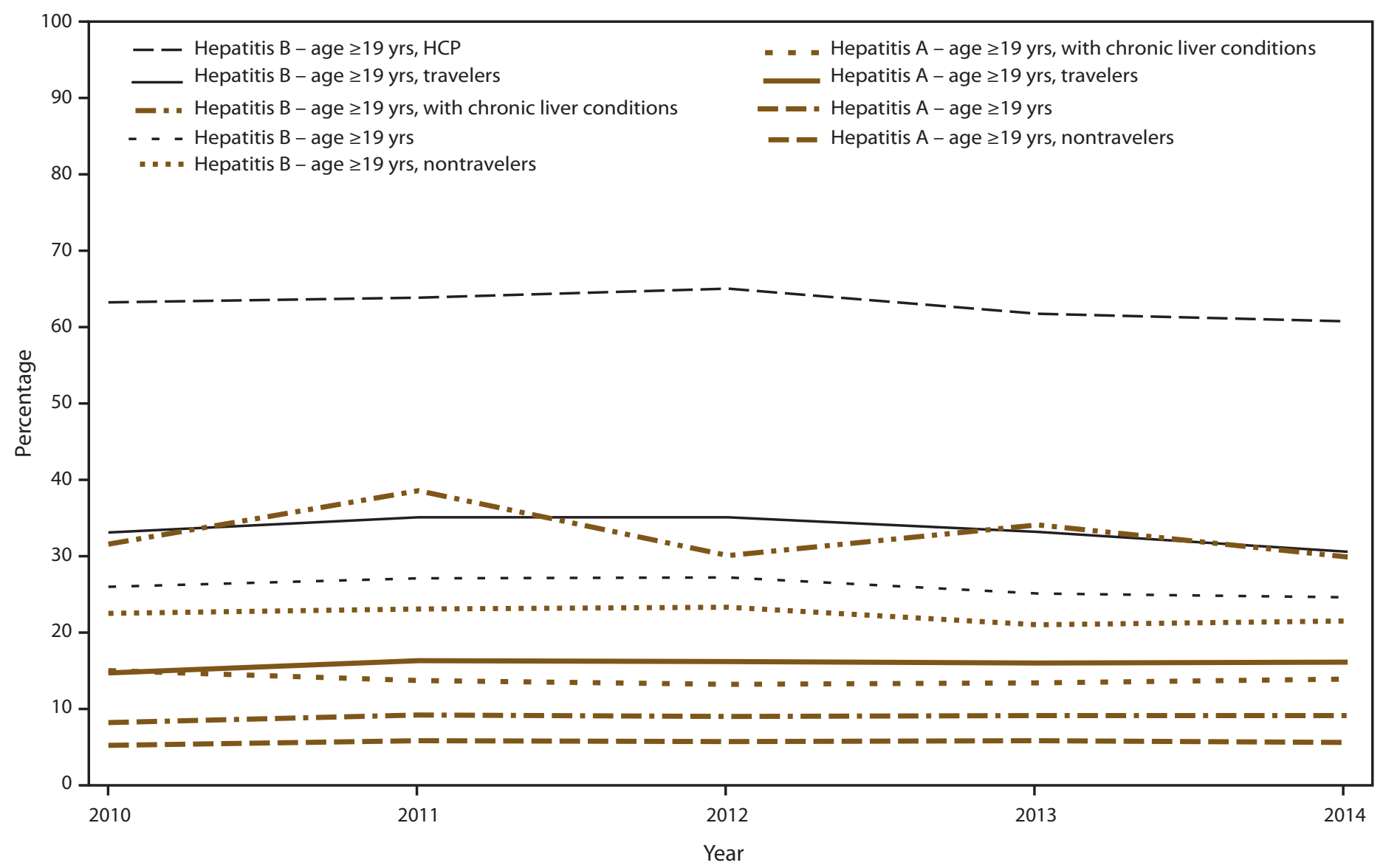

NOTE: Additional tables for this figure are available at http://stacks.cdc.gov/view/cdc/37407.

Abbreviations: $\mathrm{HCP}=$ health care personnel; travelers = persons who had traveled outside the United States to countries other than countries in Europe, Japan, Australia, New Zealand, or Canada since 1995; nontravelers = persons who had not traveled outside the United States to countries other than countries in Europe, Japan, Australia, New Zealand, or Canada since 1995. 
with chronic liver disease, and HCP varied (range: 30.5\%$35.0 \%, 20.9 \%-23.2 \%, 29.8 \%-38.5 \%$, and $60.7 \%-65.0 \%$, respectively (Figure 4).

\section{Herpes Zoster Vaccination Coverage}

In 2014, among adults aged $\geq 60$ years, $27.9 \%$ reported receiving herpes zoster vaccination to prevent shingles, an increase from the $24.2 \%$ reported in 2013 (Table 1). Whites aged $\geq 60$ years had higher herpes zoster vaccination coverage (32.0\%) compared with blacks (11.6\%), Hispanics (14.6\%), Asians (16.5\%), and those reporting other race (16.2\%). Among adults aged 60-64 years, 20.4\% reported receiving herpes zoster vaccination, with blacks $(8.1 \%)$ and Hispanics $(11.2 \%)$ reporting lower coverage compared with that for whites (24.3\%) (Table 1). Estimates were similar to those for 2013. Among adults aged $\geq 65$ years, $31.1 \%$ reported herpes zoster vaccination, a 4.3 percentage point increase compared with 2013. Whites aged $\geq 65$ years had higher herpes zoster vaccination coverage (35.0\%) compared with blacks (13.5\%), Hispanics (16.3\%), Asians (20.7\%), and those reporting other race $(19.6 \%)$ (Table 1$)$. Herpes zoster vaccination among adults aged $\geq 60$ years increased from $14.4 \%$ in 2010 to $27.9 \%$ in 2014 (Figures 1 and 5).

\section{HPV Vaccination Coverage}

In 2014, among women aged $19-26$ years, $40.2 \%$ reported receipt of $\geq 1$ dose of HPV vaccine, similar to the estimate reported for 2013 (Table 1). Coverage was $44.8 \%$ among women aged $19-21$ years, similar to the 2013 estimate. Coverage was $37.6 \%$ among those aged $22-26$ years, a 5.3 percentage point increase compared with the 2013 estimate. Among women aged 19-26 years, Hispanics $(28.1 \%)$ and Asians (22.8\%) had lower coverage compared with whites (46.3\%), but coverage for blacks (37.4\%) and adults who indicated other race $(47.3 \%)$ was similar to that for whites. Receipt of $\geq 1$ dose of HPV vaccine among males aged 19-26 years was $8.2 \%$, similar to the 2013 estimate. Coverage was $13.3 \%$ for males aged $19-21$ years, a 5.6 percentage point increase compared with the estimate from 2013. Coverage was $5.4 \%$ for those aged 22-26 years, similar to the 2013 estimate.

Among women aged $19-26$ years, $2.1 \%$ reported receiving the first dose of HPV vaccine at age $8-10$ years, $7.4 \%$ at age $11-12$ years, $58.1 \%$ at age $13-17$ years, $12.5 \%$ at age 18 years, and $19.9 \%$ at age $19-26$ years (Table 5 ). Among males aged 19-26 years, $13.0 \%$ reported receiving the first dose of HPV vaccine at age $8-10$ years, $3.5 \%$ at age $11-12$ years, $33.1 \%$ at age $13-17$ years, $24.4 \%$ at age 18 years, and $25.9 \%$ at

FIGURE 5. Estimated proportion of adults aged $\geq 19$ years who received herpes zoster and human papillomavirus* vaccines, by age group — National Health Interview Survey, United States, 2010-2014

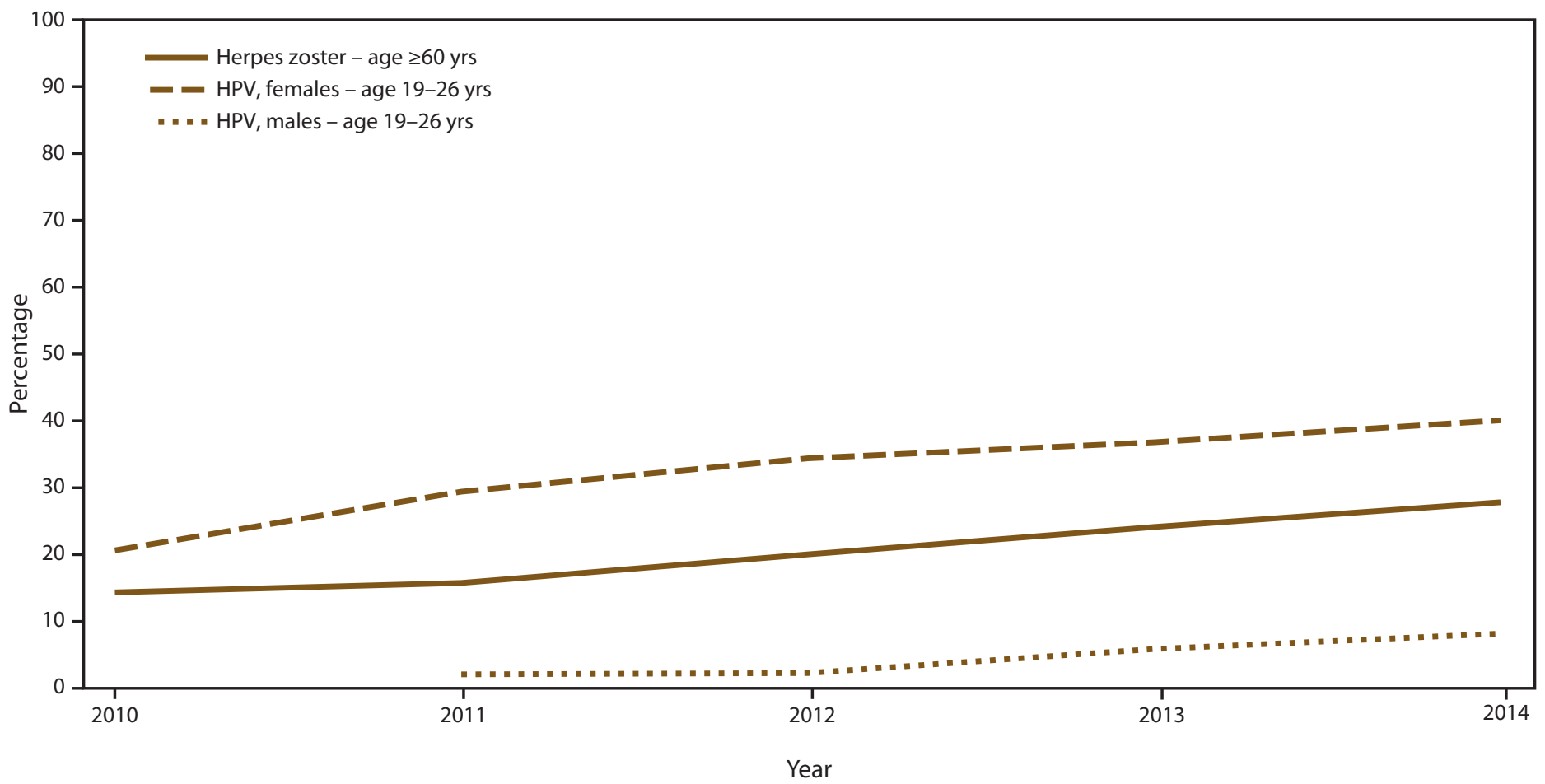

NOTE: Additional tables for this figure are available at http://stacks.cdc.gov/view/cdc/37407.

Abbreviation: $\mathrm{HPV}=$ human papillomavirus.

* The $2010 \mathrm{HPV}$ vaccination coverage estimate among males is suppressed due to relative standard error $>30 \%$. 
age 19-26 years. Among respondents aged 19-26 years, the difference between the age reported at the time of the interview and the age at which respondents indicated that the first dose of HPV vaccine was received was $\geq 10$ years for $7.1 \%$ of women and for $13.8 \%$ of males. This would imply receipt of vaccination in 2004 or earlier, before HPV vaccine was licensed for use in 2006. Among females and males aged 19-26 years who had not received HPV prior to age 19 years, $11.8 \%$ and $2.3 \%$ reported receiving the first dose of HPV vaccine at age 19-26 years, respectively (Table 1). Fewer Hispanic females aged $19-26$ years $(7.4 \%)$ reported receiving the first dose of HPV vaccine at age 19-26 years compared with white females aged 19-26 years (13.9\%) (Table 1). HPV vaccination increased from $20.7 \%$ in 2010 to $40.2 \%$ in 2014 for females aged $19-26$ years, and from $2.1 \%$ in 2011 to $8.2 \%$ in 2014 among males aged 19-26 years (Figures 1 and 5).

\section{Trends in Adult Vaccination Coverage}

Estimated proportions of adults aged $\geq 19$ years who received selected vaccinations during the period 2010-2014 are shown (Figures 1, 2, 3, 4, and 5). Although the point estimates for each year vary by only a few percentage points, linear trend tests indicated that influenza vaccination coverage significantly increased overall among persons aged $\geq 19$ years from the 2009-10 influenza season to the 2013-14 season (test for trend: $p=0.01$ ) (Figures 1 and 2). Influenza vaccination coverage did not increase significantly among HCP during this period (test for trend: $\mathrm{p}=0.17$ ) (Figure 2). During 2010-2014, pneumococcal vaccination coverage increased significantly only among high-risk persons aged 19-64 years (test for trend: $p=0.01$ ) (Figures 1 and 2). During 2010-2014, significant increases also occurred for Tdap vaccination overall among persons aged $\geq 19$ years (test for trend: $\mathrm{p}<0.01$ ) and among HCP aged 19-64 years and those aged $\geq 65$ years (tests for trend: $\mathrm{p}<0.01$ and 0.03 , respectively), herpes zoster vaccination of persons aged $\geq 60$ years (test for trend, $p<0.01$ ), and HPV vaccination of females and males aged 19-26 years (test for trend, $\mathrm{p}<0.01$ ) (Figures 1, 3, and 5). There was a significant downward trend for hepatitis $B$ vaccination among travelers to countries with high or intermediate endemicity and for nontravelers (test for trend: $\mathrm{p}<0.01$ ) (Figure 4). Coverage did not show statistically significant changes during 2010-2014 for the other vaccines routinely recommended for adult populations (pneumococcal vaccination [persons aged $\geq 65$ years] and overall tetanus vaccination [persons aged $\geq 19$ years]) (tests for trend: $p>0.05$ ) (Figure 1 ).

\section{Association of Health Insurance Status with Vaccination Coverage Among Adult Populations}

Most study respondents (86.7\%) indicated having some type of health insurance. Overall, vaccination coverage was lower among adults without health insurance compared with those with health insurance, except for overall hepatitis B vaccination among those aged $\geq 19$ years with chronic liver conditions or diabetes (Table 6). For influenza, pneumococcal, Tdap, herpes zoster, and HPV vaccination, coverage was two to five times higher among those with health insurance compared with those without insurance (Table 6).

Adult vaccination coverage differed by the type of health insurance. Vaccination coverage was higher among adults with private health insurance compared with those reporting public health insurance for pneumococcal vaccination among adults aged $\geq 65$ years, tetanus and Tdap vaccination (all ages), overall hepatitis A vaccination among adults aged $\geq 19$ years, hepatitis $B$ vaccination among adults aged $\geq 19$ years overall and those with diabetes aged $\geq 19$ years and $\geq 60$ years, and herpes zoster vaccination among adults aged $\geq 60$ years (Table 6). Vaccination coverage was significantly lower among adults with private insurance compared with those with public insurance for overall influenza vaccination among adults aged $\geq 19$ years and for pneumococcal vaccination among adults aged 19-64 years with high-risk conditions (Table 6).

\section{Association of Health Insurance Status and Having a Usual Place for Health Care with Vaccination Coverage}

Generally, adults with a usual place for health care were more likely to report having received recommended vaccinations than those who did not have a usual place for health care, regardless of whether they had health insurance. Among adults with health insurance, coverage was significantly higher among those who reported having a usual place for health care compared with those who did not have a usual place for health care except for hepatitis A vaccination and hepatitis B vaccination (Table 7). Among adults without health insurance, coverage was significantly higher among adults who had a usual place for health care compared with those who did not for influenza vaccination, pneumococcal vaccination among adults aged 19-64 years with high-risk conditions, and overall tetanus vaccination among adults aged $\geq 19$ years (Table 7 ). 


\section{Adult Vaccination Coverage by Health Insurance Status and Physician Contacts}

With a few exceptions (overall hepatitis A vaccination among adults aged $\geq 19$ years and HPV vaccination among women aged 19-26 years), vaccination coverage was significantly higher among those reporting having had one or more physician contacts in the past year compared with those who had not visited a physician in the past year, regardless of whether they had health insurance (Table 8). In addition, vaccination coverage generally increased as the number of physician contacts increased (Table 8).

Among adults who had health insurance and reported having had $\geq 10$ physician contacts within the past year, $23.8 \%-88.8 \%$ reported not receiving vaccinations that either are recommended for all persons or are recommended for those with some specific indication (not receiving influenza vaccination, 39.4\% [aged $\geq 19$ years], 51.4\% [aged 19-49 years], 38.3\% [aged 50-64 years], $23.8 \%$ [aged $\geq 65$ years]; not receiving pneumococcal vaccination, $61.4 \%$ [high-risk, aged 19-64 years], 29.3\% [aged $\geq 65$ years]; not receiving $\mathrm{Td}, 30.1 \%$ [aged $\geq 19$ years]; not receiving Tdap, 68.7\% [aged 19-64 years], 83.9\% [aged $\geq 65$ years]; hepatitis A, $82.4 \%$ [travelers aged $\geq 19$ years], $82.0 \%$ [persons aged $\geq 19$ years with chronic liver conditions]; hepatitis B, 62.9\% [travelers aged $\geq 19$ years], $67.1 \%$ [persons aged $\geq 19$ years with chronic liver conditions], $64.7 \%$ [adults aged 19-59 with diabetes], 88.8\% [adults aged $\geq 60$ years with diabetes]; herpes zoster, $67.7 \%$; and HPV, 51.6\% [women aged 19-26 years]) (Table 8).

\section{Association of Respondent Age with Adult Vaccination Coverage}

Influenza and pneumococcal vaccination coverage among adults aged $\geq 65$ years was higher compared with coverage among adults aged 19-64 years; however, Td and Tdap coverage among adults aged $\geq 65$ years was lower compared with coverage among adults aged $<65$ years. Hepatitis $B$ vaccination coverage among adults with diabetes aged $\geq 60$ years was lower compared with coverage among adults aged 19-59 years with diabetes (Tables 6, 7, and 8). Herpes zoster coverage among adults aged $\geq 65$ years was higher compared with coverage among adults aged 60-64 years (Table 6).

\section{Adult Vaccination Coverage Adjusted for Selected Demographic and Access to Care Characteristics}

Adults without health insurance were significantly less likely than those with health insurance to be vaccinated after adjusting for confounders for influenza (aged $\geq 19$ years); pneumococcal (aged 19-64 years with high-risk conditions); hepatitis B (aged $\geq 19$ years and 19-49 years); herpes zoster (aged $\geq 60$ years), and HPV (females aged 19-26 years) vaccination (Table 9). The difference in adjusted vaccination coverage between respondents with and without health insurance for those for whom the difference was statistically significant ranged from $2.9 \%$ (hepatitis B vaccination among adults aged $\geq 19$ years) to $13.3 \%$ (influenza vaccination among adults aged $\geq 19$ years) (Table 9 ).

\section{Adult Vaccination Coverage by Nativity, Years Living in the United States, and Citizenship}

Overall, vaccination coverage among U.S.-born respondents was significantly higher than that of foreign-born respondents with few exceptions (Table 10). Exceptions were noted for influenza vaccination (adults aged 19-49 years), overall hepatitis A vaccination (adults aged $\geq 19$ years), hepatitis B vaccination among adults with diabetes aged $\geq 19$ years and those aged $\geq 60$ years, and HPV vaccination of males aged 19-26 years. Vaccination coverage was higher for foreignborn persons living in the United States $\geq 10$ years compared with those in the United States $<10$ years for influenza vaccination (overall for persons aged $\geq 19$ years and adults aged $\geq 65$ years). Vaccination coverage was significantly lower for foreign-born persons living in the United States $\geq 10$ years compared with those living in the United States $<10$ years for hepatitis A vaccination (adults aged $\geq 19$ years overall), and hepatitis B vaccination (among adults $\geq 19$ years overall and those aged $\geq 19$ years with diabetes). Except for pneumococcal vaccination of adults aged $\geq 65$ years, $T d$ vaccination of adults aged $\geq 65$ years, hepatitis $A$ vaccination, hepatitis $B$ vaccination among adults with diabetes aged $\geq 19$ years, and HPV vaccination among females aged 19-26 years, coverage among foreign-born adults who were U.S. citizens was higher than that for foreign-born respondents who were not U.S. citizens (Table 10).

\section{Discussion}

In 2014, adult vaccination coverage in the United States did not improve from 2013, except for modest increases in Tdap vaccination for adults aged $\geq 19$ years and herpes zoster vaccination among adults $\geq 60$ years. Vaccination coverage estimates for the four vaccines in this report that are included in Healthy People 2020 (influenza, pneumococcal, herpes zoster, and hepatitis B [for HCP] vaccines) are below the respective target levels, including among insured adults and adults with 
multiple health care visits in the past year. Racial/ethnic gaps in coverage persisted for all seven vaccines in this report and widened for Tdap and herpes zoster vaccination, with higher coverage generally for whites compared with most other groups. These data indicate multiple missed opportunities for vaccination and the need to increase routine assessment of adult vaccination needs, and vaccination with needed vaccines.

\section{Influenza Vaccination}

Since 2010, ACIP has recommended that all persons aged $\geq 6$ months be vaccinated annually against influenza to prevent illness and related complications (20). Fewer than half of adults aged $\geq 19$ years were vaccinated during the influenza seasons spanning the 2009-10 through 2013-14 seasons. Higher vaccination rates could have resulted in prevention of a substantial greater number of influenza cases and hospitalizations. For example, using a model published in 2013 (21), CDC estimated the amount of influenzaassociated outcomes during the 2012-13 influenza season, a moderately severe season, that might have been prevented by influenza vaccination (22). For the 2013-14 influenza season, using updated estimates of vaccination coverage, vaccine effectiveness, and influenza hospitalizations, CDC estimates that influenza vaccination prevented approximately 7.2 million illnesses, 3.1 million medically attended illnesses, and 90,000 hospitalizations associated with influenza (23). If influenza vaccination levels had reached the Healthy People 2020 target of $70 \%$, an estimated additional 5.9 million illnesses, 2.3 million medically attended illnesses, and 42,000 hospitalizations associated with influenza might have been averted. For the U.S. population to benefit more fully from influenza vaccines, more effort is needed to reach the Healthy People 2020 target. Ensuring that all persons who visit a health care provider during the influenza season receive a vaccination recommendation and offer from their provider and use of vaccination information systems could increase influenza vaccination rates and reduce the incidence of illness $(24,25)$.

HCP are recommended for routine annual influenza vaccination $(20,26)$. Preventing influenza among HCP who might serve as sources of influenza virus transmission provides additional protection to patients at risk for influenza complications. Although annual vaccination has long been recommended for HCP and is a high priority for reducing morbidity associated with influenza in health care settings (27-29), influenza vaccination coverage level among HCP aged $\geq 19$ years during the $2013-14$ season was $65.4 \%$ overall and $65.1 \%$ among those with direct patient care responsibilities. Higher HCP influenza vaccination coverage has been associated with employer requirements for vaccination and access to vaccination at the workplace at no cost for $>1$ day $(17,30)$. Although less effective than workplace on-site vaccination, active employer promotion of influenza vaccine through such methods as incentives and personal reminders also has been associated with higher coverage compared with HCP whose employers did not implement any policies or activities related to influenza vaccination (17). These results indicate that a comprehensive strategy that includes easy access to vaccination at no cost on multiple days along with promotion of vaccination might increase HCP vaccination coverage. Employers and health care administrators can make use of the Guide to Community Preventive Services (24), which provides guidance on effective interventions to increase uptake of influenza vaccination among HCP.

\section{Pneumococcal Vaccination}

In August 2014, ACIP recommended routine use of PCV13 among adults aged $\geq 65$ years (31). PCV13 should be administered in series with PPSV23, the vaccine recommended for adults aged $\geq 65$ years since 1983 . PPSV23 contains 12 serotypes in common with PCV13 and 11 additional serotypes. PCV13 vaccine reduces the risk for pneumococcal pneumonia and both PCV13 and PPSV23 have been demonstrated to reduce the risk for invasive pneumococcal infections $(31,32)$. Because of the high proportion of invasive pneumococcal disease caused by serotypes unique to PPSV23, broader protection is expected to be provided through use of both PCV13 and PPSV23 in series. Adults who have already received PPSV23 and are recommended to receive PCV13 should receive PCV13 at least 1 year after PPSV23 vaccine. The survey data from 2014 NHIS could not be used to estimate the proportion of pneumococcal vaccinations by type (PCV13 versus PPSV23). The overall pneumococcal vaccination estimates in this report include respondents who might have received PCV13 and/or PPSV23. Pneumococcal vaccination of persons aged 19-64 years at high risk increased during the 5 years covered in this report but was unchanged among those aged $\geq 65$ years, and both were well below Healthy People 2020 targets of $60 \%$ for persons aged 18-64 years at high risk and $90 \%$ for adults aged $\geq 65$ years. Among persons aged $\geq 65$ years, using PCV13 in series with PPSV23 could prevent an estimated 230 cases of invasive pneumococcal disease and approximately 12,000 cases of community-acquired pneumonia over the lifetime of a single cohort of persons aged 65 years (31). Achieving higher pneumococcal vaccination levels could improve these benefits. 


\section{Tetanus Toxoid-Containing Vaccination}

In 2012, ACIP updated the adult Tdap vaccination recommendation to include all adults aged $\geq 19$ years who have not yet received a dose of Tdap, including those aged $\geq 65$ years (33). Tdap, when indicated, should be administered regardless of interval since the most recent $\mathrm{Td}$. A single dose of Tdap is particularly important for adults who have or who anticipate having close contact with an infant aged $<1$ year (e.g., parents, grandparents, child care providers, and health care personnel) to reduce the risk for transmitting pertussis to infants too young to be vaccinated who are at greatest risk for severe pertussis, including hospitalization and death. Although there were modest increases in Tdap vaccination of adults from 2010 to 2014, coverage has remained low for all age groups and among adults living with an infant aged $<1$ year.

In hospital settings, transmission of pertussis has occurred from hospital visitors to patients, from HCP to patients, and from patients to HCP (34-37). Vaccinating HCP with Tdap will help protect them against pertussis and might reduce transmission to patients, other HCP, household members, and persons in the community $(26,38)$. Health care providers should not miss an opportunity to vaccinate adults aged $\geq 19$ years who have not received Tdap previously.

\section{Hepatitis A Vaccination}

Hepatitis A vaccination is recommended for any person seeking protection from hepatitis A virus infection, if some risk factor is present (e.g., on the basis of lifestyle, occupation, medical, or other indication), and for persons traveling to or working in countries that have high or intermediate endemicity of hepatitis A (15). Comprehensive information on all risk and occupation indications for hepatitis A vaccination were not collected in the 2014 NHIS. Information was available only for those with foreign travel to areas of high or intermediate endemicity and those with chronic liver disease. Although hepatitis A vaccination of persons who had traveled outside the United States to a country in which hepatitis A is of high or intermediate endemicity was higher in 2014 and preceding years than among respondents who did not travel outside the United States or had traveled only to countries in which the disease is of low endemicity, overall hepatitis A vaccination among travelers and persons with chronic liver disease has remained low. Health care providers are encouraged to assess the needs of their clients for this vaccine and offer it whenever appropriate.

\section{Hepatitis B Vaccination}

In December 2011, ACIP recommended that all previously unvaccinated adults aged 19-59 years with diabetes mellitus (type 1 and type 2 ) be vaccinated against hepatitis B as soon as possible after receiving a diagnosis of diabetes and that unvaccinated adults aged $\geq 60$ years with diabetes may be vaccinated at the discretion of the treating clinician after assessing their risk and the likelihood of an adequate immune response to vaccination (39). Hepatitis B vaccination coverage in 2014 among persons with diabetes showed no improvement over estimates obtained before this recommendation, which underscores the need to improve awareness of increased risk for contracting acute hepatitis $\mathrm{B}$ among persons with diabetes and to increase hepatitis $B$ vaccination in this population.

During 1982, when hepatitis B vaccine was first recommended for HCP, an estimated 10,000 infections occurred among persons employed in a medical or dental field. By 2004, the number of hepatitis $B$ virus (HBV) infections among HCP had decreased to an estimated 304 infections, largely resulting from the implementation of routine pre-exposure vaccination and improved infection-control precautions (40-42). The risk for acquiring $\mathrm{HBV}$ infection from occupational exposures is dependent on the frequency of percutaneous and mucosal exposures to blood or body fluids (e.g., semen, and wound exudates) containing HBV, particularly fluids containing hepatitis $\mathrm{B}$ e antigen, a marker for high HBV replication and viral load (26). The risk is higher during the professional training period and can vary throughout a person's career (43). All unvaccinated persons whose work- and trainingrelated activities involve reasonably anticipated risk for exposure to blood or other infectious body fluids (e.g., HCP, long-term-care facility staff, and public safety workers) should be vaccinated with the complete, $\geq 3$-dose hepatitis $B$ vaccine series and undergo postvaccination serological testing to demonstrate protective antibody levels (44). During 2010-2014, estimates of hepatitis vaccination among HCP have not improved, ranging from 61\%-65\%, well below the Healthy People 2020 target of 90\%. The Hospital Infection Control Practices Advisory Committee (HICPAC) has encouraged all facilities or organizations that provide direct patient care to formulate a comprehensive vaccination policy for all $\mathrm{HCP}$ (45). Implementation of HICPAC and $\mathrm{CDC}$ recommendations can assist hospital administrators, infection-control practitioners, employee health clinicians, and $\mathrm{HCP}$ in optimizing infection prevention and control programs.

\section{Herpes Zoster Vaccination}

ACIP recommends herpes zoster vaccination for adults aged $\geq 60$ years (46). Although herpes zoster vaccination coverage increased in 2014 compared with 2013, it was 2.1 percentage points below the Healthy People 2020 target of $30 \%$. Shortages of herpes zoster vaccine and a resulting lack of vaccine promotion likely contributed to low uptake during the first years after licensure. These shortages now appear to be resolved; however, 
other barriers persist, particularly the high cost for providers to purchase a supply, challenges to stocking the vaccine (which requires freezer storage), coverage for the vaccine under Medicare Part D, which results in billing challenges for medical providers (except pharmacist vaccine providers), and out-of-pocket payments for some Medicare Part D beneficiaries depending on their specific plan $(47,48)$. Providers often refer patients to pharmacies for herpes zoster vaccination because reimbursement for Medicare Part D benefits is less complex. For adults aged $\geq 60$ years with nongrandfathered private health insurance plans, herpes zoster vaccine is available with no out-of-pocket costs because of provisions of the Affordable Care Act $(14,47,48)$.

\section{HPV Vaccination}

Although HPV vaccination increased significantly among age-eligible females during 2010-2014 (5,49,50), coverage has remained low. Since 2006, ACIP has recommended routine vaccination of adolescent girls and boys at ages 11 or 12 years and vaccination for females aged 13-26 years who have not been vaccinated previously (51). Since 2011, ACIP has recommended vaccination for males aged 13-21 years who have not been vaccinated previously or who have not completed the 3-dose series; males aged 22-26 years may be vaccinated. Approximately $12 \%$ of females and $2 \%$ of males aged 19-26 years not vaccinated at age $\leq 18$ years reported receiving the first dose of HPV vaccine as catch-up at age 19-26 years. As more adolescents are vaccinated at the target age group and age into the group monitored in NHIS, vaccine coverage estimates are expected to increase.

Data on age at first dose of HPV vaccination of adults was collected for the first time in 2013. Most female and male respondents in the 2014 NHIS reported receiving the first dose of HPV vaccine at age $\geq 13$ years, consistent with the fact that female respondents aged $\geq 21$ years and all male respondents would have been aged $>13$ years at the time HPV vaccination was first recommended. Some respondents also indicated the first HPV vaccination dose was received before HPV vaccine was licensed for use in 2006, suggesting inaccurate recall.

In 2014, white women reported higher HPV coverage than Hispanic or Asian women. Black women and women reporting other race had coverage similar to that for whites. The findings for black, Hispanic, and Asian women contrast with data on HPV vaccination of adolescent girls aged 13-17 years reported in the 2014 National Immunization Survey-Teen (NIS-Teen) (52), which indicated that, among females, $\geq 1, \geq 2$, and $\geq 3 \mathrm{HPV}$ dose coverage was higher among Hispanic adolescents and similar for Asian adolescents compared with white adolescents. Among black adolescents, $\geq 1$ and $\geq 2$ HPV dose coverage was also higher compared with estimates for white adolescents. HPV vaccination coverage for each HPV dose was higher for females living below poverty level compared with those at or above the poverty level. The higher coverage in NIS-Teen among black and Hispanic females and those living below the poverty level might be attributable in part to the continued effectiveness of the Vaccines for Children program, which provides recommended vaccines at no cost to eligible children through age 18 years (53). NIS-Teen estimates also are based on provider reports from medical records whereas NHIS vaccination data are selfreported. Young adults might not be able to recall accurately which vaccines they received as adolescents.

Although vaccination coverage has increased since a licensed HPV vaccine has been available and recommended by ACIP, many adolescent and young adult females remain unvaccinated and vulnerable to develop cancers that safe, effective HPV vaccines can prevent (51). Studies on the prevalence of genital HPV infection among women in the United States (54) and the seroprevalence of the nine HPV types in the 9-valent vaccine (55) indicated that many adult women have not been infected with high-risk HPV types, supporting implementation of ACIPrecommended catch-up vaccination. Until HPV vaccination increases among adolescents, a high proportion of unprotected young women eligible for HPV vaccination will be expected. Results from modeling and studies of the cost-effectiveness of $\mathrm{HPV}$ vaccination of young women have suggested that catch-up vaccination could reduce the amount of time needed to achieve population level impacts of vaccination $(56,57)$. Findings from initial studies of vaccine impact in settings in which catch-up vaccination programs were successful in achieving high coverage rates among young women are consistent with these models $(56,57)$. Continued efforts are needed to improve coverage among members of the primary target group for HPV vaccine, girls and boys aged 11-12 years, and among all racial and ethnic groups. Efforts also are needed to improve catch-up vaccination among those who have not started or completed their vaccination.

\section{Health Insurance Status and Usual Place for Health Care}

The findings in this report are consistent with a previous report (12) indicating that having health insurance was generally associated with a greater likelihood of having received recommended vaccinations. Even after demographic and accessto-care variables are controlled for, persons with health insurance were more likely to be vaccinated than those without insurance for several vaccines. The type of health insurance indicated by respondents had a significant association with vaccination coverage. Vaccination coverage was higher among adults with private health insurance compared with those reporting public health insurance for many of the vaccines, but this finding 
was not consistent for all vaccines and age groups. The factors contributing to vaccination levels by type of health insurance are not well understood. In one study (58), the percentage of persons with private health insurance declined during 1999-2011, ranging from $67 \%$ to $74 \%$ during $1999-2008$, and was $64 \%$ during 2009-2011. This downward shift in private insurance coverage might have had an impact on adult vaccination coverage. The Affordable Care Act also might have had an impact on vaccination coverage (48). A better understanding of factors influencing vaccination by type of health insurance is needed.

Health insurance coverage, although beneficial in improving access to health care services, might not be sufficient in itself to achieve optimal adult vaccination. In this report, even among those with health insurance and $\geq 10$ contacts with physicians during the preceding year and no contraindications, vaccination was still not routine. Up to $88.8 \%$ of adults reported not receiving one or more recommended vaccines. Provider attitudes toward adult vaccination, practice patterns that do not routinely incorporate assessments for vaccines for adults, and other barriers to vaccination might determine whether patients are offered and receive vaccines $(6,8-10,12,14,59)$.

In general, persons with a usual place for health care were more likely to report having received recommended vaccinations than those who did not have a usual place for health care, regardless of whether they had health insurance, and vaccination coverage generally increased as the number of physician contacts increased. This observation suggests that an increased number of physician contacts might have facilitated opportunities to be reminded of the need for vaccinations, discussions about indicated vaccinations, and a recommendation and decision to vaccinate. These findings are also consistent with previous reports indicating that persons who have a usual place for health care or medical home and who seek medical care one or more times during the year are more likely to be vaccinated and receive other preventive services than those without a usual place for health care $(59,60)$. Having a usual place for health care and routine physician contact can provide important opportunities for providers to educate their patients about vaccine-preventable diseases and recommend and offer vaccination (61-65).

\section{Nativity}

Overall, vaccination coverage was generally lower among the foreign-born compared with U.S.-born persons. Vaccination coverage for the foreign born differed by time lived in the United States. In a previous report (65), vaccination also was associated with language used for interview, race/ethnicity, and birth country/ region. Among foreign born, vaccination coverage was generally lower among those who were not U.S. citizens, those interviewed in a language other than English, and non-Hispanic blacks or
Hispanics compared with U.S. citizens, those interviewed in English, and non-Hispanic whites. The Hispanic foreign born had the lowest coverage for several vaccines. This finding is notable because foreign-born persons from Latin America account for more than half of all foreign-born adults in the United States (66-68). Vaccination coverage among the foreign born in the United States depends on the vaccinations they received as children or adults premigration, during migration, postmigration, or during return visits to their country of origin. Vaccination coverage and immunization schedules are different in many countries compared with the United States and vary by country and even by regions within countries $(65,69-71)$. Although immigrant visa applicants and refugees destined for permanent resettlement in the United States are subject to ACIP-recommended vaccination requirements, the differences between the United States and other countries in the schedules of routine vaccinations among adults might contribute to differences in the coverage levels of the vaccines studied. In most countries, vaccination programs have focused historically on children (72-74). Depending on their origin, age at arrival, and year of arrival, foreign-born adults arriving in the United States might have differences in vaccination coverage compared with U.S.-born populations (75,76). After arrival in the United States, many foreign-born adults experience socioeconomic, cultural, linguistic, and other barriers to accessing health care and preventive services, including vaccination $(66,67,77)$. The percentage of uninsured persons also is higher among non-U.S. citizens, recent immigrants, and those with poor/ fair English proficiency $(68,78)$. These populations might also be less aware of U.S. adult immunization recommendations (79). As the size and race/ethnic diversity of the foreign born population in the United States continues to increase, the findings of this and previous studies indicate that this population will be increasingly important to elimination of national adult vaccination disparities (80). Public policy makers, vaccination programs, and healthcare providers should consider foreign-born populations in their public health assessment, evaluation, and outreach programs that target disadvantaged groups (80).

\section{Improving Adult Vaccination Coverage}

Racial/ethnic gaps in coverage persisted for all seven vaccines in this report with higher coverage generally for whites compared with most other groups. Previous research has indicated a variety of factors that contribute to racial/ethnic differences in adult vaccination rates, including patient, provider, and system factors (81-84). Standardized offering of vaccines reduces these differences $(85,86)$. Using an intensive combination of patient tracking, vaccination reminders for providers and patients, 
and patient outreach and assistance also reduces racial/ethnic vaccination differences (87). Incorporating standards for adult vaccination practices, which include routinely assessing vaccination needs during clinical encounters, providing a strong recommendation for vaccination to patients with indications, and then offering vaccination at the visit, can have a substantial impact on reducing vaccination disparities (25).

Many factors contribute to low adult vaccination rates, including limited awareness among the public about adult vaccinations, vaccine needs assessment often not routinely included in adult patient care, lack of vaccine requirements for adults, complexities in how adult vaccinations are paid for by private and public insurers, the financial risks for providers to stock vaccines and provide vaccination services, limited funding for programs to vaccinate uninsured adults, and acute medical care taking precedence over preventive services $(6-14)$.

The most successful strategies to improve adult immunizations involve organizational change, such as initiating standing orders or protocols to ensure immunization assessment is routinely done and needed vaccines administered when indicated. The Community Preventive Services Task Force has evaluated vaccination interventions and identified effective, evidence-based strategies to improve vaccine use which can be applied to the adult population, including systems interventions, such as the use of standing orders or protocols for vaccinations, provider reminders, and reminders for patients for vaccines that are due (6,24). Provider recommendation remains an important factor associated with receipt of vaccine (18). In addition, ensuring convenient access to vaccination also is important for adults $(88,89)$. The expanded availability of vaccine services in pharmacies and other retail settings provides an opportunity for patients to receive vaccines not stocked by their medical provider and to obtain vaccines outside of typical office hours $(88,89)$.

Challenges posed by increasing access to vaccines for adults among a range of providers include vaccine record keeping and ensuring good communication among providers about a patient's vaccination history. Both are essential to ensuring patients receive needed vaccines at recommended intervals and do not receive unnecessary vaccinations. State-based immunization information systems (also known as vaccine registries) are available for entry of adult vaccinations in 47 states (http://www. cdc.gov/vaccines/programs/iis/about.html) and can serve as a central point of access for providers to check for vaccinations received by adult patients and to document vaccinations they provide (90). Providers should check with their health department to identify those immunization information systems that have the capacity to enroll adult providers as some systems might be limited in their capacity to substantially expand access to immunization information systems beyond pediatric vaccine providers. Information about and contact information regarding use of IIS is available at http://www.cdc.gov/vaccines/programs/ iis/contacts-registry-staff.html.

The use of clinical decision support systems in electronic medical records systems also can facilitate improved vaccination rates. For example, use of prompts in electronic medical records systems for adult vaccines by the Indian Health Service has resulted in substantially higher coverage rates compared to national estimates from the NHIS (G).

On the basis of the importance of the provider recommendation, evidence-based strategies for improving vaccine uptake in adults, the recognition that not all medical providers stock all ACIPrecommended vaccines for adults, the need for improved communication among the different health care providers that adults might have and other factors, the National Vaccine Advisory Committee published updated standards for adult immunization practice in 2014 with the intent of improving adult vaccination coverage of ACIP recommended vaccines. This guidance calls on health care providers, including those who do not stock vaccines, to 1 ) assess the vaccination status of patients at every clinical encounter; 2) recommend needed vaccines for patients; 3 ) offer recommended vaccines or, for providers who do not stock a needed vaccine, refer patients to a vaccine provider; and 4) document vaccines administered, including in IIS when available for use among adult patients (25). Resources to assist providers with implementation of the standards for adult immunization practice are available at http:// www.cdc.gov/vaccines/hcp/patient-ed/adults/for-practice/ standards/index.html. Additional resources are also available through the National Adult and Influenza Summit (NAIIS) (http://www.izsummitpartners.org) website resource library. NAIIS is a national coalition representing more than 130 public and private organizations interested in improving the use of ACIP-recommended vaccines for adults and influenza vaccine for persons of all ages.

\section{Limitations}

The findings in this report are subject to at least seven limitations. First, the NHIS sample excludes persons in the military and those residing in institutions, which might result in underestimation or overestimation of vaccination coverage levels. Second, the response rate was $58.9 \%$. Nonresponse bias can result if respondents and nonrespondents differ in their vaccination rates. Third, the determination of vaccination status and identification of high-risk conditions in NHIS were not validated by medical records. Fourth, self-report of vaccination might be subject to recall bias. Young adults particularly might not be able to recall accurately vaccines received as infants or adolescents. However, adult self-reported vaccination status is 
sensitive for all seven vaccines in this report and specific for all except tetanus vaccination (91). Fifth, demographic and other characteristics (e.g., insurance status, usual source, and frequency of health care) were self-reported and were not validated. Sixth, the Tdap estimate is subject to considerable uncertainty. Respondents who reported a tetanus vaccination but were unable to say whether Td or Tdap was used during 2005-2014 were excluded from estimations of Tdap coverage, creating a potential for bias. Sensitivity calculations were conducted to assess the magnitude of potential bias. Depending on what proportion of excluded respondents actually received Tdap, actual Tdap coverage could fall within the range of $14.5 \%-46.9 \%$ for adults aged $19-64$ years and $9.5 \%-41.6 \%$ for adults aged $\geq 65$ years. Comparisons of Tdap coverage across years within subgroups might be affected by bias resulting from excluding persons who did not report the type of tetanus vaccine they received. Finally, the prevalence of selected behavioral characteristics in populations, including the use of preventive health services, vaccine safety concerns, state laws and vaccination intervention programs, cultural, religious, and other factors might affect vaccination coverage. Although NHIS collects information on use of other preventive health services, this information was not included in this analysis. NHIS did not collect information on these other factors.

\section{Conclusion}

Vaccination coverage levels among U.S. adults are low. Improvement in adult vaccination is needed to reduce the health consequences of vaccine-preventable diseases among adults. Awareness of the need for vaccines for adults is low among the general population and adult patients rely on provider recommendations for vaccination $(6-9,11)$. Successful vaccination programs combine 1 ) education of potential vaccine recipients and publicity to promote vaccination; 2) increased access to vaccination services in health care settings; and 3) use of practices that improve vaccination coverage, including reminder-recall systems, efforts to remove administrative and financial barriers to vaccination, use of standing order programs for vaccination, and assessment of practice-level vaccination rates with feedback to staff members $(24,25,92)$. Health care provider recommendations for vaccination are strongly associated with a patient's receipt of vaccines $(10,62-64)$. Incorporation of routine assessment of adult patient vaccination needs, recommendation, and offer of needed vaccinations for adults into routine clinical care of adults can help improve vaccination rates and narrow widening racial and ethnic disparities in vaccination coverage (24,25). The adult immunization schedule (15), updated annually, provides current recommendations for vaccinating adults and a ready resource for persons who provide health care services for adults in various settings. Assessing associations with vaccination is important for understanding factors that contribute to low coverage rates and to disparities in vaccination, and for implementing strategies to improve vaccination coverage.

\section{References}

1. CDC. Estimates of deaths associated with seasonal influenza — United States, 1976-2007. MMWR Morb Mortal Wkly Rep 2010;59:1057-62.

2. Thompson WW, Shay DK, Weintraub E, et al. Influenza-associated hospitalizations in the United States. JAMA 2004;292:1333-40. http:// dx.doi.org/10.1001/jama.292.11.1333.

3. Tomczyk S, Bennett NM, Stoecker C, et al. Use of 13-valent pneumococcal conjugate vaccine and 23 -valent pneumococcal polysaccharide vaccine among adults aged $\geq 65$ years: recommendations of the Advisory Committee on Immunization Practices (ACIP). MMWR Morb Mortal Wkly Rep 2014;63:822-5.

4. Yawn BP, Saddier P, Wollan PC, Sauver JLS, Kurland MJ, Sy LS. A population-based study of the incidence and complication rates of herpes zoster before zoster vaccine introduction. Mayo Clin Proc 2007;82:1341-9. http://dx.doi.org/10.4065/82.11.1341.

5. Williams WW, Lu P-J, O'Halloran A, et al. Vaccination coverage among adults, excluding influenza vaccination-United States, 2013. MMWR Morb Mortal Wkly Rep 2015;64:95-102.

6. Bridges CB, Hurley LP, Williams WW, Ramakrishnan A, Dean AK, Groom AV. Meeting the challenges of immunizing adults. Am J Prev Med 2015;49:S455-64.

7. Joon Lee T, Hayes S, Cummings DM, et al. Herpes zoster knowledge, prevalence, and vaccination rate by race. J Am Board Fam Med 2013;26:45-51. http://dx.doi.org/10.3122/jabfm.2013.01.120154.

8. Johnson DR, Nichol KL, Lipczynski K. Barriers to adult immunization. Am J Med 2008;121(Suppl 2):S28-35. http://dx.doi.org/10.1016/j. amjmed.2008.05.005.

9. Armstrong K, Berlin M, Schwartz JS, Propert K, Ubel PA. Barriers to influenza immunization in a low-income urban population. Am J Prev Med 2001;20:21-5. http://dx.doi.org/10.1016/S0749-3797(00)00263-4.

10. Winston CA, Wortley PM, Lees KA. Factors associated with vaccination of medicare beneficiaries in five U.S. communities: Results from the racial and ethnic adult disparities in immunization initiative survey, 2003. J Am Geriatr Soc 2006;54:303-10. http://dx.doi.org/10.1111/j.1532-5415.2005.00585.x.

11. National Foundation for Infectious Diseases. Call to action: adult vaccination saves lives. Bethesda, MD: National Foundation for Infectious Diseases; 2012. http://www.adultvaccination.org/resources/ cta-adult.pdf.

12. Lu PJ, O'Halloran A, Williams WW. Impact of health insurance status on vaccination coverage among adult populations. Am J Prev Med 2015;48:647-61. http://dx.doi.org/10.1016/j.amepre.2014.12.008.

13. Stewart AM, Lindley MC, Chang KH, Cox MA. Vaccination benefits and cost-sharing policy for non-institutionalized adult Medicaid enrollees in the United States. Vaccine 2014;32:618-23. http://dx.doi. org/10.1016/j.vaccine.2013.11.050.

14. Hurley LP, Bridges CB, Harpaz R, et al. U.S. physicians' perspective of adult vaccine delivery. Ann Intern Med 2014;160:161-70. http://dx.doi. org/10.7326/M13-2332.

15. CDC. Advisory Committee on Immunization Practices recommended immunization schedule for adults aged 19 years and older-United States, 2016. MMWR Morb Mortal Wkly Rep 2016. In press.

16. CDC. Flu vaccination coverage, United States, 2014-15 influenza season. Atlanta, GA: US Department of Health and Human Services, CDC; 2015. http://www.cdc.gov/flu/fluvaxview/coverage-1415estimates.htm. 
17. Black CL, Yue X, Ball SW, et al. Influenza vaccination coverage among health care personnel-United States, 2014-15 influenza season. MMWR Morb Mortal Wkly Rep 2015;64:993-9.

18. Ding H, Black CL, Ball S, et al. Influenza vaccination among pregnant women-United States, 2014-15 influenza season. MMWR Morb Mortal Wkly Rep 2015;64:1000-5.

19. CDC. Surveillance of influenza vaccination coverage-United States, 2007-08 through 2011-12 influenza seasons. MMWR Surveill Summ 2013;62(No. SS-4).

20. CDC. Prevention and control of seasonal influenza with vaccines. Recommendations of the Advisory Committee on Immunization Practices-United States, 2013-2014. MMWR Recomm Rep 2013;62(No. RR-7).

21. Kostova D, Reed C, Finelli L, et al. Influenza illness and hospitalizations averted by influenza vaccination in the United States, 2005-2011. PLoS One 2013;8:e66312. http://dx.doi.org/10.1371/journal.pone.0066312.

22. CDC. Estimated influenza illnesses and hospitalizations averted by influenza vaccination-United States, 2012-13 influenza season. MMWR Morb Mortal Wkly Rep 2013;62:997-1000.

23. Reed C, Kim IK, Singleton JA, et al. Estimated influenza illnesses and hospitalizations averted by vaccination-United States, 2013-14 influenza season. MMWR Morb Mortal Wkly Rep 2014;63:1151-4.

24. Community Preventive Services Task Force. The guide to community preventive services. Increasing appropriate vaccination: universally recommended vaccinations. Atlanta, GA: US Department of Health and Human Services, CDC; 2011. http://www.thecommunityguide. org/vaccines/index.html.

25. National Vaccine Advisory Committee. Recommendations from the National Vaccine Advisory committee: standards for adult immunization practice. Public Health Rep 2014;129:115-23.

26. CDC. Immunization of health-care personnel: recommendations of the Advisory Committee on Immunization Practices (ACIP). MMWR MMWR Recomm Rep 2011;60(No. RR-7).

27. National Foundation for Infectious Diseases. Best practices poster. Bethesda, MD: National Foundation for Infectious Diseases; 2015. http://www.nfid.org/idinfo/influenza/poster.html.

28. Pavia AT. Mandate to protect patients from health care-associated influenza. Clin Infect Dis 2010;50:465-7. http://dx.doi.org/10.1086/650753.

29. Poland GA, Tosh P, Jacobson RM. Requiring influenza vaccination for health care workers: seven truths we must accept. Vaccine 2005;23:2251-5. http://dx.doi.org/10.1016/j.vaccine.2005.01.043.

30. Black CL, Yue X, Ball SW, et al. Influenza vaccination coverage among health care personnel-United States, 2013-14 influenza season. MMWR Morb Mortal Wkly Rep 2014;63:805-11.

31. Tomczyk S, Bennett NM, Stoecker C, et al. Use of 13-valent pneumococcal conjugate vaccine and 23-valent pneumococcal polysaccharide vaccine among adults aged $\geq 65$ years: recommendations of the Advisory Committee on Immunization Practices (ACIP). MMWR Morb Mortal Wkly Rep 2014;63:822-5.

32. CDC. Use of 13-valent pneumococcal conjugate vaccine and 23-valent pneumococcal polysaccharide vaccine for adults with immunocompromising conditions: recommendations of the Advisory Committee on Immunization Practices (ACIP). MMWR Morb Mortal Wkly Rep 2012;61:816-9.

33. CDC. Updated recommendations for use of tetanus toxoid, reduced diphtheria toxoid, and acellular pertussis (Tdap) vaccine in adults aged 65 years and older-Advisory Committee on Immunization Practices (ACIP), 2012. MMWR Morb Mortal Wkly Rep 2012;61:468-70.

34. Christie CD, Glover AM, Willke MJ, Marx ML, Reising SF, Hutchinson NM. Containment of pertussis in the regional pediatric hospital during the Greater Cincinnati epidemic of 1993. Infect Control Hosp Epidemiol 1995;16:556-63. http://dx.doi.org/10.2307/30141094.

35. Kurt TL, Yeager AS, Guenette S, Dunlop S. Spread of pertussis by hospital staff. JAMA 1972;221:264-7. http://dx.doi.org/10.1001/ jama.1972.03200160016004.
36. Linnemann CC Jr, Perlstein PH, Ramundo N, Minton SD, Englender GS. Use of pertussis vaccine in an epidemic involving hospital staff. Lancet 1975;306:540-3. http://dx.doi.org/10.1016/S0140-6736(75)90907-1.

37. Valenti WM, Pincus PH, Messner MK. Nosocomial pertussis: possible spread by a hospital visitor. Am J Dis Child 1980;134:520-1.

38. Calugar A, Ortega-Sánchez IR, Tiwari T, Oakes L, Jahre JA, Murphy TV. Nosocomial pertussis: costs of an outbreak and benefits of vaccinating health care workers. Clin Infect Dis 2006;42:981-8. http:// dx.doi.org/10.1086/500321.

39. CDC. Use of hepatitis B vaccination for adults with diabetes mellitus: recommendations of the Advisory Committee on Immunization Practices (ACIP). MMWR Morb Mortal Wkly Rep 2011;60:1709-11.

40. CDC. Hepatitis surveillance report No. 60. Atlanta, GA: US Department of Health and Human Services, CDC; 2005.

41. Alter MJ, Hadler SC, Margolis HS, et al. The changing epidemiology of hepatitis $\mathrm{B}$ in the United States. Need for alternative vaccination strategies. JAMA 1990;263:1218-22. http://dx.doi.org/10.1001/jama.1990.03440090052025.

42. Osterholm MT, Garayalde SM. Clinical viral hepatitis B among Minnesota hospital personnel. Results of a ten-year statewide survey. JAMA 1985;254:3207-12. http://dx.doi.org/10.1001/jama.1985.03360220073032.

43. CDC. Immunization of health-care workers: recommendations of the Advisory Committee on Immunization Practices (ACIP) and the Hospital Infection Control Practices Advisory Committee (HICPAC). MMWR Morb Mortal Wkly Rep 1997;46(No. RR-18).

44. Schillie S, Murphy TV, Sawyer M, et al. CDC guidance for evaluating healthcare personnel for hepatitis $\mathrm{B}$ virus protection and for administering postexposure management. MMWR Recomm Rep 2013;62(RR-10):1-19.

45. Bolyard EA, Tablan OC, Williams WW, Pearson ML, Shapiro CN, Deitchman SD; Hospital Infection Control Practices Advisory Committee. Guideline for infection control in healthcare personnel, 1998. Infect Control Hosp Epidemiol 1998;19:407-63. http://dx.doi.org/10.2307/30142429.

46. Hales CM, Harpaz R, Ortega-Sanchez I, Bialek SR. Update on recommendations for use of herpes zoster vaccine. MMWR Morb Mortal Wkly Rep 2014;63:729-31.

47. United States Government Accountability Office. Report to Congressional Committees. Medicare-many factors, including administrative challenges, affect access to Part D vaccinations. GAO-12-61. December 2011. http://www.gao.gov/products/GAO-12-61.

48. Hurley LP, Lindley MC, Harpaz R, et al. Barriers to the use of herpes zoster vaccine. Ann Intern Med 2010;152:555-60. http://dx.doi. org/10.7326/0003-4819-152-9-201005040-00005.

49. CDC. Noninfluenza vaccination coverage among adults_-United States, 2011. MMWR Morb Mortal Wkly Rep 2013;62:66-72.

50. Williams WW, Lu P-J, O'Halloran A, et al. Noninfluenza vaccination coverage among adults_-United States, 2012. MMWR Morb Mortal Wkly Rep 2014;63:95-102.

51. Markowitz LE, Dunne EF, Saraiya M, et al. Human papillomavirus vaccination: recommendations of the Advisory Committee on Immunization Practices (ACIP). MMWR Recomm Rep 2014;63(No. RR-5):1-30.

52. Reagan-Steiner S, Yankey D, Jeyarajah J, et al. National, regional, state, and selected local area vaccination coverage among adolescents aged 13-17 years-United States, 2014. MMWR Morb Mortal Wkly Rep 2015;64:784-92. http://dx.doi.org/10.15585/mmwr.mm6429a3.

53. Elam-Evans LD, Yankey D, Jeyarajah J, et al. National, regional, state, and selected local area vaccination coverage among adolescents aged 13-17 years-United States, 2013. MMWR Morb Mortal Wkly Rep 2014;63:625-33.

54. Hariri S, Unger ER, Sternberg M, et al. Prevalence of genital human papillomavirus among females in the United States, the National Health and Nutrition Examination Survey, 2003-2006. J Infect Dis 2011;204:566-73. http://dx.doi.org/10.1093/infdis/jir341.

55. Liu G, Markowitz LE, Hariri S, Panicker G, Unger ER. Seroprevalence of 9 human papillomavirus types in the United States, 2005-2006. J Infect Dis 2015;213:191-8. 
56. Burger EA, Sy S, Nygård M, Kristiansen IS, Kim JJ. Too late to vaccinate? The incremental benefits and cost-effectiveness of a delayed catch-up program using the 4-valent human papillomavirus vaccine in Norway. J Infect Dis 2015;211:206-15. http://dx.doi.org/10.1093/infdis/jiu413.

57. Chesson HW, Markowitz LE. The cost-effectiveness of human papillomavirus vaccine catch-up programs for women. J Infect Dis 2015;211:172-4. http://dx.doi.org/10.1093/infdis/jiu414.

58. DeNavas-Walt C, Proctor BD, Smith JC. Income, poverty, and health insurance coverage in the United States: 2011. Washington, DC: US Department of Commerce, US Census Bureau; 2012. http://www. census.gov/prod/2012pubs/p60-243.pdf.

59. Sudano JJ Jr, Baker DW. Intermittent lack of health insurance coverage and use of preventive services. Am J Public Health 2003;93:130-7. http://dx.doi.org/10.2105/AJPH.93.1.130.

60. Beal AC, Doty MM, Hernandez SE, Shea KK, Davis K. Closing the divide: how medical homes promote equity in health care-results from the Commonwealth Fund 2006 Health Care Quality Survey. New York, NY: The Commonwealth Fund; 2007.

61. Lu PJ, Euler GL, Harpaz R. Herpes zoster vaccination among adults aged 60 years and older, in the U.S., 2008. Am J Prev Med 2011;40:e1-6. http://dx.doi.org/10.1016/j.amepre.2010.10.012.

62. Lu PJ, Euler GL, Jumaan AO, Harpaz R. Herpes zoster vaccination among adults aged 60 years or older in the United States, 2007: uptake of the first new vaccine to target seniors. Vaccine 2009;27:882-7. http:// dx.doi.org/10.1016/j.vaccine.2008.11.077.

63. CDC. Influenza vaccination among pregnant women, the 2011-12 season. MMWR Morb Mortal Wkly Rep 2012;61:758-63.

64. CDC. Influenza vaccination coverage among health-care personnel-the 2011-12 season. MMWR Morb Mortal Wkly Rep 2012;61:753-7.

65. Lu P-J, Rodriguez-Lainz A, O'Halloran A, Greby S, Williams WW. Adult vaccination disparities among foreign-born populations in the U.S., 2012. Am J Prev Med 2014;47:722-33. http://dx.doi.org/10.1016/j.amepre.2014.08.009.

66. Grieco EM, Acosta YD, de la Cruz GP, et al. The foreign born population in the United States, 2010. Washington, DC: US Department of Commerce, US. Census Bureau; 2012. http://www.census.gov/prod/2012pubs/acs-19.pdf.

67. Malone N, Baluja KF, Costanzo JM, Davis CJ. The foreign born population in the United States, 2000. Washington, DC: US Department of Commerce, US. Census Bureau; 2003. http://www.census.gov/ $\mathrm{prod} / 2003 \mathrm{pubs} / \mathrm{c} 2 \mathrm{kbr}-34 . \mathrm{pdf}$.

68. Pew Hispanic Center. Statistical portrait of the foreign born population in the United States, 2011. Washington DC: Pew Hispanic Center; 2015. http://www.pewhispanic.org/2013/01/29/statistical-portrait-ofthe-foreign-born-population-in-the-united-states-2011.

69. Bridges CB, Coyne-Beasley T. Advisory Committee on Immunization Practices recommended immunization schedule for adults aged 19 years or olderUnited States, 2014. MMWR Morb Mortal Wkly Rep 2014;63:110-2.

70. CDC. Global routine vaccination coverage, 2011. MMWR Morb Mortal Wkly Rep 2012;61:883-5.

71. Walker PF, Barnett ED. An introduction to the field of refugee and immigrant healthcare. In: Walker PF, Barnett ED, eds. Immigrant medicine. Philadelphia, PA: Saunders Elsevier; 2007.

72. World Health Organization. WHO recommendations for routine immunization: summary tables. Geneva, Switzerland: World Health Organization; 2015. http://www.who.int/immunization/policy/ immunization_tables/en.

73. World Health Organization. WHO vaccine-preventable diseases: monitoring system. 2014 global summary. Geneva, Switzerland: World Health Organization; 2015. http://apps.who.int/immunization_monitoring/ globalsummary/schedules?sc\%5Bd\%5D=8sc\%5BOK\%5D=OK.

74. UNICEF. Immunization. New York, NY: UNICEF. http://www.unicef. org/immunization.

75. Reynolds MA, Kruszon-Moran D, Jumaan A, Schmid DS, McQuillan GM. Varicella seroprevalence in the U.S.: data from the National Health and Nutrition Examination Survey, 1999-2004. Public Health Rep 2010;125:860-9.
76. Ayers JW, Juon HS, Lee S, Park E. Hepatitis B vaccination prevalence and its predictors among Asian, Pacific Islander, Native American, and multiracial adults in the National Health and Nutrition Examination Survey. J Immigr Minor Health 2010;12:847-52. http://dx.doi.org/10.1007/s10903-009-9309-9.

77. Derose KP, Escarce JJ, Lurie N. Immigrants and health care: sources of vulnerability. Health Aff (Millwood) 2007;26:1258-68. http://dx.doi. org/10.1377/hlthaff.26.5.1258.

78. Alegría M, Cao Z, McGuire TG, et al. Health insurance coverage for vulnerable populations: contrasting Asian Americans and Latinos in the United States. Inquiry 2006;43:231-54. http://dx.doi.org/10.5034/ inquiryjrnl_43.3.231.

79. Lu PJ, Williams WW, Li J, et al. Human papillomavirus vaccine initiation and awareness: U.S. young men in the 2010 National Health Interview Survey. Am J Prev Med 2013;44:330-8. http://dx.doi.org/10.1016/j. amepre.2012.11.027.

80. Buelow VH, Van Hook J. Timely immunization series completion among children of immigrants. J Immigr Minor Health 2008;10:37-44. http:// dx.doi.org/10.1007/s10903-007-9048-8.

81. Singleton JA, Santibanez TA, Wortley PM. Influenza and pneumococcal vaccination of adults aged $>$ or $=65: \mathrm{racial} / \mathrm{ethnic}$ differences. Am J Prev Med 2005;29:412-20. http://dx.doi.org/10.1016/j.amepre.2005.08.012.

82. Lindley MC, Wortley PM, Winston CA, Bardenheier BH. The role of attitudes in understanding disparities in adult influenza vaccination. Am J Prev Med 2006;31:281-5. http://dx.doi.org/10.1016/j.amepre.2006.06.025.

83. Bach PB, Pham HH, Schrag D, Tate RC, Hargraves JL. Primary care physicians who treat blacks and whites. N Engl J Med 2004;351:575-84. http://dx.doi.org/10.1056/NEJMsa040609.

84. Gemson DH, Elinson J, Messeri P. Differences in physician prevention practice patterns for white and minority patients. J Community Health 1988;13:53-64. http://dx.doi.org/10.1007/BF01321480.

85. Schwartz KL, Neale AV, Northrup J, et al. Racial similarities in response to standardized offer of influenza vaccination. J Gen Intern Med 2006;21:34651. http://dx.doi.org/10.1111/j.1525-1497.2006.00401.x.

86. Daniels NA, Gouveia S, Null D, Gildengorin GL, Winston CA. Acceptance of pneumococcal vaccine under standing orders by race and ethnicity. J Natl Med Assoc 2006;98:1089-94.

87. Humiston SG, Bennett NM, Long C, et al. Increasing inner-city adult influenza vaccination rates: a randomized controlled trial. Public Health Rep 2011;126(Suppl 2):39-47.

88. Lu PJ, O'Halloran A, Ding H, Williams WW, Bridges CB, Kennedy ED. National and state-specific estimates of place of influenza vaccination among adult populations - United States, 2011-12 influenza season. Vaccine 2014;32:3198-204. http://dx.doi.org/10.1016/j.vaccine.2014.04.003.

89. Goad JA, Taitel MS, Fensterheim LE, Cannon AE. Vaccinations administered during off-clinic hours at a national community pharmacy: implications for increasing patient access and convenience. Ann Fam Med 2013;11:429-36. http://dx.doi.org/10.1370/afm.1542.

90. Martin DW, Lowery NE, Brand B, Gold R, Horlick G. Immunization information systems: a decade of progress in law and policy. J Public Health Manag Pract 2015;21:296-303. http://dx.doi.org/10.1097/ PHH.0000000000000040.

91. Rolnick SJ, Parker ED, Nordin JD, et al. Self-report compared to electronic medical record across eight adult vaccines: do results vary by demographic factors? Vaccine 2013;31:3928-35. http://dx.doi.org/10.1016/j. vaccine.2013.06.041.

92. Poland GA, Shefer AM, McCauley M, Webster PS, Whitley-Williams PN, Peter G; National Vaccine Advisory Committee, Ad Hoc Working Group for the Development of Standards for Adult Immunization Practices. Standards for adult immunization practices. Am J Prev Med 2003;25:144-50 http://dx.doi.org/10.1016/S0749-3797(03)00120-X. 
TABLE 1. Estimated proportion of adults aged $\geq 19$ years who received selected vaccinations, by age group, high-risk status, ${ }^{*}$ and race/ ethnicity ${ }^{\dagger}-$ National Health Interview Survey, United States, 2014

\begin{tabular}{lcccc}
\hline $\begin{array}{l}\text { Vaccination, age group, } \\
\text { high-risk status, and } \\
\text { race/ethnicity }\end{array}$ & $\begin{array}{c}\text { Sample } \\
\text { size }\end{array}$ & $\%$ & $(95 \% \mathrm{Cl})$ & $\begin{array}{c}\text { Simple } \\
\text { difference } \\
\text { from 2013 }\end{array}$ \\
\hline
\end{tabular}

Influenza vaccination, 2013-14 season ${ }^{\S}$

$\geq 19$ yrs

\begin{tabular}{|c|c|c|c|}
\hline Total & 32,296 & 43.2 & (42.1-44.4) \\
\hline White & 19,836 & 46.7 & $(45.3-48.2)$ \\
\hline Black & 4,424 & 36.5 & $(34.2-39.0)^{9}$ \\
\hline Hispanic or Latino & 5,341 & 33.2 & $(30.8-35.7)^{9}$ \\
\hline Asian & 1,847 & 44.6 & $(40.4-49.0)$ \\
\hline Other & 848 & 38.6 & $(32.6-45.3)^{9}$ \\
\hline \multicolumn{4}{|l|}{$19-49 \mathrm{yrs}$} \\
\hline Total & 16,454 & 31.5 & $(30.1-32.9)$ \\
\hline White & 8,954 & 32.8 & $(30.8-34.8)$ \\
\hline Black & 2,249 & 29.8 & $(26.7-33.0)$ \\
\hline Hispanic or Latino & 3,619 & 27.0 & $(24.2-30.0)^{9}$ \\
\hline Asian & 1,145 & 36.0 & $(31.6-40.8)$ \\
\hline Other & 487 & 32.4 & $(24.5-42.0)$ \\
\hline \multicolumn{4}{|l|}{$50-64$ yrs } \\
\hline Total & 8,401 & 47.7 & $(45.7-49.7)$ \\
\hline White & 5,522 & 49.8 & $(47.4-52.3)$ \\
\hline Black & 1,304 & 39.9 & $(35.5-44.5)^{9}$ \\
\hline Hispanic or Latino & 1,014 & 40.7 & $(36.2-45.6)^{9}$ \\
\hline Asian & 347 & 51.6 & $(42.3-61.6)$ \\
\hline Other & 214 & 43.9 & $(31.6-58.5)$ \\
\hline \multicolumn{4}{|l|}{$\geq 65 \mathrm{yrs}$} \\
\hline Total & 7,441 & 71.5 & (69.6-73.3) \\
\hline White & 5,360 & 73.4 & $(71.2-75.5)$ \\
\hline Black & 871 & 60.5 & $(54.3-66.9)^{\natural}$ \\
\hline Hispanic or Latino & 708 & 64.0 & $(58.2-69.7)^{\natural}$ \\
\hline Asian & 355 & 72.5 & $(63.2-81.1)$ \\
\hline Other & 147 & 63.6 & $(50.7-76.4)$ \\
\hline
\end{tabular}

Pneumococcal vaccination, ever**

19-64 yrs, high risk

\begin{tabular}{|c|c|c|c|c|}
\hline Total & 9,478 & 20.3 & $(19.0-21.6)$ & -0.9 \\
\hline White & 5,976 & 21.1 & $(19.5-22.8)$ & -1.2 \\
\hline Black & 1,450 & 20.2 & $(17.6-23.2)$ & -1.0 \\
\hline Hispanic or Latino & 1,403 & 16.4 & $(14.1-18.9)^{\text {๓ }}$ & -1.5 \\
\hline Asian & 300 & 14.6 & $(9.9-20.9)^{9}$ & 3.6 \\
\hline Other & 349 & 25.3 & $(18.5-33.6)$ & 5.5 \\
\hline \multicolumn{5}{|l|}{$\geq 65$ yrs } \\
\hline Total & 8,281 & 61.3 & $(59.9-62.7)$ & 1.6 \\
\hline White & 6,054 & 64.7 & $(63.1-66.3)$ & 1.1 \\
\hline Black & 955 & 49.8 & $(45.4-54.1)^{\natural}$ & 1.1 \\
\hline Hispanic or Latino & 739 & 45.2 & $(40.8-49.7)^{\natural}$ & 6.1 \\
\hline Asian & 372 & 47.7 & $(41.3-54.2)^{\natural}$ & 2.4 \\
\hline Other & 161 & 69.4 & $(57.7-79.1)$ & 14.8 \\
\hline
\end{tabular}

Tetanus vaccination (received in past 10 years) ${ }^{\text {t† }}$

\section{$\geq 19$ yrs}

\begin{tabular}{lrrrr} 
Total & 34,347 & 62.2 & $(61.4-63.1)$ & 0.3 \\
White & 21,443 & 67.3 & $(66.3-68.2)$ & 0.8 \\
Black & 4,591 & 50.7 & $(48.7-52.7)^{q}$ & -1.6 \\
Hispanic or Latino & 5,601 & 52.1 & $(50.5-53.8)^{\natural}$ & -0.2 \\
Asian & 1,839 & 50.5 & $(47.2-53.7)^{q}$ & -1.1 \\
Other & 873 & 71.4 & $(66.6-75.8)$ & 3.8 \\
\hline
\end{tabular}

See table footnotes on page 22 .
TABLE 1. (Continued) Estimated proportion of adults aged $\geq 19$ years who received selected vaccinations, by age group, high-risk status, * and race/ethnicity ${ }^{\dagger}$ — National Health Interview Survey, United States, 2014

\begin{tabular}{|c|c|c|c|c|}
\hline $\begin{array}{l}\text { Vaccination, age group, } \\
\text { high-risk status, and } \\
\text { race/ethnicity }\end{array}$ & $\begin{array}{l}\text { Sample } \\
\text { size }\end{array}$ & $\%$ & $(95 \% \mathrm{Cl})$ & $\begin{array}{c}\text { Simple } \\
\text { difference } \\
\text { from } 2013\end{array}$ \\
\hline \multicolumn{5}{|l|}{$19-49$ yrs } \\
\hline Total & 17,231 & 62.6 & $(61.5-63.7)$ & -0.3 \\
\hline White & 9,526 & 69.0 & $(67.7-70.3)$ & 0 \\
\hline Black & 2,319 & 52.8 & $(50.1-55.6)^{9}$ & -1.3 \\
\hline Hispanic or Latino & 3,769 & 51.9 & $(49.9-53.9)^{9}$ & -0.6 \\
\hline Asian & 1,110 & 51.8 & $(47.5-56.1)^{9}$ & -0.9 \\
\hline Other & 507 & 72.0 & $(66.0-77.3)$ & 6.0 \\
\hline \multicolumn{5}{|l|}{$50-64$ yrs } \\
\hline Total & 9,024 & 64.7 & $(63.1-66.1)$ & 0.7 \\
\hline White & 6,012 & 69.5 & $(67.7-71.2)$ & 2.1 \\
\hline Black & 1,325 & 49.9 & $(46.1-53.6)^{9}$ & -4.5 \\
\hline Hispanic or Latino & 1,104 & 54.6 & $(51.3-57.8)^{\uparrow}$ & -0.4 \\
\hline Asian & 373 & 49.1 & $(41.8-56.4)^{9}$ & -4.3 \\
\hline Other & 210 & 74.9 & $(66.1-82.1)$ & 5.1 \\
\hline \multicolumn{5}{|l|}{$\geq 65$ yrs } \\
\hline Total & 8,092 & 57.7 & $(56.3-59.2)$ & 1.4 \\
\hline White & 5,905 & 60.6 & $(58.9-62.3)$ & 1.1 \\
\hline Black & 947 & 43.1 & $(39.4-47.0)^{9}$ & 2.8 \\
\hline Hispanic or Latino & 728 & 49.1 & $(44.7-53.6)^{9}$ & 3.9 \\
\hline Asian & 356 & 46.6 & $(40.2-53.1)^{9}$ & 3.8 \\
\hline Other & 156 & 63.1 & $(51.9-73.0)$ & -9.3 \\
\hline
\end{tabular}

Tetanus vaccination including pertussis vaccine (received in past $9 \mathrm{yrs})^{\S \S}$ $\geq 19$ yrs

\begin{tabular}{|c|c|c|c|c|}
\hline Total & 22,867 & 20.1 & $(19.3-20.8)$ & $2.9^{\text {ติ }}$ \\
\hline White & 13,743 & 23.8 & $(22.8-24.8)$ & $4.1^{\text {กา }}$ \\
\hline Black & 3,212 & 11.6 & $(10.1-13.3)^{\natural}$ & -1.0 \\
\hline Hispanic or Latino & 3,945 & 12.4 & $(11.2-13.8)^{\natural}$ & 2.3 ๆกी \\
\hline Asian & 1,366 & 15.5 & $(13.2-18.2)^{\natural}$ & 0.1 \\
\hline Other & 601 & 27.4 & $(22.2-33.3)$ & 5.0 \\
\hline $\begin{array}{l}\text { Living with an infant } \\
\text { aged }<1 \mathrm{yr}\end{array}$ & 707 & 32.0 & $(27.7-36.6)$ & 2.6 \\
\hline $\begin{array}{l}\text { Not living with an infant } \\
\text { aged }<1 \mathrm{yr}\end{array}$ & 22,160 & 19.6 & $(18.8-20.4)$ & 2.9 ศึ \\
\hline \multicolumn{5}{|l|}{$19-64$ yrs } \\
\hline Total & 17,503 & 21.5 & $(20.6-22.3)$ & $3.1^{\text {ๆศ }}$ \\
\hline White & 9,957 & 26.1 & $(25.0-27.3)$ & 4.5 ๆๆ \\
\hline Black & 2,542 & 12.7 & $(10.9-14.6)^{9}$ & -1.0 \\
\hline Hispanic or Latino & 3,422 & 13.0 & $(11.6-14.6)^{9}$ & 2.6 ๆ9 \\
\hline Asian & 1,094 & 15.6 & $(13.2-18.3)^{9}$ & -0.6 \\
\hline Other & 488 & 28.6 & $(23.0-35.0)$ & 5.8 \\
\hline $\begin{array}{l}\text { Living with an infant } \\
\text { aged }<1 \mathrm{yr}\end{array}$ & 692 & 32.5 & $(28.1-37.1)$ & 2.9 \\
\hline $\begin{array}{l}\text { Not living with an infant } \\
\text { aged }<1 \mathrm{yr}\end{array}$ & 16,811 & 20.9 & $(20.1-21.8)$ & 3.1 ๆศก \\
\hline \multicolumn{5}{|l|}{$\geq 65$ yrs } \\
\hline Total & 5,364 & 14.0 & $(12.7-15.5)$ & 2.2 \\
\hline White & 3,786 & 15.7 & $(14.1-17.6)$ & $2.8^{\text {ตๆ }}$ \\
\hline Black & 670 & 5.0 & $(3.6-7.0)^{9}$ & -1.5 \\
\hline Hispanic or Latino & 523 & 6.6 & $(4.5-9.5)^{9}$ & -0.8 \\
\hline Asian & 272 & 15.2 & $(10.2-22.1)$ & 4.1 \\
\hline Other & 113 & 20.1 & $(11.6-32.5)$ & 1.8 \\
\hline $\begin{array}{l}\text { Living with an infant } \\
\text { aged }<1 \mathrm{yr}\end{array}$ & 15 & 一*** & - & - \\
\hline $\begin{array}{l}\text { Not living with an infant } \\
\text { aged }<1 \mathrm{yr}\end{array}$ & 5,349 & 14.0 & $(12.7-15.5)$ & 2.2 \\
\hline
\end{tabular}

See table footnotes on page 22 . 
TABLE 1. (Continued) Estimated proportion of adults aged $\geq 19$ years who received selected vaccinations, by age group, high-risk status, ${ }^{*}$ and race/ethnicity ${ }^{\dagger}$ — National Health Interview Survey, United States, 2014

\begin{tabular}{lcccc}
\hline $\begin{array}{l}\text { Vaccination, age group, } \\
\text { high-risk status, and } \\
\text { race/ethnicity }\end{array}$ & $\begin{array}{c}\text { Sample } \\
\text { size }\end{array}$ & $\%$ & $(95 \% \mathrm{Cl})$ & $\begin{array}{c}\text { Simple } \\
\text { difference } \\
\text { from } 2013\end{array}$ \\
\hline
\end{tabular}

Hepatitis A vaccination (at least 2 doses), ever ${ }^{\text {t+t }}$

$\geq 19$ yrs

Total

Traveler§§§

Nontraveler १ศศต

With chronic liver

conditions, overall

$\begin{array}{rrcr}31,392 & 9.0 & (8.5-9.5) & -0.1 \\ 9,781 & 16.0 & (14.9-17.0) & 0.1 \\ 21,570 & 5.5 & (5.0-6.0)^{* * * *} & -0.2 \\ 422 & 13.8 & (10.0-18.8) & 0.5\end{array}$

19-49 yrs

Total

White

Black

Hispanic or Latino

Asian

Other

Traveler

Nontraveler

With chronic liver

conditions, overall

$\geq 50$ yrs

Total

Traveler

Nontraveler

With chronic liver

conditions, overall

$\begin{array}{rrcr}15,069 & 12.1 & (11.3-12.9) & -0.2 \\ 8,292 & 12.7 & (11.7-13.9) & 0.2 \\ 2,063 & 11.1 & (9.5-13.0) & 0.1 \\ 3,323 & 9.6 & (8.1-11.2)^{4} & -1.1 \\ 957 & 15.2 & (12.4-18.4) & -0.9 \\ 434 & 14.7 & (10.5-20.2) & -0.5 \\ 5,487 & 18.8 & (17.4-20.4) & 0.1 \\ 9,564 & 8.1 & (7.4-8.9)^{* * * *} & -0.5 \\ 100 & 18.2 & (10.3-30.0) & 3.7\end{array}$

Hepatitis B vaccination (at least 3 doses), ever ${ }^{\text {t+t+ }}$

$\geq 19$ yrs

Total

Traveler

Nontraveler

With chronic liver

conditions, overall

$\begin{array}{rr}16,323 & 5.5 \\ 4,294 & 11.9 \\ 12,006 & 2.9\end{array}$

$(5.1-6.0)$

$(10.8-13.2)$

$(2.5-3.4)^{* * * * *}$

0.2

0.2

0.1

$(8.3-17.9)$

$-0.4$

\section{9-49 yrs}

\section{Total}

White

Black

Hispanic or Latino

Asian

Other

Traveler

Nontraveler

With chronic liver

conditions, overall

\section{$\geq 50$ yrs}

Total

Traveler

Nontraveler

With chronic liver

conditions, overall

$\begin{array}{rlll}32,571 & 24.5 & (23.8-25.3) & -0.5 \\ 10,442 & 30.5 & (29.2-31.8) & -2.6 \text { ตी } \\ 22,088 & 21.4 & (20.5-22.3)^{* * * *} & 0.5 \\ 448 & 29.8 & (23.9-36.5) & -4.2\end{array}$

With diabetes, overall

\begin{tabular}{lllll}
$19-59$ yrs & 1,367 & 23.5 & $(20.7-26.7)$ & -2.8 \\
$\geq 60$ yrs & 2,097 & 13.5 & $(11.4-16.0)$ & -0.3 \\
\hline
\end{tabular}

See table footnotes on page 22 .
TABLE 1. (Continued) Estimated proportion of adults aged $\geq 19$ years who received selected vaccinations, by age group, high-risk status, * and race/ethnicity ${ }^{\dagger}$ — National Health Interview Survey, United States, 2014

\begin{tabular}{lcccc}
\hline $\begin{array}{l}\text { Vaccination, age group, } \\
\text { high-risk status, and } \\
\text { race/ethnicity }\end{array}$ & $\begin{array}{c}\text { Sample } \\
\text { size }\end{array}$ & $\%$ & $(95 \% \mathrm{Cl})$ & $\begin{array}{c}\text { Simple } \\
\text { difference } \\
\text { from } 2013\end{array}$ \\
\hline
\end{tabular}

Herpes zoster (shingles) vaccination, ever $\$ \S \S \S$

$\geq 60$ yrs

Total

White

Black

Hispanic or Latino

$11,263 \quad 27.9$

(26.6-29.1) $\quad 3.6$ กา

Asian

$8,153 \quad 32.0$

$(30.5-33.5)$

$(9.6-13.8)^{9}$

$\begin{array}{lll}1,352 & 11.6 & (9.6-13.8) \\ 1,037 & 14.6 & (12.2-17.5)^{9}\end{array}$

$(12.9-20.8)^{9}$

Other

$492 \quad 16.5$

$(9.9-25.3)^{9}$

4.6 ศी

0.9

$5.2^{\text {१19 }}$

$-6.1$

60-64 yrs

Total

$229 \quad 16.2$

$-8.3$

White

Black

Hispanic or Latino

$2,912 \quad 20.4$

(18.4-22.5)

$2,038 \quad 24.3 \quad(21.9-26.9)$

$(5.1-12.5)^{\natural}$

$\begin{array}{lll}394 & 11.2 \quad(7.6-16.3)^{9}\end{array}$

2.2

Asian

Other

$\geq 65$ yrs

Total

White

Black

Hispanic or Latino

118 -

$-$

3.4

0.3

3.7

Asian

Other

$8,351 \quad 31.1$

(29.6-32.6)

(33.3-36.9)

$(11.0-16.4)^{9}$

$(13.2-20.1)^{9}$

$(16.3-26.1)^{9}$

$(11.2-32.0)^{9}$

-

HPV vaccination among females (at least 1 dose), ever ๆๆงๆ 19-21 yrs

$\begin{array}{lrrrr}\begin{array}{l}\text { Total } \\ \text { 22-26 yrs }\end{array} & 613 & 44.8 & (37.3-52.6) & 0.2 \\ \begin{array}{l}\text { Total } \\ \text { 19-26 yrs }\end{array} & 1,427 & 37.6 & (34.2-41.2) & 5.3^{\text {กา }} \\ \text { Total } & & & & \\ \text { White } & 2,040 & 40.2 & (36.6-44.0) & 3.4 \\ \text { Black } & 1,137 & 46.3 & (40.9-51.7) & 4.5 \\ \text { Hispanic or Latino } & 279 & 37.4 & (30.6-44.6) & 6.8 \\ \text { Asian } & 408 & 28.1 & (22.6-34.3)^{9} & -2.3 \\ \text { Other } & 137 & 22.8 & (15.4-32.2)^{9} & 2.9 \\ & 79 & 47.3 & (31.3-63.9) & 4.2\end{array}$

HPV vaccination among males (at least 1 dose), ever ๆงๆา

19-26 yrs

$\begin{array}{lllll}\text { Total } & 1,895 & 8.2 & (6.6-10.3) & 2.3\end{array}$

19-21 yrs

$\begin{array}{lllll}\text { Total } & 596 & 13.3 & (9.7-18.0) & 5.6 \text { กา }\end{array}$

$22-26$ yrs

$\begin{array}{lllll}\text { Total } & 1,299 & 5.4 & (4.0-7.2) & 0.4\end{array}$

HPV vaccination among females (at least 1 dose), ever १ึ१ๆๆ who reported first HPV dose at age 19-26 $\mathrm{yrs}^{* * * * *}$

\begin{tabular}{lrrrr} 
Total & $\mathbf{1 , 4 2 0}$ & $\mathbf{1 1 . 8}$ & $(\mathbf{9 . 8}-14.3)$ & $-\mathbf{2 . 1}$ \\
White & 734 & 13.9 & $(10.8-17.7)$ & -2.1 \\
Black & 208 & 14.1 & $(9.2-21.1)$ & 1.8 \\
Hispanic or Latino & 314 & 7.4 & $(4.6-11.6)^{9}$ & -2.8 \\
Asian & 113 & - & - & - \\
Other & 51 & - & - & - \\
\hline
\end{tabular}

See table footnotes on page 22 . 
TABLE 1. (Continued) Estimated proportion of adults aged $\geq 19$ years who received selected vaccinations, by age group, high-risk status, ${ }^{*}$ and race/ethnicity ${ }^{\dagger}$ — National Health Interview Survey, United States, 2014

\begin{tabular}{lcccc}
\hline $\begin{array}{l}\text { Vaccination, age group, } \\
\text { high-risk status, and } \\
\text { race/ethnicity }\end{array}$ & $\begin{array}{c}\text { Sample } \\
\text { size }\end{array}$ & $\%$ & $(95 \% \mathrm{Cl})$ & $\begin{array}{c}\text { Simple } \\
\text { difference } \\
\text { from } 2013\end{array}$ \\
\hline
\end{tabular}

HPV vaccination among males (at least 1 dose), ever HPV dose at age $19-26 \mathrm{yrs}^{* * * * *}$

$\begin{array}{lrrrr}\text { Total } & \mathbf{1 , 7 8 1} & \mathbf{2 . 3} & (\mathbf{1 . 5}-3.5) & 0.6 \\ \text { White } & 999 & 2.0 & (1.1-3.4) & 0.1 \\ \text { Black } & 215 & - & - & - \\ \text { Hispanic or Latino } & 372 & - & - & - \\ \text { Asian } & 124 & - & - & - \\ \text { Other } & 71 & - & - & -\end{array}$

Abbreviations: $\mathrm{Cl}=$ confidence interval; $\mathrm{HPV}=$ human papillomavirus; $\mathrm{Td}=$ tetanusdiphtheria toxoid; Tdap = tetanus, diphtheria, and acellular pertussis vaccine.

* Adults were considered at high risk for pneumococcal disease if they had ever been told by a doctor or other health professional that they had diabetes, emphysema, chronic obstructive pulmonary disease, coronary heart disease, angina, heart attack, or other heart condition; had a diagnosis of cancer during the previous 12 months (excluding nonmelanoma skin cancer); had ever been told by a doctor or other health professional that they had lymphoma, leukemia, or blood cancer; had been told by a doctor or other health professional that they had chronic bronchitis or weak or failing kidneys during the preceding 12 months; had an asthma episode or attack during the preceding 12 months; or were current smokers. For hepatitis A and hepatitis B vaccination, data were collected on selected respondent characteristics that increase the risk for infection (travel to countries where hepatitis A infections are endemic and having chronic liver disease; having diabetes, travel to countries where hepatitis B infections are endemic, and having chronic liver disease, respectively).

${ }^{\dagger}$ Race/ethnicity was categorized as follows: Hispanic, black, white, Asian and "other." In this report, persons identified as Hispanic might be of any race. Persons identified as black, white, Asian, or other race are nonHispanic. "Other" includes American Indian/Alaska Native and multiple race. The five racial/ethnic categories are mutually exclusive.

$\S$ Respondents were asked if they had received an influenza shot or nasal spray in the past 12 months and if so, in which month and year. Missing month and year were imputed (3.1\%) and interviews conducted during August 2013-June 2014 were used to estimate vaccination coverage during July 2013-May 2014 using Kaplan-Meier survival analysis. Differences were measured as the simple difference between the 2012-13 and 2013-14 influenza seasons.

I $\mathrm{p}<0.05$ by $\mathrm{T}$ test for comparisons with non-Hispanic white as the reference.
TABLE 1. (Continued) Estimated proportion of adults aged $\geq 19$ years who received selected vaccinations, by age group, high-risk status, ${ }^{*}$ and race/ethnicity ${ }^{\dagger}$ - National Health Interview Survey, United States, 2014

** Respondents were asked if they had ever had a pneumonia shot.

${ }^{t+}$ Respondents were asked if they had received a tetanus shot in the past 10 years. Vaccinated respondents included adults who received Td during the past 10 years or Tdap during 2005-2014.

$\S \S$ Respondents who had received a tetanus shot in the past 10 years were asked if their most recent shot was given in $\mathbf{2 0 0 5}$ or later. Respondents who had received a tetanus shot since 2005 were asked if they were told that their most recent tetanus shot included the pertussis or whooping cough vaccine. Among 36,324 respondents aged $\geq 19$ yrs, those without a "yes" or "no" classification for tetanus vaccination status within the preceding 10 years $(n=1,977[5.4 \%])$, for tetanus vaccination status during 2005-2014 $(n=1,098$ [3.0\%]), or those who reported tetanus vaccination during 2005-2014, but were not told vaccine type by the provider $(n=8,612[23.7 \%])$, did not know vaccine type (Td or Tdap) ( $n=1,765[4.9 \%])$, or refused to answer or for whom data were not obtained $(n=5[0.01 \%])$ were excluded, yielding a sample of 22,867 respondents aged $\geq 19$ years for whom Tdap vaccination status could be assessed. In February 2012, ACIP recommended Tdap vaccination for all adults aged $\geq 19$ years, including adults aged $\geq 65$ years.

กๆ $p<0.05$ by $T$ test for comparisons between 2014 and 2013 within each level of each characteristic.

*** Estimate is not reliable due to small sample size $(n<30)$ or relative standard error (standard error/estimates) $>0.3$.

${ }^{+\dagger+}$ Respondents were asked if they had ever received the hepatitis A vaccine, and if yes, were asked how many doses were received.

$\S \S \S$ Had traveled outside the United States to countries other than countries in Europe, Japan, Australia, New Zealand, or Canada since 1995.

กาศ $\mathrm{Had}$ not traveled outside the United States to countries other than countries in Europe, Japan, Australia, New Zealand, or Canada since 1995.

**** $\mathrm{p}<0.05$ by $\mathrm{T}$ test for comparisons between persons who had traveled outside the United States to countries other than countries in Europe, Japan, Australia, New Zealand, or Canada since 1995 and persons who had not traveled outside the United States to these areas since 1995.

${ }^{+t+t}$ Respondents were asked if they had ever received the hepatitis B vaccine, and if yes, if they had received at least 3 doses or less than 3 doses.

$\S \S \S \S$ Respondents were asked if they had ever received a shingles vaccine.

ๆาๆๆ Respondents were asked if they had ever received the HPV shot or cervical cancer vaccine, and if yes, age at the first dose.

***** The denominator includes persons aged 19-26 years without HPV vaccination prior to age 19 years, and the numerator includes those in the denominator who reported first HPV dose at age 19-26 years. 
TABLE 2. Estimated proportion of health care personnel* who received selected vaccinations, by race/ethnicity ${ }^{\dagger}$ - National Health Interview Survey, United States, 2014

\begin{tabular}{|c|c|c|c|c|}
\hline $\begin{array}{l}\text { Vaccination and } \\
\text { race/ethnicity }\end{array}$ & $\begin{array}{l}\text { Sample } \\
\text { size }\end{array}$ & $\%$ & $(95 \% \mathrm{Cl})$ & $\begin{array}{l}\text { Simple } \\
\text { differenc } \\
\text { from } 201\end{array}$ \\
\hline \multicolumn{5}{|c|}{ Influenza vaccination, 2013-14 season $\$$} \\
\hline \multicolumn{5}{|l|}{$\geq 19 \mathrm{yrs}$} \\
\hline Total & 2,636 & 65.4 & $(61.0-69.9)$ & -1.9 \\
\hline White & 1,729 & 67.6 & $(61.7-73.4)$ & -2.7 \\
\hline Black & 406 & 50.3 & $(42.9-58.2)^{9}$ & -1.8 \\
\hline Hispanic or Latino & 288 & 65.6 & $(53.3-77.7)$ & 6.1 \\
\hline Asian & 157 & 77.7 & $(63.9-89.0)$ & -2.6 \\
\hline Other & 56 & 60.3 & $(37.1-84.1)$ & -0.4 \\
\hline \multicolumn{5}{|l|}{$19-49$ yrs } \\
\hline Total & 1,590 & 61.7 & $(55.3-68.1)$ & -1.5 \\
\hline White & 947 & 63.4 & $(54.6-72.2)$ & 0.3 \\
\hline Black & 268 & 48.0 & $(38.8-58.1)^{\pi}$ & -7.4 \\
\hline Hispanic or Latino & 222 & 67.3 & $(50.8-82.9)$ & 12.7 \\
\hline Asian & 109 & 75.3 & $(62.6-86.4)$ & -8.7 \\
\hline Other & 44 & 61.0 & $(36.6-85.7)$ & -8.0 \\
\hline \multicolumn{5}{|l|}{$50-64$ yrs } \\
\hline Total & 770 & 71.1 & $(65.8-76.3)$ & -2.7 \\
\hline White & 556 & 72.1 & $(66.0-77.9)$ & $-8.9^{* *}$ \\
\hline Black & 117 & 58.5 & $(43.6-74.0)$ & 19.5 \\
\hline Hispanic or Latino & 53 & 77.9 & $(60.0-91.7)$ & 8.1 \\
\hline Asian & 37 & 78.8 & $(48.4-97.4)$ & 22.3 \\
\hline Other & 7 & $-^{\dagger+}$ & - & - \\
\hline \multicolumn{5}{|l|}{$\geq 65 \mathrm{yrs}$} \\
\hline Total & 276 & 75.2 & $(66.6-83.0)$ & -3.2 \\
\hline White & 226 & 79.6 & $(70.8-87.2)$ & 1.7 \\
\hline Black & 21 & - & - & - \\
\hline Hispanic or Latino & 13 & - & - & - \\
\hline Asian & 11 & - & - & - \\
\hline Other & 5 & - & - & - \\
\hline
\end{tabular}

Tetanus vaccination including pertussis vaccine, past 9 years $\S^{\S}$

\section{$\geq 19$ yrs}

Tota

White

Black

Hispanic or Latino

Asian

Other

19-64 yrs

Total

White

Black

Hispanic or Latino

Asian

Other

2,062

1,353

42.1

46.4

(39.1-45.0)

(42.7-50.2)

$(18.8-31.9)^{\natural}$

$(27.8-44.7)^{9}$

(29.9-53.5)

(24.3-57.1)

4.7

$6.5^{* *}$

$-7.4$

6.3

8.5

120

41.2

56

$(40.0-46.1)$

(44.0-51.8)

$(18.9-32.3)^{9}$

$(28.2-45.4)^{9}$

(30.3-54.7)

(24.0-57.7)

$-7.3$

5.1

$7.1^{* *}$

$-8.3$

7.8

8.2

$-9.2$

$\geq 65$ yrs

Total

White

Black

Hispanic or Latino

Asian

Other
TABLE 2. (Continued) Estimated proportion of health care personnel* who received selected vaccinations, by race/ethnicity ${ }^{\dagger}$ - National Health Interview Survey, United States, 2014

\begin{tabular}{|c|c|c|c|c|}
\hline $\begin{array}{l}\text { Vaccination and } \\
\text { race/ethnicity }\end{array}$ & $\begin{array}{c}\text { Sample } \\
\text { size }\end{array}$ & $\%$ & $(95 \% \mathrm{Cl})$ & $\begin{array}{c}\text { Simple } \\
\text { difference } \\
\text { from } 2013\end{array}$ \\
\hline \multicolumn{5}{|c|}{ Hepatitis B vaccination (at least 3 doses), ever ๆๆ } \\
\hline $\begin{array}{l}\geq 19 \text { yrs } \\
\text { Total }\end{array}$ & 2,757 & 60.7 & $(58.1-63.2)$ & -1.0 \\
\hline White & 1,822 & 63.0 & $(59.7-66.3)$ & 0.1 \\
\hline Black & 420 & 51.4 & $(45.6-57.1)^{\natural}$ & -7.5 \\
\hline Hispanic or Latino & 295 & 51.1 & $(43.2-59.0)^{\natural}$ & -2.9 \\
\hline Asian & 154 & 68.2 & $(58.7-76.5)$ & -0.7 \\
\hline Other & 66 & 60.8 & $(44.7-74.8)$ & 4.8 \\
\hline
\end{tabular}

Abbreviations: $\mathrm{Cl}=$ confidence interval; $\mathrm{Td}=$ tetanus-diphtheria toxoid; Tdap = tetanus, diphtheria, and acellular pertussis vaccine.

* Adults were classified as health care personnel if they reported they currently volunteer or work in a hospital, medical clinic, doctor's office, dentist's office, nursing home or some other health care facility including part-time and unpaid work in a health care facility as well as professional nursing care provided in the home.

† Race/ethnicity was categorized as follows: Hispanic, black, white, Asian and "other." In this report, persons identified as Hispanic might be of any race. Persons identified as black, white, Asian, or other race are non-Hispanic. "Other" includes American Indian/Alaska Native and multiple race. The five racial/ethnic categories are mutually exclusive.

$\S$ Respondents were asked if they had received an influenza shot or nasal spray in the past 12 months and if so, in which month and year. Missing month and year were imputed (3.1\%), and interviews conducted during August 2013-June 2014 were used to estimate vaccination coverage during July 2013-May 2014 using Kaplan-Meier survival analysis. Differences were measured as the simple difference between the 2012-13 and 2013-14 influenza seasons.

I $\mathrm{p}<0.05$ by $\mathrm{T}$ test for comparisons with non-Hispanic white as the reference. ** $p<0.05$ by $T$ test for comparisons between 2014 and 2013 within each level of each characteristic.

${ }^{\text {t† }}$ Estimate is not reliable due to small sample size $(\mathrm{n}<30)$ or relative standard error (standard error/estimates) $>0.3$.

$\S \S$ Respondents who had received a tetanus shot in the past 10 years were asked if their most recent shot was given in 2005 or later. Respondents who had received a tetanus shot since 2005 were asked if they were told that their most recent tetanus shot included the pertussis or whooping cough vaccine. Among 2,933 health care personnel aged $\geq 19$ years, those without a "yes" or "no" classification for tetanus vaccination status within the preceding 10 years $(n=68[2.3 \%])$, for tetanus vaccination status during 2005-2014 ( $n=75$ [2.6\%]), or those who reported tetanus vaccination during 2005-2014, but were not told vaccine type by the provider $(n=608$ [20.7\%]) or did not know vaccine type (Td or Tdap) $(n=120$ [4.1\%]) were excluded, yielding a sample of 2,062 respondents aged $\geq 19$ years for whom Tdap vaccination status could be assessed. In February 2012, ACIP recommended Tdap vaccination for all adults aged $\geq 19$ years, including adults aged $\geq 65$ years.

กศ Respondents were asked if they had ever received the hepatitis B vaccine, and if yes, if they had received at least 3 doses or less than 3 doses. 
TABLE 3. Estimated proportion of health care personnel* with direct patient care responsibilities who received selected vaccinations, by race/ethnicity - National Health Interview Survey, United States, 2014

\begin{tabular}{|c|c|c|c|c|}
\hline $\begin{array}{l}\text { Vaccination, direct patient } \\
\text { care responsibilities, }{ }^{\dagger} \text { and } \\
\text { race/ethnicity }{ }^{\S}\end{array}$ & $\begin{array}{l}\text { Sample } \\
\text { size }\end{array}$ & $\%$ & $(95 \% \mathrm{Cl})$ & $\begin{array}{l}\text { Simple } \\
\text { difference } \\
\text { from } 2013\end{array}$ \\
\hline
\end{tabular}

Influenza vaccination, 2013-14 season"

$\geq 19 \mathrm{yrs}$, with direct patient care responsibilities

$\begin{array}{lrrrr}\text { Total } & 1,620 & 65.1 & (58.6-71.6) & -2.9 \\ \text { White } & 1,037 & 65.6 & (56.7-74.3) & -6.4 \\ \text { Black } & 268 & 52.9 & (43.8-62.5) & 4.3 \\ \text { Hispanic or Latino } & 175 & 74.8 & (57.8-89.0) & 20.8^{* *} \\ \text { Asian } & 105 & 79.8 & (62.9-92.5) & -6.2 \\ \text { Other } & 35 & 60.7 & (32.0-89.5) & -4.4 \\ \geq 19 \text { yrs, without direct patient care responsibilities } & \\ \text { Total } & 1,016 & 66.0 & (59.9-72.1) & -0.1 \\ \text { White } & 692 & 70.7 & (63.3-77.8) & 3.0 \\ \text { Black } & 138 & 43.9 & (33.8-55.4)^{\dagger+} & -11.9 \\ \text { Hispanic or Latino } & 113 & 52.6 & (35.8-71.6) & -16.9 \\ \text { Asian } & 52 & 72.3 & (50.6-90.3) & 0.1 \\ \text { Other } & 21 & -\$ \$ & - & -\end{array}$

Tetanus vaccination including pertussis vaccine, past 9 years ใी $\geq 19$ yrs, with direct patient care responsibilities

\begin{tabular}{|c|c|c|c|c|}
\hline Total & 1,355 & 47.5 & $(43.9-51.2)$ & 5.6 \\
\hline White & 880 & 52.4 & $(47.9-56.8)$ & $7.6^{* *}$ \\
\hline Black & 220 & 28.9 & $(21.8-37.2)^{\dagger \dagger}$ & -7.7 \\
\hline Hispanic or Latino & 139 & 43.5 & $(33.0-54.7)$ & 8.5 \\
\hline Asian & 82 & 45.1 & $(30.6-60.5)$ & 10.7 \\
\hline Other & 34 & 46.4 & $(25.7-68.3)$ & -7.0 \\
\hline \multicolumn{5}{|c|}{$\geq 19 \mathrm{yrs}$, without direct patient care responsibilities } \\
\hline Total & 707 & 31.6 & $(26.9-36.8)^{* * *}$ & 2.0 \\
\hline White & 473 & 35.5 & $(29.2-42.4)^{* * *}$ & 3.4 \\
\hline Black & 95 & - & - & - \\
\hline Hispanic or Latino & 79 & 22.8 & $(12.5-38.1)^{* * *}$ & 3.5 \\
\hline Asian & 38 & 33.6 & $(18.2-53.7)$ & 4.3 \\
\hline Other & 22 & - & - & - \\
\hline \multicolumn{5}{|c|}{ Hepatitis B vaccination (at least 3 doses), ever ${ }^{\dagger+\dagger}$} \\
\hline \multicolumn{5}{|c|}{$\geq 19$ yrs, with direct patient care responsibilities } \\
\hline Total & 1,754 & 67.7 & $(63.8-71.4)$ & -5.0 \\
\hline White & 1,140 & 70.9 & $(65.6-75.8)$ & -3.8 \\
\hline Black & 287 & 56.6 & $(49.6-63.3)^{\dagger+}$ & $-11.2^{* *}$ \\
\hline Hispanic or Latino & 178 & 59.4 & $(48.1-69.7)$ & -5.6 \\
\hline Asian & 107 & 69.2 & $(56.8-79.3)$ & -4.1 \\
\hline Other & 42 & 70.2 & $(52.4-83.5)$ & -7.8 \\
\hline \multicolumn{5}{|c|}{$\geq 19$ yrs, without direct patient care responsibilities } \\
\hline Total & 1,003 & 47.6 & $(43.6-51.7)^{* * *}$ & 2.5 \\
\hline White & 682 & 49.1 & $(43.7-54.4)^{* * *}$ & 4.0 \\
\hline Black & 133 & 38.4 & $(29.4-48.3)^{* * *}$ & -7.8 \\
\hline Hispanic or Latino & 117 & 38.7 & $(29.0-49.4)^{* * *}$ & 2.7 \\
\hline Asian & 47 & 66.2 & $(48.3-80.4)$ & 3.7 \\
\hline Other & 24 & - & - & —§§ \\
\hline
\end{tabular}

TABLE 3. (Continued) Estimated proportion of health care personnel* with direct patient care responsibilities who received selected vaccinations, by race/ethnicity - National Health Interview Survey, United States, 2014

Abbreviations: $\mathrm{Cl}=$ confidence interval; $\mathrm{HCP}=$ health care personnel; $\mathrm{Td}=$ tetanusdiphtheria toxoid; Tdap = tetanus, diphtheria, and acellular pertussis vaccine.

* Adults were classified as HCP if they reported that they currently volunteer or work in a hospital, medical clinic, doctor's office, dentist's office, nursing home or some other health care facility including part-time and unpaid work in a health care facility as well as professional nursing care provided in the home.

${ }^{\dagger} \mathrm{HCP}$ were classified as having direct patient care responsibilities if they reported providing direct patient care (physical or hands-on contact with patients) as part of their routine work.

$\S$ Race/ethnicity was categorized as follows: Hispanic, black, white, Asian and "other." In this report, persons identified as Hispanic might be of any race. Persons identified as black, white, Asian, or other race are non-Hispanic. "Other" includes American Indian/Alaska Native and multiple race. The five racial/ethnic categories are mutually exclusive.

" Respondents were asked if they had received an influenza shot or nasal spray in the past 12 months and if so, in which month and year. Missing month and year were imputed (3.1\%), and interviews conducted during August 2013-June 2014 were used to estimate vaccination coverage during July 2013-May 2014 using Kaplan-Meier survival analysis. Differences were measured as the simple difference between the 2012-13 and 2013-14 influenza seasons.

** $p<0.05$ by $T$ test for comparisons between 2014 and 2013 within each level of each characteristic.

${ }^{+t} p<0.05$ by $T$ test for comparisons with non-Hispanic white as the reference.

$\S \S$ Estimate is not reliable due to small sample size $(\mathrm{n}<30)$ or relative standard error (standard error/estimates) $>0.3$.

กा Respondents who had received a tetanus shot in the past 10 years were asked if their most recent shot was given in 2005 or later. Respondents who had received a tetanus shot since 2005 were asked if they were told that their most recent tetanus shot included the pertussis or whooping cough vaccine. Among 2,933 HCP aged $\geq 19$ years, those without a "yes" or "no" classification for tetanus vaccination status within the preceding 10 years $(n=68[2.3 \%])$, for tetanus vaccination status during 2005-2014 $(n=75$ [2.6\%]), or those who reported tetanus vaccination during 2005-2014, but were not told vaccine type by the provider $(n=608$ [20.7\%]) or did not know vaccine type (Td or Tdap) $(n=120[4.1 \%]$ ) were excluded, yielding a sample of 2,062 respondents aged $\geq 19$ years for whom Tdap vaccination status could be assessed. In February 2012, ACIP recommended Tdap vaccination for all adults aged $\geq 19$ years, including adults aged $\geq 65$ years.

*** $p<0.05$ by $T$ test for comparisons between HCP with direct patient care responsibilities and $\mathrm{HCP}$ without direct patient care responsibilities.

${ }^{\mathrm{t+}}$ Respondents were asked if they had ever received the hepatitis B vaccine, and if yes, if they had received at least 3 doses or less than 3 doses. 
TABLE 4. Type of tetanus vaccine received, and proportion that were tetanus, diphtheria, acellular pertussis (Tdap) vaccine, among adults aged $\geq 19$ years, by selected characteristics - National Health Interview Survey, United States, 2014

\begin{tabular}{|c|c|c|c|c|c|c|c|c|c|c|c|c|}
\hline \multirow[b]{3}{*}{ Characteristic } & \multicolumn{9}{|c|}{ Type of tetanus toxoid-containing vaccine received during 2005-2014 } & \multirow{2}{*}{\multicolumn{3}{|c|}{$\begin{array}{l}\text { Proportion that was Tdap of the } \\
\text { total tetanus toxoid-containing } \\
\text { vaccine received during } \\
2005-2014^{*}\end{array}$}} \\
\hline & \multirow[b]{2}{*}{$\begin{array}{l}\text { No. in } \\
\text { sample }\end{array}$} & \multicolumn{2}{|c|}{ Received Tdap } & \multicolumn{2}{|c|}{$\begin{array}{l}\text { Received other } \\
\text { tetanus vaccine }\end{array}$} & \multicolumn{2}{|c|}{$\begin{array}{l}\text { Doctor did not } \\
\text { inform patient }\end{array}$} & \multicolumn{2}{|c|}{$\begin{array}{l}\text { Could not recall } \\
\text { vaccine type }\end{array}$} & & & \\
\hline & & $\%$ & $(95 \% \mathrm{Cl})$ & $\%$ & $(95 \% \mathrm{Cl})$ & $\%$ & $(95 \% \mathrm{Cl})$ & $\%$ & $(95 \% \mathrm{Cl})$ & $\begin{array}{l}\text { No. in } \\
\text { sample }\end{array}$ & $\%$ & $(95 \% \mathrm{Cl})$ \\
\hline \multicolumn{13}{|l|}{ Age group (yrs) } \\
\hline \multicolumn{13}{|l|}{$\geq 19$} \\
\hline Total & 16,823 & 26.2 & $(25.2-27.3)$ & 11.2 & $(10.4-12.0)$ & 51.3 & $(49.9-52.8)$ & 11.3 & $(10.3-12.3)$ & 6,437 & 70.1 & $(68.2-72.0)$ \\
\hline $\mathrm{HCP}^{\dagger}$ & 1,800 & 46.6 & $(43.3-50.0)$ & 11.2 & $(9.2-13.6)$ & 35.1 & $(30.7-39.7)$ & 7.1 & $(5.4-9.3)$ & 1,072 & $80.6^{\S}$ & $(77.2-83.6)$ \\
\hline Non-HCP & 15,009 & 23.8 & $(22.7-24.9)$ & 11.2 & $(10.4-12.1)$ & 53.3 & $(51.8-54.7)$ & 11.7 & $(10.8-12.8)$ & 5,363 & 68.0 & $(65.9-70.1)$ \\
\hline \multicolumn{13}{|l|}{$19-64$} \\
\hline Total & 13,364 & 27.4 & $(26.3-28.6)$ & 11.4 & $(10.5-12.3)$ & 50.0 & $(48.5-51.5)$ & 11.2 & $(10.2-12.3)$ & 5,358 & 70.7 & $(68.6-72.7)$ \\
\hline $\mathrm{HCP}$ & 1,614 & 48.3 & $(44.7-51.9)$ & 11.3 & $(9.2-13.7)$ & 33.5 & $(28.9-38.3)$ & 7.0 & $(5.2-9.2)$ & 996 & $81.1^{\S}$ & $(77.8-84.1)$ \\
\hline Non-HCP & 11,738 & 24.6 & $(23.4-25.8)$ & 11.4 & $(10.4-12.4)$ & 52.2 & $(50.7-53.8)$ & 11.8 & $(10.8-12.9)$ & 4,360 & 68.4 & $(66.0-70.7)$ \\
\hline \multicolumn{13}{|l|}{$\geq 65$} \\
\hline Total & 3,459 & 20.5 & $(18.6-22.6)$ & 10.3 & $(8.9-11.9)$ & 57.7 & $(55.2-60.2)$ & 11.4 & $(10.0-13.1)$ & 1,079 & 66.5 & $(62.3-70.5)$ \\
\hline $\mathrm{HCP}$ & 186 & 27.2 & $(19.8-36.0)$ & 10.6 & $(6.1-17.7)$ & 53.3 & $(44.2-62.2)$ & 8.9 & $(4.1-18.2)$ & 76 & 71.9 & $(57.1-83.1)$ \\
\hline Non-HCP & 3,271 & 20.2 & $(18.2-22.3)$ & 10.3 & $(8.9-11.9)$ & 58.0 & (55.5-60.5) & 11.5 & $(10.0-13.2)$ & 1,003 & 66.2 & $(61.8-70.3)$ \\
\hline
\end{tabular}

Abbreviations: $\mathrm{Cl}=$ confidence interval; $\mathrm{HCP}=$ health care personnel; $\mathrm{Td}=$ tetanus-diphtheria toxoid; $\mathrm{Tdap}=$ tetanus, diphtheria, and acellular pertussis vaccine.

* Calculated by dividing the number of respondents who reported receiving Tdap by the sum of those who reported receiving Tdap and those who reported receiving other tetanus vaccination; respondents who reported that the doctor did not inform them of the vaccine type they received and those who could not recall the vaccine type were excluded.

+ Adults were classified as HCP if they reported they currently volunteer or work in a hospital, medical clinic, doctor's office, dentist's office, nursing home or some other health care facility including part-time and unpaid work in a health care facility as well as professional nursing care provided in the home.

$\S p<0.05$ by $T$ test for comparisons between HCP and non-HCP. 
TABLE 5. Age at first dose of human papillomavirus vaccination* and difference between age at interview ${ }^{\dagger}$ among adults aged 19-26 years - National Health Interview Survey, 2014, United States

\begin{tabular}{|c|c|c|c|c|}
\hline \multirow[b]{2}{*}{ Characteristic } & \multicolumn{2}{|c|}{ Female $(\mathrm{N}=811)$} & \multicolumn{2}{|c|}{ Male $(\mathrm{N}=159)$} \\
\hline & No. & Weighted \% & No. & Weighted \% \\
\hline \multicolumn{5}{|c|}{ Age at first dose (yrs) } \\
\hline $8-10$ & 21 & 2.1 & 18 & 13.0 \\
\hline 8 & 7 & 0.8 & 8 & 6.4 \\
\hline 9 & 6 & 0.5 & 2 & 0.1 \\
\hline 10 & 8 & 0.8 & 8 & 6.5 \\
\hline $11-12$ & 37 & 7.4 & 9 & 3.5 \\
\hline 11 & 5 & 0.6 & 2 & 0.6 \\
\hline 12 & 32 & 6.8 & 7 & 2.9 \\
\hline $13-17$ & 443 & 58.1 & 45 & 33.1 \\
\hline 13 & 55 & 6.4 & 8 & 3.2 \\
\hline 14 & 65 & 7.1 & 4 & 1.2 \\
\hline 15 & 86 & 11.7 & 7 & 5.1 \\
\hline 16 & 147 & 22.6 & 12 & 10.0 \\
\hline 17 & 90 & 10.4 & 14 & 13.5 \\
\hline 18 & 119 & 12.5 & 42 & 24.4 \\
\hline $19-26$ & 191 & 19.9 & 45 & 25.9 \\
\hline 19 & 49 & 6.5 & 9 & 7.3 \\
\hline 20 & 49 & 4.3 & 12 & 8.4 \\
\hline 21 & 28 & 2.8 & 4 & 2.8 \\
\hline 22 & 18 & 1.4 & 8 & 3.0 \\
\hline 23 & 20 & 2.3 & 7 & 1.9 \\
\hline 24 & 19 & 1.9 & 2 & 0.8 \\
\hline 25 & 6 & 0.5 & 2 & 0.3 \\
\hline 26 & 2 & 0.2 & 1 & 1.5 \\
\hline \multicolumn{5}{|c|}{ Difference between age at interview and age at first dose (yrs) } \\
\hline 0 & 14 & 2.0 & 10 & 3.2 \\
\hline 1 & 32 & 3.7 & 19 & 10.8 \\
\hline 2 & 55 & 5.4 & 23 & 21.5 \\
\hline 3 & 72 & 11.9 & 13 & 10.4 \\
\hline 4 & 90 & 11.2 & 25 & 16.2 \\
\hline 5 & 97 & 11.1 & 10 & 6.5 \\
\hline 6 & 111 & 11.7 & 13 & 5.7 \\
\hline 7 & 130 & 15.5 & 15 & 7.8 \\
\hline 8 & 86 & 14.4 & 4 & 1.9 \\
\hline 9 & 52 & 5.9 & 3 & 2.2 \\
\hline 10 & 31 & 3.8 & 1 & 0 \\
\hline 11 & 15 & 1.2 & 4 & 5.2 \\
\hline 12 & 10 & 0.9 & 7 & 2.4 \\
\hline 13 & 8 & 0.5 & 7 & 4.3 \\
\hline 14 & 6 & 0.6 & 2 & 1.0 \\
\hline 15 & 1 & 0.1 & 0 & 0 \\
\hline 16 & 1 & 0 & 1 & 0.6 \\
\hline 17 & 0 & 0 & 1 & 0 \\
\hline 18 & 0 & 0 & 1 & 0.3 \\
\hline
\end{tabular}

Abbreviation: $\mathrm{HPV}=$ human papillomavirus.

* Respondents were asked, "How old were you when you received your first HPV shot?"

† The simple difference between age reported at time of interview and age the respondent indicated the first dose of the HPV vaccine was received. A difference of "zero" indicates that a respondent's reported age at first dose was the same as their age at interview. 
TABLE 6. Estimated proportion of adults aged $\geq 19$ years who received selected vaccinations, by age group, high-risk status, ${ }^{*}$ and health insurance status ${ }^{\dagger}$ - National Health Interview Survey, United States, 2014

\begin{tabular}{|c|c|c|c|c|c|c|c|c|}
\hline \multirow[b]{3}{*}{ Vaccination, age group, high-risk status } & \multicolumn{6}{|c|}{ With health insurance } & \multirow{2}{*}{\multicolumn{2}{|c|}{$\begin{array}{l}\text { Without health } \\
\text { insurance }\end{array}$}} \\
\hline & \multicolumn{2}{|r|}{ Overall } & \multicolumn{2}{|r|}{ Public } & \multicolumn{2}{|r|}{ Private } & & \\
\hline & $\%$ & $(95 \% \mathrm{Cl})$ & $\%$ & $(95 \% \mathrm{Cl})$ & $\%$ & $(95 \% \mathrm{Cl})$ & $\%$ & $(95 \% \mathrm{Cl})$ \\
\hline \multicolumn{9}{|l|}{ Influenza vaccination (2013-14 season) ${ }^{\S}$} \\
\hline$\geq 19 \mathrm{yrs}$ & 48.0 & $(46.8-49.2)^{9}$ & 54.3 & $(52.3-56.3)^{\uparrow, * *}$ & 45.7 & $(44.2-47.2)^{9}$ & 15.9 & $(14.2-17.9)$ \\
\hline $19-49$ yrs & 35.9 & $(34.3-37.6)^{9}$ & 37.0 & $(33.2-41.0)^{9}$ & 35.7 & $(33.9-37.6)^{9}$ & 14.3 & $(12.4-16.5)$ \\
\hline $50-64$ yrs & 51.3 & $(49.1-53.5)^{9,+\dagger}$ & 54.2 & $(50.3-58.2)^{9,+十}$ & 50.5 & $(47.9-53.2)^{\uparrow,+\dagger}$ & 20.4 & $(16.6-24.8)^{\dagger+}$ \\
\hline$\geq 65$ yrs & 72.0 & $(70.1-73.8)^{9,+十}$ & 70.2 & $(67.5-72.8)^{\uparrow,+\dagger}$ & 73.7 & $(71.0-76.4)^{\natural,+十 ~}$ & 35.1 & $(22.3-52.5)^{+\dagger}$ \\
\hline \multicolumn{9}{|l|}{ Pneumococcal vaccination, ever $\S^{\S}$} \\
\hline 19-64 yrs, high risk & 22.5 & $(21.1-23.9)^{9}$ & 29.2 & $(26.8-31.8)^{9, * * *}$ & 19.5 & $(17.8-21.2)^{\text {ศ }}$ & 11.0 & $(9.3-13.1)$ \\
\hline$\geq 65$ yrs & 61.7 & $(60.2-63.1)^{9,+\dagger}$ & 58.3 & $(56.4-60.3)^{\uparrow, * *, t \dagger}$ & 64.9 & $(62.8-66.8)^{\uparrow,+十}$ & 24.3 & $(14.1-38.7)^{+\dagger}$ \\
\hline \multicolumn{9}{|l|}{ Tetanus vaccination, past 10 years } \\
\hline$\geq 19 \mathrm{yrs}$ & 63.9 & $(63.0-64.7)^{9}$ & 58.2 & $(56.7-59.8)^{\uparrow, * *}$ & 65.8 & $(64.8-66.8)^{\text {ฯ }}$ & 52.0 & $(50.0-54.0)$ \\
\hline $19-49$ yrs & 65.0 & $(63.7-66.1)^{9}$ & 61.7 & $(59.0-64.3)^{\mathfrak{9}, * *}$ & 65.7 & $(64.4-67.0)^{\natural}$ & 52.5 & $(50.2-54.8)$ \\
\hline $50-64$ yrs & 66.5 & $(64.9-68.1)^{9}$ & 60.7 & $(57.7-63.7)^{\uparrow, * *}$ & 68.0 & $(66.1-69.8)^{\uparrow,+\dagger}$ & 50.7 & $(46.8-54.6)$ \\
\hline$\geq 65$ yrs & 57.9 & $(56.5-59.4)^{q,+十}$ & 53.8 & $(51.7-55.8)^{\uparrow, * *,+\dagger}$ & 61.9 & $(59.9-63.9)^{\natural,+\dagger}$ & 37.1 & $(24.8-51.4)^{+\dagger}$ \\
\hline \multicolumn{9}{|c|}{ Tetanus vaccination including pertussis vaccine, past 9 years*** } \\
\hline$\geq 19$ yrs & 21.5 & $(20.7-22.3)^{9}$ & 17.1 & $(15.7-18.6)^{\uparrow, * *}$ & 23.1 & $(22.1-24.1)^{\uparrow}$ & 11.5 & $(10.0-13.2)$ \\
\hline $19-64$ yrs & 23.5 & $(22.6-24.5)^{\pi}$ & 20.6 & $(18.5-22.8)^{\mathfrak{9}, * * *}$ & 24.3 & $(23.2-25.3)^{\natural}$ & 11.5 & $(10.0-13.2)$ \\
\hline$\geq 65$ yrs & 14.1 & $(12.8-15.5)^{\dagger \dagger}$ & 12.3 & $(10.5-14.2)^{* *,+\dagger}$ & 16.0 & $(14.0-18.2)^{\dagger \dagger}$ & -t+t $^{\text {t+t }}$ & - \\
\hline \multicolumn{9}{|c|}{ Hepatitis A vaccination (at least 2 doses), ever $\S_{\S}$} \\
\hline$\geq 19$ yrs, all adults & 9.2 & $(8.7-9.8)^{\Re}$ & 7.6 & $(6.8-8.5)^{* *}$ & 9.8 & $(9.1-10.4)^{9}$ & 7.6 & $(6.6-8.7)$ \\
\hline$\geq 19$ yrs, traveler & 16.7 & $(15.6-17.8)^{\natural}$ & 15.7 & $(13.2-18.6)^{9}$ & 16.9 & $(15.7-18.1)^{\natural}$ & 11.0 & $(8.5-14.1)$ \\
\hline \multicolumn{9}{|c|}{ Hepatitis B vaccination (at least 3 doses), ever**** } \\
\hline$\geq 19 \mathrm{yrs}$, all adults & 25.2 & $(24.4-26.0)^{9}$ & 19.5 & $(18.2-20.9)^{* *}$ & 27.2 & $(26.3-28.2)^{9}$ & 20.2 & $(18.4-22.1)$ \\
\hline $19-49$ yrs & 34.6 & $(33.4-35.8)^{9}$ & 32.5 & $(29.7-35.4)^{\natural}$ & 35.1 & $(33.8-36.4)^{\natural}$ & 22.8 & $(20.7-25.1)$ \\
\hline$\geq 19$ yrs, traveler & 31.5 & $(30.1-32.8)^{n}$ & 26.7 & $(24.0-29.6)^{* *}$ & 32.5 & $(31.0-34.0)^{4}$ & 23.2 & $(20.1-26.6)$ \\
\hline$\geq 19 \mathrm{yrs}$, with chronic liver conditions & 29.1 & $(23.0-36.1)$ & 20.6 & $(14.0-29.1)^{* *}$ & 36.4 & $(27.5-46.5)$ & 37.0 & $(21.3-56.0)$ \\
\hline$\geq 19 \mathrm{yrs}$, with diabetes & 18.2 & $(16.4-20.3)$ & 14.3 & $(12.2-16.6)^{* *}$ & 21.4 & $(18.6-24.5)^{\natural}$ & 14.1 & $(9.3-20.8)$ \\
\hline $19-59 \mathrm{yrs}$, with diabetes & 25.1 & $(22.0-28.6)^{9}$ & 22.0 & $(17.5-27.3)^{\natural}$ & 26.8 & $(22.7-31.4)^{9}$ & 12.9 & $(7.8-20.6)$ \\
\hline$\geq 60 \mathrm{yrs}$, with diabetes & 13.5 & $(11.3-15.9)^{\dagger+}$ & 10.6 & $(8.4-13.3)^{* *,+\dagger}$ & 16.4 & $(13.1-20.4)^{\dagger \dagger}$ & - & - \\
\hline \multicolumn{9}{|l|}{ Herpes zoster (shingles) vaccination, ever ${ }^{\dagger+t \dagger}$} \\
\hline$\geq 60$ yrs & 28.7 & $(27.4-30.0)^{9}$ & 25.6 & $(23.9-27.4)^{\Upsilon_{* *}}$ & 30.9 & $(29.2-32.6)^{9}$ & 5.6 & $(3.2-9.4)$ \\
\hline $60-64$ yrs & 22.0 & $(19.9-24.2)^{9}$ & 15.5 & $(12.2-19.4)^{\uparrow, * * *}$ & 23.9 & $(21.5-26.5)^{9}$ & 6.0 & (3.4-10.5) \\
\hline$\geq 65$ yrs & 31.3 & $(29.8-32.8)^{\dagger \dagger}$ & 27.5 & $(25.6-29.4)^{* *,+\dagger}$ & 34.9 & $(32.9-37.1)^{\dagger \dagger}$ & - & - \\
\hline
\end{tabular}

See table footnotes on page 28 . 
TABLE 6. (Continued) Estimated proportion of adults aged $\geq 19$ years who received selected vaccinations, by age group, high-risk status, ${ }^{*}$ and health insurance status ${ }^{\dagger}$ - National Health Interview Survey, United States, 2014

\begin{tabular}{|c|c|c|c|c|c|c|c|c|}
\hline \multirow[b]{3}{*}{ Vaccination, age group, high-risk status } & \multicolumn{6}{|c|}{ With health insurance } & \multirow{2}{*}{\multicolumn{2}{|c|}{$\begin{array}{l}\text { Without health } \\
\text { insurance }\end{array}$}} \\
\hline & \multicolumn{2}{|r|}{ Overall } & \multicolumn{2}{|r|}{ Public } & \multicolumn{2}{|r|}{ Private } & & \\
\hline & $\%$ & $(95 \% \mathrm{Cl})$ & $\%$ & $(95 \% \mathrm{Cl})$ & $\%$ & $(95 \% \mathrm{Cl})$ & $\%$ & $(95 \% \mathrm{Cl})$ \\
\hline \multicolumn{9}{|c|}{ Human papillomavirus (HPV) vaccination among females (at least 1 dose), ever ${ }^{\S \S \S \S}$} \\
\hline $19-26$ yrs & 44.5 & $(40.4-48.7)^{9}$ & 39.4 & $(32.8-46.5)^{\natural}$ & 46.6 & $(41.4-51.8)^{\text {凡 }}$ & 21.3 & $(16.1-27.6)$ \\
\hline \multicolumn{9}{|c|}{ HPV vaccination among males (at least 1 dose), ever $\S_{\S \S \S}$} \\
\hline \multicolumn{9}{|c|}{ Human papillomavirus (HPV) vaccination among females (at least 1 dose), ever $\S_{\S \S \S}$ who reported first HPV dose at age $19-26$ years } \\
\hline $19-26$ yrs & 13.8 & $(11.3-16.8)^{9}$ & 12.1 & $(8.5-17.0)^{9}$ & 14.5 & $(11.3-18.4)^{\text {q }}$ & 5.5 & $(3.2-9.3)$ \\
\hline \multicolumn{9}{|c|}{ HPV vaccination among males (at least 1 dose), ever ${ }^{\S \S \S \S}$ who reported first HPV dose at age $19-26$ years } \\
\hline $19-26$ yrs & 2.9 & $(1.9-4.5)$ & - & - & 2.7 & $(1.7-4.3)$ & - & - \\
\hline
\end{tabular}

Abbreviations: $\mathrm{Cl}=$ confidence interval; $\mathrm{HPV}=$ human papillomavirus; $\mathrm{Td}=$ tetanus-diphtheria toxoid; $\mathrm{Tdap}=$ tetanus, diphtheria, and acellular pertussis vaccine.

* Adults were considered at high risk for pneumococcal disease if they had ever been told by a doctor or other health professional that they had diabetes, emphysema, chronic obstructive pulmonary disease, coronary heart disease, angina, heart attack, or other heart condition; had a diagnosis of cancer during the previous 12 months (excluding nonmelanoma skin cancer); had ever been told by a doctor or other health professional that they had lymphoma, leukemia, or blood cancer; had been told by a doctor or other health professional that they had chronic bronchitis or weak or failing kidneys during the preceding 12 months; had an asthma episode or attack during the preceding 12 months; or were current smokers. For hepatitis $A$ and hepatitis B vaccination, data were collected on selected respondent characteristics that increase the risk for infection (travel to countries where hepatitis A infections are endemic and having chronic liver disease; having diabetes, travel to countries where hepatitis B infections are endemic, and having chronic liver disease, respectively).

${ }^{\dagger}$ Adults were considered insured if they reported having public health insurance coverage (Medicare, Medicaid, military health care (TRICARE/VA/CHAMP-VA), Indian Health Service, state-sponsored health plan, or other government program insurance) or private health insurance coverage.

$\S$ Respondents were asked if they had received an influenza shot or nasal spray in the past 12 months and if so, in which month and year. Missing month and year were imputed (3.1\%), and interviews conducted during August 2013-June 2014 were used to estimate vaccination coverage during July 2013-May 2014 using Kaplan-Meier survival analysis.

" $p<0.05$ by T test for comparisons with "without health insurance" as the reference group.

** $\mathrm{p}<0.05$ by $T$ test for comparisons between private and public health insurance within each level of each characteristic.

${ }^{+t} p<0.05$ by $T$ test comparing persons aged $50-64$ years and aged $\geq 65$ years with persons aged 19-49 years for influenza; persons aged 19-64 years with high-risk conditions with persons aged $\geq 65$ years for pneumococcal; persons aged 50-64 years and $\geq 65$ years with persons aged 19-49 years for tetanus; persons aged 19-64 years with persons aged $\geq 65$ years for Tdap; persons aged 19-59 years with diabetes with persons aged $\geq 60$ years with diabetes for hepatitis B; and persons aged 60-64 years with persons aged $\geq 65$ years for shingles.

$\S \S$ Respondents were asked if they had ever had a pneumonia shot.

ๆๆ Respondents were asked if they had received a tetanus shot in the past 10 years. Vaccinated respondents included adults who received Td during the past 10 years or Tdap during 2005-2014.

*** Respondents who had received a tetanus shot in the past 10 years were asked if their most recent shot was given in 2005 or later. Respondents who had received a tetanus shot since 2005 were asked if they were told that their most recent tetanus shot included the pertussis or whooping cough vaccine. Among 36,324 respondents aged $\geq 19$ years, those without a"yes" or "no" classification for tetanus vaccination status within the preceding 10 years ( $n=1,977$ [5.4\%]), for tetanus vaccination status during 2005-2014 ( $n=1,098$ [3.0\%]), or those who reported tetanus vaccination during 2005-2014, but were not told vaccine type by the provider ( $n=8,612[23.7 \%]$ ), did not know vaccine type (Td or Tdap) $(n=1,765[4.9 \%])$, or refused to answer or for whom data were not obtained $(n=5[0.01 \%])$ were excluded, yielding a sample of 22,867 respondents aged $\geq 19$ years for whom Tdap vaccination status could be assessed. In February 2012, ACIP recommended Tdap vaccination for all adults aged $\geq 19$ years, including adults aged $\geq 65$ years.

${ }^{t+t}$ Estimate is not reliable due to small sample size $(\mathrm{n}<30)$ or relative standard error (standard error/estimates) $>0.3$.

$\S \S \S$ Respondents were asked if they had ever received the hepatitis A vaccine, and if yes, were asked how many doses were received.

ๆศศ Had traveled outside the United States to countries other than countries in Europe, Japan, Australia, New Zealand, or Canada since 1995.

**** Respondents were asked if they had ever received the hepatitis B vaccine, and if yes, if they had received at least 3 doses or less than 3 doses.

$t_{t+t}$ Respondents were asked if they had ever received a shingles vaccine.

$\S \S \S \S$ Respondents were asked if they had ever received the HPV shot or cervical cancer vaccine, and if yes, age at the first dose.

ๆางๆ The denominator includes persons aged 19-26 years without HPV vaccination prior to age 19 years, and the numerator includes those in the denominator who reported first HPV dose at age 19-26 years. 
TABLE 7. Estimated proportion of adults aged $\geq 19$ years who received selected vaccinations, by age group, high-risk status, ${ }^{*}$ health insurance status, $^{\dagger}$ and having a usual place for health care - National Health Interview Survey, United States, 2014

\begin{tabular}{|c|c|c|c|c|c|c|c|c|}
\hline \multirow[b]{3}{*}{ Vaccination, age group, high-risk status } & \multicolumn{4}{|c|}{ With health insurance } & \multicolumn{4}{|c|}{ Without health insurance } \\
\hline & \multicolumn{2}{|c|}{$\begin{array}{l}\text { Have a usual place } \\
\text { for health care }{ }^{\S}\end{array}$} & \multicolumn{2}{|c|}{$\begin{array}{l}\text { Do not have a usual place } \\
\text { for health care }\end{array}$} & \multicolumn{2}{|c|}{$\begin{array}{l}\text { Have a usual place } \\
\text { for health care }\end{array}$} & \multicolumn{2}{|c|}{$\begin{array}{l}\text { Do not have a usual } \\
\text { place for health care }\end{array}$} \\
\hline & $\%$ & $(95 \% \mathrm{Cl})$ & $\%$ & $(95 \% \mathrm{Cl})$ & $\%$ & $(95 \% \mathrm{Cl})$ & $\%$ & $(95 \% \mathrm{Cl})$ \\
\hline \multicolumn{9}{|l|}{ Influenza vaccination (2013-14 season) } \\
\hline$\geq 19 \mathrm{yrs}$ & 50.1 & $(48.9-51.4)$ & 24.2 & $(20.8-28.2)^{* *}$ & 21.7 & $(19.0-24.7)$ & 9.7 & $(7.8-12.1)^{* *}$ \\
\hline $19-49 \mathrm{yrs}$ & 37.7 & $(35.9-39.5)$ & 23.9 & $(20.3-28.0)^{* *}$ & 19.7 & $(16.7-23.2)$ & 9.3 & $(7.3-11.8)^{* *}$ \\
\hline $50-64$ yrs & 52.8 & $(50.8-54.9)^{\dagger \dagger}$ & 24.1 & $(16.2-35.0)^{* *}$ & 26.1 & $(20.9-32.2)$ & 10.4 & $(6.0-17.6)^{* *}$ \\
\hline$\geq 65$ yrs & 73.1 & $(71.2-74.9)^{\dagger+}$ & 30.0 & $(19.6-44.2)^{* *}$ & 40.6 & $(23.2-64.2)^{\dagger+}$ & —§§ & - \\
\hline \multicolumn{9}{|l|}{ Pneumococcal vaccination, ever ${ }^{\text {ๆๆ }}$} \\
\hline 19-64 yrs, HR & 24.0 & $(22.5-25.5)$ & 7.9 & $(5.8-10.6)^{* *}$ & 13.9 & $(11.5-16.7)$ & 7.8 & $(5.5-10.9)^{* *}$ \\
\hline$\geq 65$ yrs & 62.6 & $(61.2-64.0)^{\dagger \dagger}$ & 24.2 & $(17.8-32.0)^{* *,+\dagger}$ & 34.0 & $(17.5-55.5)^{\dagger \dagger}$ & - & - \\
\hline \multicolumn{9}{|l|}{ Tetanus vaccination, past 10 years ${ }^{* * *}$} \\
\hline$\geq 19 \mathrm{yrs}$ & 64.7 & $(63.8-65.6)$ & 54.4 & $(51.5-57.3)^{* *}$ & 54.5 & $(51.7-57.2)$ & 49.3 & $(46.2-52.4)^{* *}$ \\
\hline $19-49$ yrs & 66.1 & $(64.7-67.4)$ & 57.1 & $(54.2-60.0)^{* *}$ & 54.9 & $(51.6-58.3)$ & 50.3 & $(46.7-53.8)$ \\
\hline $50-64$ yrs & 67.3 & $(65.8-68.9)$ & 51.3 & $(41.8-60.8)^{* *}$ & 53.5 & $(48.5-58.5)$ & 46.1 & $(39.8-52.6)$ \\
\hline$\geq 65$ yrs & 58.6 & $(57.1-60.1)^{\dagger \dagger}$ & 30.3 & $(22.5-39.4)^{* *,+\dagger}$ & 48.6 & $(30.8-66.7)$ & - & - \\
\hline \multicolumn{9}{|c|}{ Tetanus vaccination including pertussis vaccine, past 9 years ${ }^{\dagger+\dagger}$} \\
\hline$\geq 19$ yrs & 22.0 & $(21.1-22.9)$ & 16.3 & $(13.9-18.9)^{* *}$ & 13.0 & $(11.0-15.3)$ & 10.0 & $(7.9-12.5)$ \\
\hline $19-64$ yrs & 24.3 & $(23.3-25.3)$ & 17.2 & $(14.7-20.1)^{* *}$ & 13.0 & $(11.0-15.3)$ & 10.0 & $(8.0-12.6)$ \\
\hline$\geq 65$ yrs & 14.4 & $(13.0-15.9)^{\dagger \dagger}$ & - & - & - & - & - & - \\
\hline \multicolumn{9}{|c|}{ Hepatitis A vaccination (at least 2 doses), ever §§§ } \\
\hline$\geq 19 \mathrm{yrs}$ & 9.0 & $(8.5-9.6)$ & 11.4 & $(9.6-13.4)^{* *}$ & 7.7 & $(6.3-9.3)$ & 7.5 & $(5.8-9.6)$ \\
\hline$\geq 19$ yrs, traveler & 16.3 & $(15.2-17.5)$ & 20.5 & $(17.3-24.0)^{* *}$ & 8.8 & $(6.7-11.5)$ & 13.1 & $(8.9-18.9)$ \\
\hline \multicolumn{9}{|c|}{ Hepatitis B vaccination (at least 3 doses), ever**** } \\
\hline$\geq 19 \mathrm{yrs}$ & 25.0 & $(24.2-25.8)$ & 27.7 & $(25.0-30.5)$ & 21.2 & $(18.9-23.8)$ & 19.1 & $(16.5-22.0)$ \\
\hline $19-49$ yrs & 34.8 & $(33.6-36.1)$ & 32.8 & $(29.8-35.8)$ & 23.8 & $(21.1-26.8)$ & 21.9 & $(18.8-25.3)$ \\
\hline$\geq 19 \mathrm{yrs}$, traveler & 31.1 & $(29.7-32.5)$ & 35.6 & $(31.8-39.7)^{* *}$ & 24.2 & $(20.2-28.6)$ & 22.2 & $(17.3-28.1)$ \\
\hline$\geq 19 \mathrm{yrs}$, with chronic liver conditions & 29.1 & $(22.9-36.2)$ & - & - & - & - & - & - \\
\hline$\geq 19 \mathrm{yrs}$, with diabetes & 18.4 & $(16.5-20.4)$ & - & - & 13.6 & $(8.3-21.4)$ & & - \\
\hline 19-59 yrs, with diabetes & 25.5 & $(22.3-29.0)$ & - & - & - & - & - & - \\
\hline$\geq 60 \mathrm{yrs}$, with diabetes & 13.5 & $(11.3-16.0)^{\dagger+}$ & - & - & - & - & - & - \\
\hline \multicolumn{9}{|l|}{ Herpes zoster (shingles) vaccination, ever ${ }^{+t+\dagger}$} \\
\hline$\geq 60 \mathrm{yrs}$ & 29.2 & $(28.0-30.6)$ & 9.9 & $(6.2-15.5)^{* *}$ & - & - & - & - \\
\hline
\end{tabular}

See table footnotes on page 30 . 
TABLE 7. (Continued) Estimated proportion of adults aged $\geq 19$ years who received selected vaccinations, by age group, high-risk status, ${ }^{*}$ health insurance status, ${ }^{\dagger}$ and having a usual place for health care - National Health Interview Survey, United States, 2014

\begin{tabular}{|c|c|c|c|c|c|c|c|c|}
\hline \multirow[b]{3}{*}{ Vaccination, age group, high-risk status } & \multicolumn{4}{|c|}{ With health insurance } & \multicolumn{4}{|c|}{ Without health insurance } \\
\hline & \multicolumn{2}{|c|}{$\begin{array}{l}\text { Have a usual place } \\
\text { for health care }\end{array}$} & \multicolumn{2}{|c|}{$\begin{array}{l}\text { Do not have a usual place } \\
\text { for health care }\end{array}$} & \multicolumn{2}{|c|}{$\begin{array}{c}\text { Have a usual place } \\
\text { for health care } \\
\end{array}$} & \multicolumn{2}{|c|}{$\begin{array}{l}\text { Do not have a usual } \\
\text { place for health care }\end{array}$} \\
\hline & $\%$ & $(95 \% \mathrm{Cl})$ & $\%$ & $(95 \% \mathrm{Cl})$ & $\%$ & $(95 \% \mathrm{Cl})$ & $\%$ & $(95 \% \mathrm{Cl})$ \\
\hline \multicolumn{9}{|c|}{ HPV vaccination among females (at least 1 dose), ever ${ }^{\S \S \S \S ~}$} \\
\hline $19-26$ yrs & 45.9 & $(41.5-50.3)$ & 33.8 & $(26.7-41.8)^{* *}$ & 24.7 & $(17.3-33.9)$ & 17.4 & $(11.3-25.8)$ \\
\hline \multicolumn{9}{|c|}{ HPV vaccination among males (at least 1 dose), ever ${ }^{\S \S \S \S ~}$} \\
\hline $19-26$ yrs & 10.5 & $(8.0-13.5)$ & - & - & - & - & - & - \\
\hline \multicolumn{9}{|c|}{ HPV vaccination among females (at least 1 dose), ever } \\
\hline $19-26$ yrs & 14.4 & $(11.6-17.7)$ & 9.7 & $(5.9-15.5)$ & - & - & - & - \\
\hline \multicolumn{9}{|c|}{ HPV vaccination among males (at least 1 dose), ever ${ }^{\S \S \S \S}$ who reported first HPV dose at age $19-26$ years } \\
\hline $19-26$ yrs & 3.0 & $(1.9-4.9)$ & - & - & 0 & ***** & - & - \\
\hline
\end{tabular}

Abbreviations: $\mathrm{Cl}=$ confidence interval; $\mathrm{HPV}=$ human papillomavirus; $\mathrm{Td}=$ tetanus-diphtheria toxoid; $\mathrm{Tdap}=$ tetanus, diphtheria, and acellular pertussis vaccine.

* Adults were considered at high risk for pneumococcal disease if they had ever been told by a doctor or other health professional that they had diabetes, emphysema, chronic obstructive pulmonary disease, coronary heart disease, angina, heart attack, or other heart condition; had a diagnosis of cancer during the previous 12 months (excluding nonmelanoma skin cancer); had ever been told by a doctor or other health professional that they had lymphoma, leukemia, or blood cancer; had been told by a doctor or other health professional that they had chronic bronchitis or weak or failing kidneys during the preceding 12 months; had an asthma episode or attack during the preceding 12 months; or were current smokers. For hepatitis A and hepatitis B vaccination, data were collected on selected respondent characteristics that increase the risk for infection (travel to countries where hepatitis $A$ infections are endemic and having chronic liver disease; having diabetes, travel to countries where hepatitis B infections are endemic, and having chronic liver disease, respectively).

${ }^{\dagger}$ Adults were considered insured if they reported having public health insurance coverage (Medicare, Medicaid, military health care (TRICARE/VA/CHAMP-VA), Indian Health Service, state-sponsored health plan, or other government program insurance) or private health insurance coverage.

$\S$ Respondents were asked if there is a place they usually go when sick or need advice on their health. Respondents answering "yes" are defined as having a usual place for health care.

" Respondents were asked if they had received an influenza shot or nasal spray in the past 12 months and if so, in which month and year. Missing month and year were imputed (3.1\%), and interviews conducted during August 2013-June 2014 were used to estimate vaccination coverage during July $2013-$ May 2014 using Kaplan-Meier survival analysis.

** $p<0.05$ by $T$ test for comparisons with "have a usual place for healthcare" as the reference group.

${ }^{+\dagger} p<0.05$ by $T$ test comparing persons aged $50-64$ years and $\geq 65$ years with persons aged 19-49 years for influenza; persons aged 19-64 years with high-risk conditions with persons aged $\geq 65$ years for pneumococcal; persons aged 50-64 years and aged $\geq 65$ years with persons aged 19-49 years for tetanus; persons aged 19-64 years with persons aged $\geq 65$ years for Tdap; and persons aged 19-59 years with diabetes with persons aged $\geq 60$ years with diabetes for hepatitis B.

$\S \S$ Estimate is not reliable due to small sample size $(\mathrm{n}<30)$ or relative standard error (standard error/estimates) $>0.3$.

१ๆ Respondents were asked if they had ever had a pneumonia shot.

*** Respondents were asked if they had received a tetanus shot in the past 10 years. Vaccinated respondents included adults who received Td during the past 10 years or Tdap during $2005-2014$.

${ }^{+t+}$ Respondents who had received a tetanus shot in the past 10 years were asked if their most recent shot was given in 2005 or later. Respondents who had received a tetanus shot since 2005 were asked if they were told that their most recent tetanus shot included the pertussis or whooping cough vaccine. Among 36,324 respondents aged $\geq 19$ years, those without a"yes" or "no" classification for tetanus vaccination status within the preceding 10 years ( $n=1,977[5.4 \%]$ ), for tetanus vaccination status during 2005-2014 ( $n=1,098$ [3.0\%]), or those who reported tetanus vaccination during 2005-2014, but were not told vaccine type by the provider ( $n=8,612[23.7 \%]$ ), did not know vaccine type (Td or Tdap) $(n=1,765[4.9 \%])$, or refused to answer or for whom data were not obtained ( $n=5[0.01 \%])$ were excluded, yielding a sample of 22,867 respondents aged $\geq 19$ years for whom Tdap vaccination status could be assessed. In February 2012, ACIP recommended Tdap vaccination for all adults aged $\geq 19$ years, including adults aged $\geq 65$ years.

$\S \S$ Respondents were asked if they had ever received the hepatitis A vaccine, and if yes, were asked how many doses were received.

ๆศศ Had traveled outside the United States to countries other than countries in Europe, Japan, Australia, New Zealand, or Canada since 1995.

**** Respondents were asked if they had ever received the hepatitis B vaccine, and if yes, if they had received at least 3 doses or less than 3 doses.

${ }^{\dagger+t \dagger}$ Respondents were asked if they had ever received a shingles vaccine.

$\S \S \S \S$ Respondents were asked if they had ever received the HPV shot or cervical cancer vaccine, and if yes, age at the first dose.

ๆศศๆ The denominator includes persons aged 19-26 years without HPV vaccination prior to age 19 years, and the numerator includes those in the denominator who reported first HPV dose at age 19-26 years.

***** The confidence interval has not been generated because the estimate is zero. 
TABLE 8. Estimated proportion of adults aged $\geq 19$ years who received selected vaccinations, by age group, high-risk status, ${ }^{*}$ health insurance status, ${ }^{\dagger}$ and physician contacts ${ }^{\S}$ - National Health Interview Survey, United States, 2014

\begin{tabular}{|c|c|c|c|c|c|c|c|c|c|c|c|c|c|c|c|c|}
\hline \multirow{4}{*}{$\begin{array}{l}\text { Vaccination, } \\
\text { age group, } \\
\text { high-risk status }\end{array}$} & \multicolumn{8}{|c|}{ With health insurance } & \multicolumn{8}{|c|}{ Without health insurance } \\
\hline & \multicolumn{8}{|c|}{ No. of physician contacts in the past 12 months } & \multicolumn{8}{|c|}{ No. of physician contacts in the past 12 months } \\
\hline & \multicolumn{2}{|r|}{ None } & \multicolumn{2}{|r|}{$1-3$} & \multicolumn{2}{|r|}{ 4-9 } & \multicolumn{2}{|r|}{$\geq 10$} & \multicolumn{2}{|r|}{ None } & \multicolumn{2}{|r|}{$1-3$} & \multicolumn{2}{|r|}{ 4-9 } & \multicolumn{2}{|r|}{$\geq 10$} \\
\hline & $\%$ & $(95 \% \mathrm{Cl})$ & $\%$ & $(95 \% \mathrm{CI})$ & $\%$ & $(95 \% \mathrm{CI})$ & $\%$ & $(95 \% \mathrm{Cl})$ & $\%$ & $(95 \% \mathrm{Cl})$ & $\%$ & $(95 \% \mathrm{Cl})$ & $\%$ & $(95 \% \mathrm{Cl})$ & $\%$ & $(95 \% \mathrm{Cl})$ \\
\hline \multicolumn{17}{|c|}{ Influenza vaccination (2013-14 season) $)^{\text {ๆ }}$} \\
\hline$\geq 19$ yrs & 21.8 & $(19.3-24.6)$ & 44.9 & $(43.3-46.6)^{* *}$ & 60.1 & $(57.8-62.5)^{* *}$ & 60.6 & $(57.9-63.2)^{* *}$ & 9.0 & $(7.2-11.2)$ & 19.7 & $(16.6-23.4)^{* *}$ & 28.4 & $(21.6-36.8)^{* *}$ & 27.6 & $(20.1-37.1)^{* *}$ \\
\hline $19-49$ yrs & 18.6 & $(15.9-21.7)$ & 36.1 & $(33.8-38.5)^{* *}$ & 44.5 & $(40.8-48.4)^{* *}$ & 48.6 & $(43.9-53.5)^{* *}$ & 7.9 & $(6.1-10.3)$ & 19.0 & $(15.5-23.1)^{* *}$ & 26.1 & $(17.9-37.0)^{* *}$ & 25.1 & $(16.4-37.1)^{* *}$ \\
\hline $50-64$ yrs & 25.3 & $(19.7-32.1)$ & 47.9 & $(45.1-50.7)^{* *,+\dagger}$ & 61.4 & $(57.6-65.2)^{* *,+\dagger}$ & 61.7 & $(57.2-66.3)^{* *,+\dagger}$ & 13.5 & $(8.7-20.6)$ & 22.0 & $(15.7-30.4)$ & 29.8 & $(20.6-41.7)^{* * *}$ & 26.9 & $(16.0-43.1)$ \\
\hline$\geq 65$ yrs & 37.4 & $(30.4-45.5)^{\dagger+}$ & 68.6 & $(65.8-71.4)^{* *,+\dagger}$ & 78.1 & $(75.1-81.0)^{* *,+\dagger}$ & 76.2 & $(72.0-80.3)^{* *,+十}$ & —§§ & $\S \quad-$ & - & $-\quad-$ & - & - & - & - \\
\hline \multicolumn{17}{|c|}{ Pneumococcal vaccination, ever } \\
\hline $19-64$ yrs, HR & 7.1 & (5.4-9.4) & 16.6 & $(15.0-18.4)^{* *}$ & 26.3 & $(23.8-29.0)^{* *}$ & 38.6 & $(34.9-42.4)^{* *}$ & 7.8 & $(5.4-11.1)$ & 11.2 & $(8.3-14.8)$ & 19.3 & $(13.4-26.9)^{* *}$ & 18.3 & $(10.7-29.5)^{* *}$ \\
\hline$\geq 65$ yrs & 32.6 & $(27.1-38.5)^{\dagger \dagger}$ & 57.2 & $(54.9-59.5)^{* *,+\dagger}$ & 66.4 & $(64.0-68.7)^{* *,+\dagger}$ & 70.7 & $(67.4-73.8)^{* *,+\dagger}$ & - & - & - & - & - & - & - & - \\
\hline \multicolumn{17}{|c|}{ Tetanus vaccination, past 10 years ${ }^{* * *}$} \\
\hline$\geq 19$ yrs & 51.0 & $(48.6-53.3)$ & 64.2 & $(62.9-65.5)^{* *}$ & 66.9 & $(65.4-68.5)^{* *}$ & 69.9 & $(67.9-71.7)^{* *}$ & 47.7 & $(44.8-50.6)$ & 54.2 & $(50.9-57.5)^{* *}$ & 59.1 & $(52.8-65.0)^{* *}$ & 63.9 & $(55.4-71.7)^{* *}$ \\
\hline $19-49$ yrs & 52.6 & $(49.9-55.3)$ & 65.9 & $(64.3-67.5)^{* *}$ & 70.2 & $(67.4-72.8)^{* *}$ & 71.9 & $(68.5-75.0)^{* *}$ & 48.4 & $(45.1-51.8)$ & 55.9 & $(51.9-59.8)^{* *}$ & 59.6 & $(51.6-67.1)^{* *}$ & 58.1 & $(48.3-67.4)$ \\
\hline $50-64$ yrs & 52.5 & $(46.8-58.2)$ & 65.2 & $(63.0-67.3)^{* *}$ & 70.2 & $(67.5-72.7)^{* *}$ & 74.6 & $(71.2-77.7)^{* *}$ & 45.7 & (39.7-51.7) & 50.2 & $(44.0-56.3)$ & 57.7 & $(47.5-67.3)^{* * *}$ & 78.0 & $(63.5-87.8)^{* *},+\dagger$ \\
\hline$\geq 65$ yrs & 35.6 & $(29.6-42.1)^{\dagger \dagger}$ & 57.3 & $(55.0-59.6)^{* *,+\dagger}$ & 59.9 & $(57.5-62.3)^{* *},+\dagger$ & 62.2 & $(58.9-65.5)^{* *,+十}$ & - & - & - & - & - & - & - & - \\
\hline \multicolumn{17}{|c|}{ Tetanus vaccination including pertussis vaccine, past 9 years ${ }^{\dagger \dagger \dagger}$} \\
\hline$\geq 19$ yrs & 12.0 & $(10.4-13.8)$ & 22.0 & $(20.8-23.2)^{* *}$ & 23.7 & $(22.0-25.5)^{* *}$ & 26.8 & $(24.6-29.0)^{* *}$ & 9.0 & $(7.3-11.2)$ & 12.4 & $(10.1-15.3)^{* *}$ & 17.4 & $(12.3-24.1)^{* *}$ & 19.8 & $(12.9-29.1)^{* *}$ \\
\hline $19-64$ yrs & 12.7 & $(10.9-14.7)$ & 23.7 & $(22.4-25.1)^{* *}$ & 27.7 & $(25.6-29.9)^{* *}$ & 31.3 & $(28.6-34.2)^{* *}$ & 9.1 & $(7.3-11.2)$ & 12.6 & $(10.2-15.5)^{* *}$ & 17.3 & $(12.2-24.0)^{* *}$ & 19.0 & $(12.2-28.3)^{* *}$ \\
\hline$\geq 65$ yrs & 6.0 & $(3.7-9.7)^{\dagger+}$ & 13.7 & $(11.7-16.0)^{* *,+\dagger}$ & 15.2 & $(13.2-17.6)^{* *},+\dagger$ & 16.1 & $(13.0-19.7)^{* *,+\dagger}$ & - & - & - & - & - & - & - & - \\
\hline \multicolumn{17}{|c|}{ Hepatitis A vaccination (at least 2 doses), ever $\S \S$} \\
\hline$\geq 19 \mathrm{yrs}$ & 7.1 & $(6.1-8.3)$ & 9.4 & $(8.7-10.1)^{* *}$ & 9.1 & $(8.2-10.1)^{* *}$ & 11.1 & $(9.7-12.7)^{* *}$ & 6.1 & $(4.8-7.6)$ & 8.9 & $(6.7-11.6)$ & 8.4 & $(5.7-12.1)$ & 10.5 & $(6.5-16.6)$ \\
\hline$\geq 19$ yrs, traveler ศึฯ & 12.8 & $(10.5-15.6)$ & 16.5 & $(15.0-18.1)^{* *}$ & 18.4 & $(16.2-20.9)^{* *}$ & 17.6 & $(14.7-20.8)^{* *}$ & 7.7 & $(5.4-11.0)$ & 14.4 & $(9.5-21.3)^{* *}$ & 11.6 & $(6.8-19.0)$ & - & - \\
\hline $\begin{array}{l}\geq 19 \text { yrs, with } \\
\text { chronic liver } \\
\text { conditions }\end{array}$ & - & - & 13.3 & $(7.2-23.1)$ & - & - & 18.0 & $(11.1-27.9)$ & - & - & - & - & - & - & - & - \\
\hline \multicolumn{17}{|c|}{ Hepatitis B vaccination (at least 3 doses), ever**** } \\
\hline$\geq 19 \mathrm{yrs}$ & 20.4 & $(18.6-22.3)$ & 25.6 & $(24.5-26.8)^{* *}$ & 25.5 & $(23.9-27.2)^{* *}$ & 28.2 & $(26.1-30.4)^{* *}$ & 17.1 & $(14.8-19.6)$ & 22.6 & $(19.5-25.9)^{* *}$ & 22.2 & $(17.6-27.6)$ & 30.6 & $(22.9-39.5)^{* *}$ \\
\hline $19-49$ yrs & 24.4 & $(22.2-26.9)$ & 33.9 & $(32.3-35.5)^{* *}$ & 40.5 & $(37.5-43.6)^{* *}$ & 44.0 & $(40.5-47.6)^{* *}$ & 18.9 & $(16.3-21.9)$ & 26.2 & $(22.6-30.2)^{* *}$ & 27.5 & $(21.2-35.0)^{* * *}$ & 30.9 & $(21.7-42.1)^{* *}$ \\
\hline$\geq 19 \mathrm{yrs}$, traveler & 24.9 & $(21.8-28.3)$ & 31.9 & $(29.9-33.9)^{* *}$ & 30.9 & $(28.3-33.6)^{* *}$ & 37.1 & $(33.3-41.1)^{* *}$ & 16.3 & $(12.4-21.1)$ & 28.7 & $(23.3-34.8)^{* *}$ & 26.4 & $(18.1-36.9)$ & 39.8 & $(23.8-58.3)^{* *}$ \\
\hline $\begin{array}{l}\geq 19 \text { yrs, with } \\
\text { chronic liver } \\
\text { conditions }\end{array}$ & - & - & 30.1 & $(19.5-43.4)$ & 26.6 & $(17.8-37.9)$ & 32.9 & $(22.4-45.4)$ & - & - & - & - & - & - & - & - \\
\hline $\begin{array}{l}\text { 19-59 yrs, with } \\
\text { diabetes }\end{array}$ & - & - & 22.6 & $(17.7-28.3)$ & 22.6 & $(17.7-28.4)$ & 35.3 & $(28.5-42.8)$ & - & - & - & - & - & - & - & - \\
\hline $\begin{array}{c}\geq 60 \text { yrs, with } \\
\text { diabetes }\end{array}$ & - & - & 11.3 & $(8.3-15.2)^{\dagger \dagger}$ & 16.0 & $(12.4-20.4)^{\dagger \dagger}$ & 11.2 & $(8.1-15.4)^{\dagger \dagger}$ & - & - & - & - & - & - & - & - \\
\hline
\end{tabular}


TABLE 8. (Continued) Estimated proportion of adults aged $\geq 19$ years who received selected vaccinations, by age group, high-risk status, ${ }^{*}$ health insurance status, ${ }^{\dagger}$ and physician contacts ${ }^{\S}$ - National Health Interview Survey, United States, 2014

\begin{tabular}{|c|c|c|c|c|c|c|c|c|c|c|c|c|c|c|c|c|}
\hline \multirow{4}{*}{$\begin{array}{l}\text { Vaccination, } \\
\text { age group, } \\
\text { high-risk status }\end{array}$} & \multicolumn{8}{|c|}{ With health insurance } & \multicolumn{8}{|c|}{ Without health insurance } \\
\hline & \multicolumn{8}{|c|}{ No. of physician contacts in the past 12 months } & \multicolumn{8}{|c|}{ No. of physician contacts in the past 12 months } \\
\hline & \multicolumn{2}{|r|}{ None } & \multicolumn{2}{|r|}{$1-3$} & \multicolumn{2}{|r|}{ 4-9 } & \multicolumn{2}{|r|}{$\geq 10$} & \multicolumn{2}{|r|}{ None } & \multicolumn{2}{|r|}{$1-3$} & \multicolumn{2}{|r|}{$4-9$} & \multicolumn{2}{|r|}{$\geq 10$} \\
\hline & $\%$ & $(95 \% \mathrm{Cl})$ & $\%$ & $(95 \% \mathrm{CI})$ & $\%$ & $(95 \% \mathrm{Cl})$ & $\%$ & $(95 \% \mathrm{Cl})$ & $\%$ & $(95 \% \mathrm{Cl})$ & $\%$ & $(95 \% \mathrm{Cl})$ & $\%$ & $(95 \% \mathrm{Cl})$ & $\%$ & $(95 \% \mathrm{Cl})$ \\
\hline \multicolumn{17}{|c|}{ Herpes zoster (shingles) vaccination, ever ${ }^{+t+\dagger}$} \\
\hline$\geq 60$ yrs & 10.2 & $(7.8-13.2)$ & 28.0 & $(26.0-30.1)^{* *}$ & 31.0 & $(29.0-33.0)^{* *}$ & 32.3 & $(29.3-35.3)^{* *}$ & - & - & - & - & - & - & - & - \\
\hline \multicolumn{17}{|c|}{ HPV vaccination among females (at least 1 dose), ever $\S^{\S \S \S}$} \\
\hline $19-26$ yrs & 24.9 & $(18.3-33.0)$ & 41.5 & $(36.9-46.3)^{* *}$ & 57.1 & $(46.7-66.9)^{* *}$ & 48.4 & $(39.9-56.9)^{* *}$ & 20.0 & $(12.3-30.8)$ & 19.5 & $(12.6-29.0)$ & - & - & - & - \\
\hline \multicolumn{17}{|c|}{ HPV vaccination among males (at least 1 dose), ever $§ \S \S \S$} \\
\hline $19-26$ yrs & 5.7 & $(3.6-9.0)$ & 9.1 & $(6.6-12.4)$ & 19.1 & $(10.4-32.6)^{* *}$ & - & - & - & - & - & - & - & - & - & - \\
\hline \multicolumn{17}{|c|}{ HPV vaccination among females (at least 1 dose), ever $\S_{\S \S}$ who reported first HPV dose at age 19-26 years } \\
\hline $19-26$ yrs & - & - & 13.5 & $(10.4-17.4)$ & 20.3 & $(13.9-28.6)$ & 12.5 & $(7.6-19.9)$ & - & - & - & - & - & - & - & - \\
\hline \multicolumn{17}{|c|}{ HPV vaccination among males (at least 1 dose), ever§§§§ who reported first HPV dose at age 19-26 years } \\
\hline $19-26$ yrs & - & - & - & - & - & - & - & - & 0 & $* * * * *$ & - & - & - & - & - & - \\
\hline
\end{tabular}

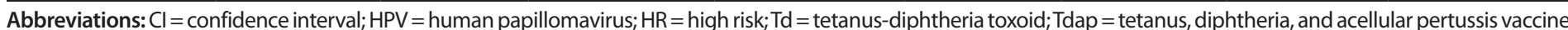

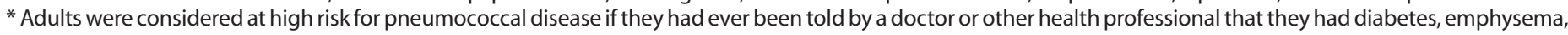

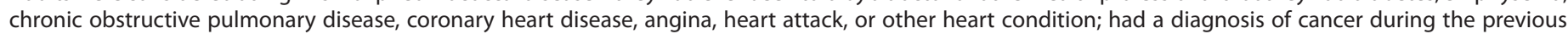

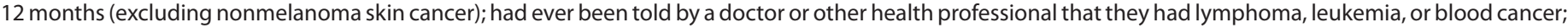

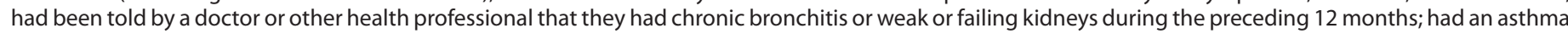

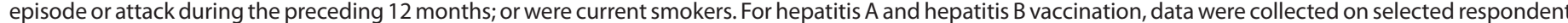

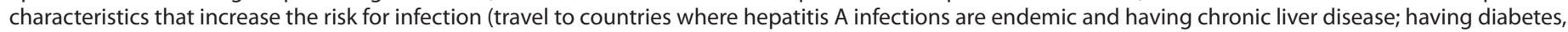
travel to countries where hepatitis B infections are endemic, and having chronic liver disease, respectively).

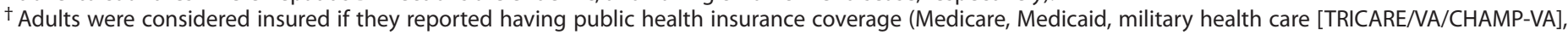
Indian Health Service, state-sponsored health plan, or other government program insurance) or private health insurance coverage.

$\S$ Respondents were asked the number of times in the past 12 months that they saw a doctor other health care professional about their own health.

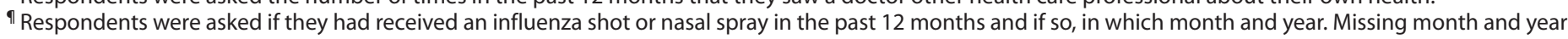

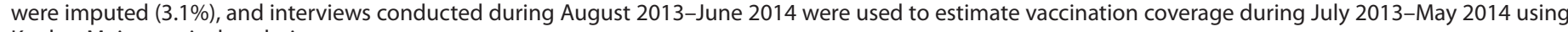
Kaplan-Meier survival analysis.

** $p<0.05$ by $T$ test for comparisons with no physician contacts in the past 12 months as the reference group.

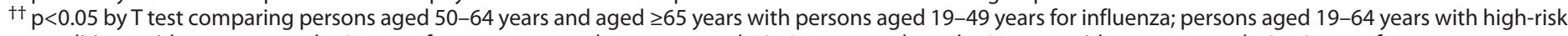

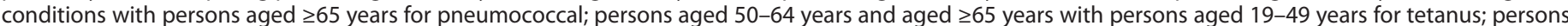

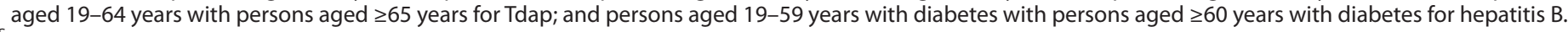

$\S \S$ Estimate is not reliable due to small sample size $(n<30)$ or relative standard error (standard error/estimates) $>0.3$.

ๆๆ Respondents were asked if they had ever had a pneumonia shot.

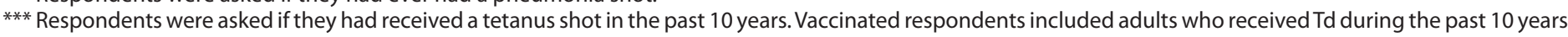
or Tdap during 2005-2014.

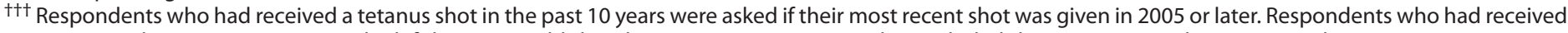

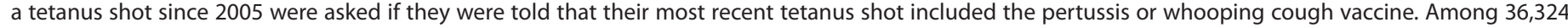

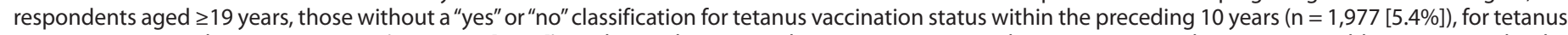

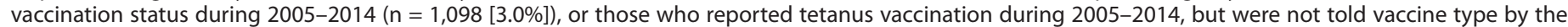

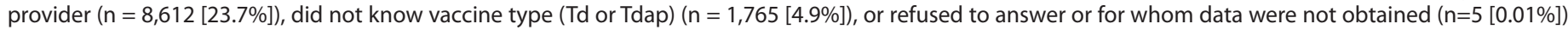

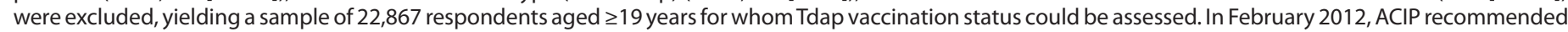
Tdap vaccination for all adults aged $\geq 19$ years, including adults aged $\geq 65$ years.

$\S \S$ Respondents were asked if they had ever received the hepatitis $A$ vaccine, and if yes, were asked how many doses were received.

ๆ ๆ Had traveled outside the United States to countries other than countries in Europe, Japan, Australia, New Zealand, or Canada since 1995.

**** Respondents were asked if they had ever received the hepatitis B vaccine, and if yes, if they had received at least 3 doses or less than 3 doses.

${ }^{++\dagger+}$ Respondents were asked if they had ever received a shingles vaccine.

$\S \S \S$ Respondents were asked if they had ever received the HPV shot or cervical cancer vaccine, and if yes, age at the first dose.

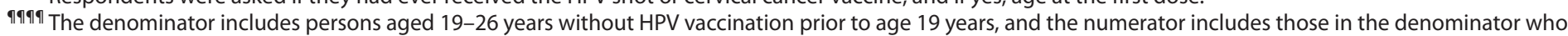
reported first HPV dose at age 19-26 years.

***** The confidence interval has not been generated because the estimate is zero. 
TABLE 9. Adjusted vaccination coverage among adults aged $\geq 19$ years, by age group, high-risk status, ${ }^{*}$ and health insurance status ${ }^{\dagger}-$ National Health Interview Survey, United States, 2014

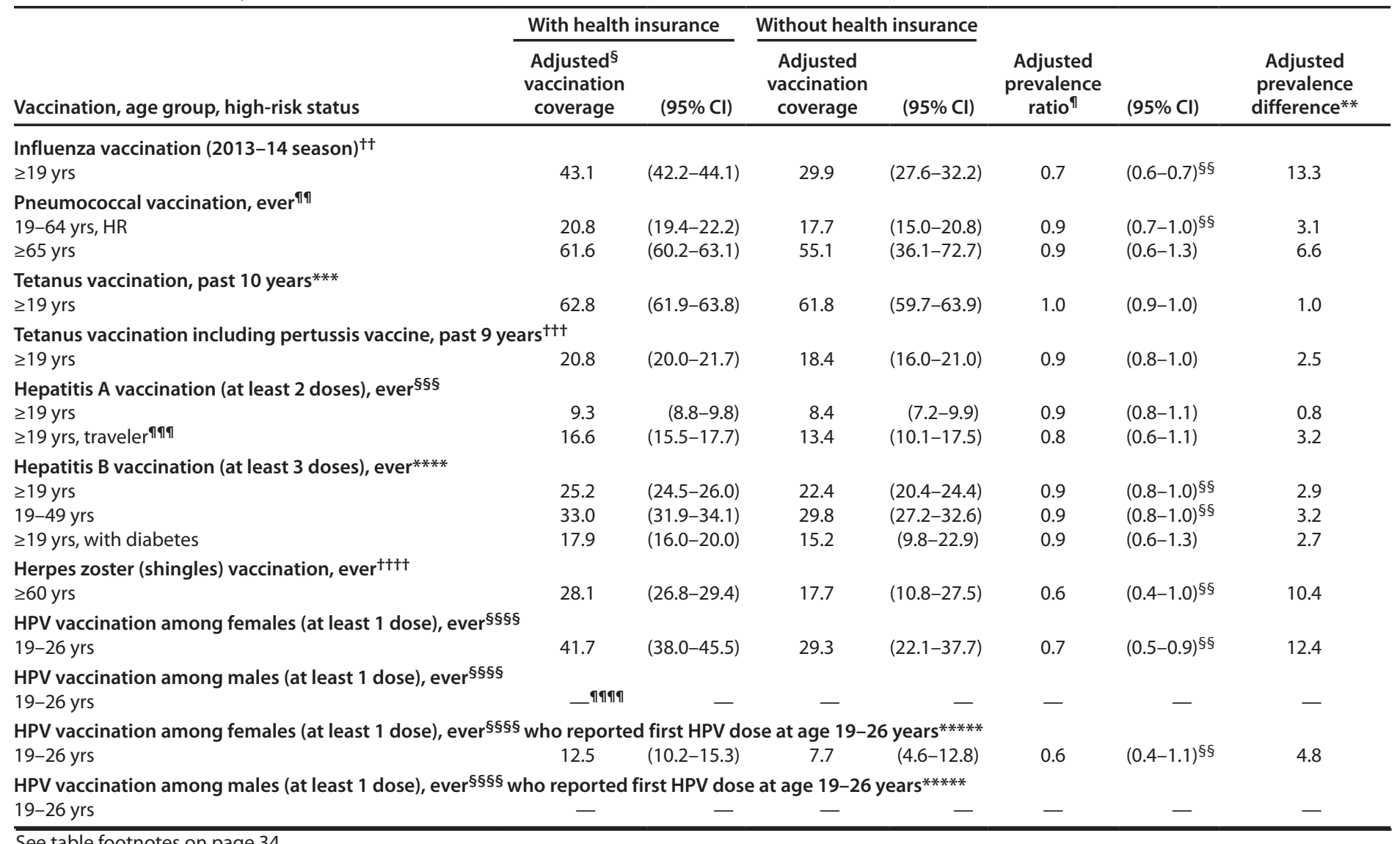


TABLE 9. (Continued) Adjusted vaccination coverage among adults aged $\geq 19$ years, by age group, high-risk status, ${ }^{*}$ and health insurance status ${ }^{\dagger}$ — National Health Interview Survey, United States, 2014

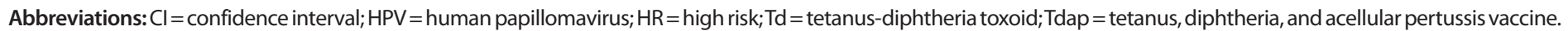

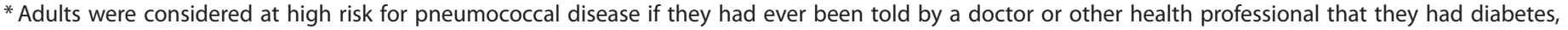

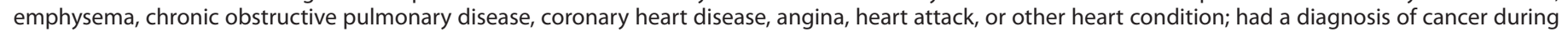

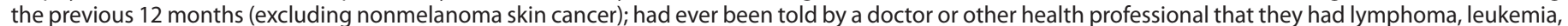

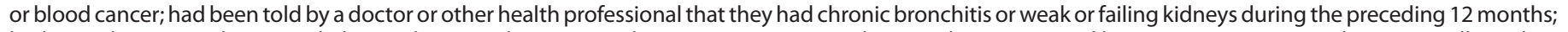

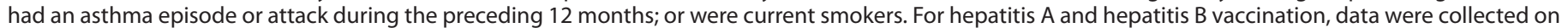

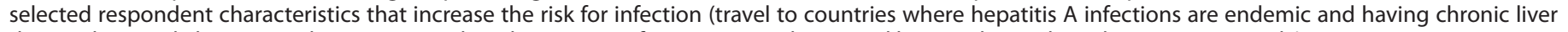
disease; having diabetes, travel to countries where hepatitis B infections are endemic, and having chronic liver disease, respectively).

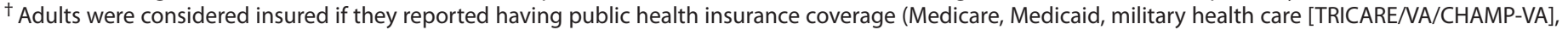
Indian Health Service, state-sponsored health plan, or other government program insurance) or private health insurance coverage.

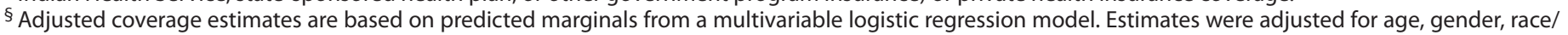

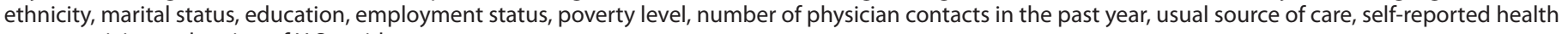
status, nativity, and region of U.S. residence.

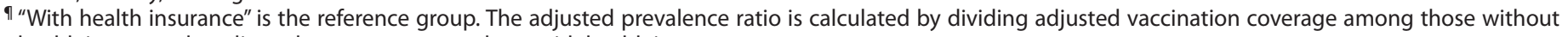
health insurance by adjusted coverage among those with health insurance.

** Adjusted coverage among those with health insurance minus adjusted coverage among those without health insurance.

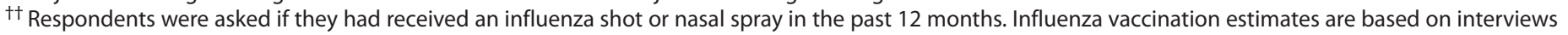
conducted during August 2013-June 2014 and vaccination received during the past 12 months.

$\S \S p<0.05$ by $T$ test comparing adjusted coverage among those with health insurance to adjusted coverage among those without health insurance.

१ी Respondents were asked if they had ever had a pneumonia shot.

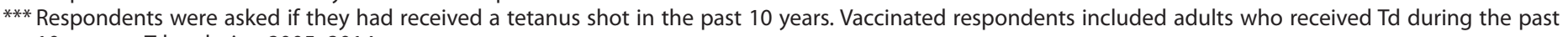
10 years or Tdap during 2005-2014.

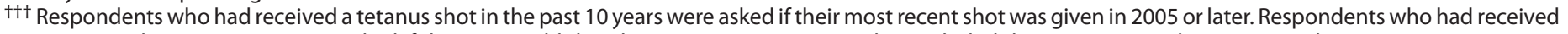

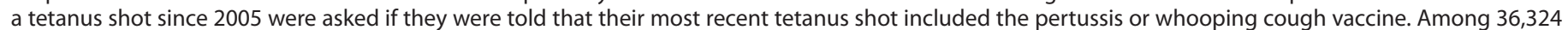

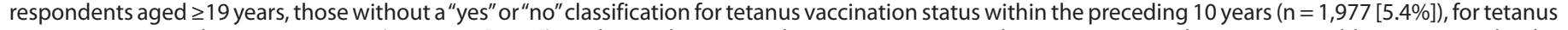

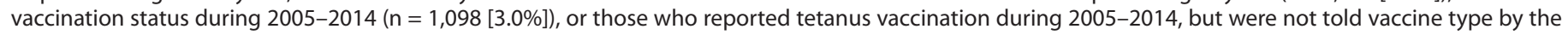

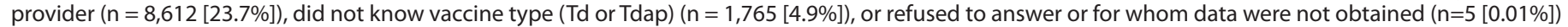

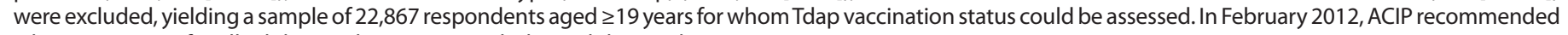
Tdap vaccination for all adults aged $\geq 19$ years, including adults aged $\geq 65$ years.

$\S \S \S$ Respondents were asked if they had ever received the hepatitis A vaccine, and if yes, were asked how many doses were received.

ๆ $ฯ$ Had traveled outside the United States to countries other than countries in Europe, Japan, Australia, New Zealand, or Canada since 1995.

**** Respondents were asked if they had ever received the hepatitis B vaccine, and if yes, if they had received at least 3 doses or less than 3 doses.

t+t+ Respondents were asked if they had ever received a shingles vaccine.

$\S \S \S \S$ Respondents were asked if they had ever received the HPV shot or cervical cancer vaccine, and if yes, age at the first dose.

ๆทાศી Sample size too small to run adjusted models.

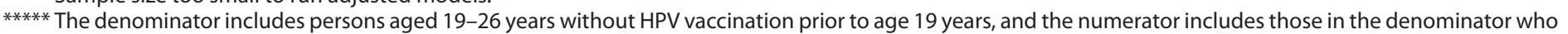
reported first HPV dose at age 19-26 years. 
TABLE 10. Estimated proportion of adults aged $\geq 19$ years who received selected vaccinations, by age group, high-risk status, ${ }^{*}$ nativity, number of years living in the United States, and citizenship - National Health Interview Survey, United States, 2014

\begin{tabular}{|c|c|c|c|c|c|c|c|c|c|c|c|c|}
\hline \multirow{3}{*}{$\begin{array}{l}\text { Vaccination, age } \\
\text { group, high-risk } \\
\text { status }\end{array}$} & \multirow{2}{*}{\multicolumn{2}{|c|}{ U.S.-born }} & \multirow{2}{*}{\multicolumn{2}{|c|}{ Foreign-born }} & \multicolumn{8}{|c|}{ Foreign-born } \\
\hline & & & & & \multicolumn{2}{|c|}{ Living in U.S. $<10 \mathrm{yrs}$} & \multicolumn{2}{|c|}{ Living in U.S. $\geq 10$ yrs } & \multicolumn{2}{|c|}{ U.S. citizen } & \multicolumn{2}{|c|}{ Non-U.S. citizen } \\
\hline & $\%$ & $(95 \% \mathrm{Cl})$ & $\%$ & $(95 \% \mathrm{Cl})$ & $\%$ & $(95 \% \mathrm{Cl})$ & $\%$ & $(95 \% \mathrm{Cl})$ & $\%$ & $(95 \% \mathrm{Cl})$ & $\%$ & $(95 \% \mathrm{Cl})$ \\
\hline \multicolumn{13}{|c|}{ Influenza vaccination (2013-14 season) ${ }^{\dagger}$} \\
\hline$\geq 19 \mathrm{yrs}$ & 44.4 & $(43.1-45.6)$ & 38.2 & $(35.9-40.6)^{\S}$ & 32.1 & $(26.9-38.0)$ & 39.8 & $(37.4-42.3)^{9}$ & 44.7 & $(41.9-47.5)$ & 30.9 & $(27.8-34.3)^{* *}$ \\
\hline $19-49$ yrs & 31.7 & $(30.2-33.3)$ & 30.4 & $(27.5-33.6)$ & 31.3 & $(25.7-37.7)$ & 30.3 & $(27.1-33.8)$ & 33.8 & $(29.7-38.2)$ & 28.1 & $(24.6-31.9)^{* *}$ \\
\hline $50-64$ yrs & 48.6 & $(46.5-50.7)^{\dagger \dagger}$ & 43.0 & $(38.6-47.7)^{\S, \dagger \dagger}$ & 36.0 & $(20.0-59.0)$ & 43.3 & $(38.8-48.1)^{\dagger \dagger}$ & 46.4 & $(40.9-52.2)^{\dagger \dagger}$ & 36.0 & $(29.0-44.0)^{* *}$ \\
\hline$\geq 65$ yrs & 72.7 & $(70.6-74.7)^{\dagger \dagger}$ & 63.8 & $(59.0-68.6)^{\S,+\dagger}$ & 38.9 & $(23.9-58.9)$ & 66.7 & $(61.9-71.6)^{9+\dagger}$ & 67.5 & $(61.9-73.1)^{\dagger \dagger}$ & 51.3 & $(41.3-62.2)^{* *,+\dagger}$ \\
\hline \multicolumn{13}{|c|}{ Pneumococcal vaccination, ever $\S^{\S}$} \\
\hline 19-64 yrs, HR & 21.1 & $(19.7-22.5)$ & 14.9 & $(12.7-17.5)^{\S}$ & 13.6 & $(8.2-21.8)$ & 15.1 & $(12.7-17.8)$ & 17.6 & $(14.1-21.7)$ & 12.2 & $(9.1-16.0)^{* *}$ \\
\hline$\geq 65 \mathrm{yrs}$ & 64.7 & $(63.3-66.2)^{\dagger \dagger}$ & 40.8 & $(37.4-44.3)^{\S, \dagger \dagger}$ & 31.8 & $(19.7-47.0)^{\dagger \dagger}$ & 41.8 & $(38.3-45.5)^{\dagger \dagger}$ & 42.2 & $(38.4-46.1)^{\dagger \dagger}$ & 35.2 & $(27.6-43.6)^{\dagger \dagger}$ \\
\hline \multicolumn{13}{|c|}{ Tetanus vaccination, past 10 years } \\
\hline$\geq 19$ yrs & 65.3 & $(64.4-66.2)$ & 48.8 & $(47.1-50.4)^{\S}$ & 47.3 & $(43.7-50.9)$ & 49.3 & $(47.4-51.2)$ & 50.9 & $(48.7-53.2)$ & 46.5 & $(44.1-48.9)^{* *}$ \\
\hline $19-49$ yrs & 66.3 & $(65.1-67.5)$ & 48.7 & $(46.6-50.9)^{\S}$ & 47.3 & $(43.5-51.2)$ & 49.5 & $(46.9-52.1)$ & 52.3 & $(48.7-56.0)$ & 46.4 & $(43.5-49.2)^{* *}$ \\
\hline $50-64$ yrs & 67.2 & $(65.6-68.8)$ & 51.5 & $(48.3-54.6)^{\S}$ & 49.5 & $(37.7-61.4)$ & 51.7 & $(48.3-55.1)$ & 54.0 & $(49.8-58.2)$ & 46.8 & $(41.3-52.3)^{* *}$ \\
\hline$\geq 65$ yrs & 59.9 & $(58.3-61.4)^{\dagger \dagger}$ & 44.5 & $(40.7-48.3)^{\S}$ & 42.0 & $(26.8-58.9)$ & 45.0 & $(41.2-49.0)$ & 43.8 & $(39.6-48.1)^{\dagger \dagger}$ & 47.8 & $(39.6-56.1)$ \\
\hline \multicolumn{13}{|c|}{ Tetanus vaccination including pertussis vaccine, past 9 years ${ }^{* * *}$} \\
\hline$\geq 19 \mathrm{yrs}$ & 22.4 & $(21.6-23.3)$ & 10.7 & $(9.5-12.0)^{\S}$ & 11.2 & $(8.9-14.0)$ & 10.6 & $(9.2-12.1)$ & 12.1 & $(10.3-14.0)$ & 9.2 & $(7.8-10.8)^{* *}$ \\
\hline $19-64$ yrs & 24.2 & $(23.2-25.2)$ & 11.2 & $(9.8-12.7)^{\S}$ & 11.3 & $(9.0-14.2)$ & 11.1 & $(9.5-12.9)$ & 13.2 & $(11.2-15.6)$ & 9.3 & $(7.9-11.1)^{* *}$ \\
\hline$\geq 65$ yrs & 15.2 & $(13.7-16.8)^{\dagger+}$ & 7.8 & $(5.7-10.7)^{\S, t \dagger}$ & $-c^{\dagger+\dagger}$ & - & 7.8 & $(5.6-10.8)^{\dagger \dagger}$ & 8.1 & $(5.7-11.5)^{\dagger \dagger}$ & - & - \\
\hline \multicolumn{13}{|c|}{ Hepatitis A vaccination (at least 2 doses), ever $§ \S \S$} \\
\hline$\geq 19 \mathrm{yrs}$ & 9.1 & $(8.6-9.6)$ & 8.3 & $(7.4-9.4)$ & 11.7 & $(9.5-14.3)$ & 7.5 & $(6.5-8.7)^{9}$ & 8.7 & $(7.4-10.2)$ & 8.0 & $(6.7-9.4)$ \\
\hline$\geq 19 \mathrm{yrs}$, traveler & 17.9 & $(16.7-19.2)$ & 11.2 & $(9.7-12.9)^{\S}$ & 13.5 & $(10.7-17.0)$ & 10.7 & $(9.1-12.5)$ & 11.8 & $(9.9-14.1)$ & 10.5 & $(8.5-12.9)$ \\
\hline \multicolumn{13}{|c|}{ Hepatitis B vaccination (at least 3 doses), ever**** } \\
\hline$\geq 19 \mathrm{yrs}$ & 25.6 & $(24.8-26.4)$ & 19.7 & $(18.4-21.2)^{\S}$ & 24.8 & $(21.8-28.0)$ & 18.7 & $(17.2-20.2)^{\natural}$ & 21.6 & $(19.7-23.7)$ & 17.7 & $(16.0-19.6)^{* *}$ \\
\hline $19-49$ yrs & 34.6 & $(33.4-35.8)$ & 23.3 & $(21.5-25.2)^{\S}$ & 25.3 & $(22.1-28.7)$ & 22.7 & $(20.7-24.8)$ & 28.7 & $(25.9-31.6)$ & 19.6 & $(17.6-21.7)^{* *}$ \\
\hline $\begin{array}{l}\geq 19 \mathrm{yrs} \text {, with } \\
\text { diabetes }\end{array}$ & 18.5 & $(16.5-20.8)$ & 14.9 & $(11.6-18.9)$ & 39.1 & $(19.8-62.4)$ & 13.5 & $(10.3-17.4)^{9}$ & 16.2 & $(12.2-21.2)$ & 12.8 & $(7.8-20.4)$ \\
\hline $\begin{array}{l}\text { 19-59 yrs, with } \\
\text { diabetes }\end{array}$ & 26.5 & $(23.1-30.2)$ & 11.6 & $(7.5-17.6)^{\S}$ & - & - & 12.5 & $(8.0-18.8)$ & 14.5 & $(8.5-23.7)$ & - & - \\
\hline $\begin{array}{l}\geq 60 \mathrm{yrs}, \text { with } \\
\text { diabetes }\end{array}$ & 12.7 & $(10.4-15.4)^{\dagger+}$ & 18.0 & $(12.8-24.6)$ & - & - & 14.4 & $(9.8-20.8)$ & 17.3 & $(11.6-25.1)$ & - & - \\
\hline
\end{tabular}

See table footnotes on page 36 . 
TABLE 10. (Continued) Estimated proportion of adults aged $\geq 19$ years who received selected vaccinations, by age group, high-risk status, ${ }^{*}$ nativity, number of years living in the United States, and citizenship - National Health Interview Survey, United States, 2014

\begin{tabular}{|c|c|c|c|c|c|c|c|c|c|c|c|c|}
\hline \multirow{3}{*}{$\begin{array}{l}\text { Vaccination, age } \\
\text { group, high-risk } \\
\text { status }\end{array}$} & \multirow{2}{*}{\multicolumn{2}{|c|}{ U.S.-born }} & \multirow{2}{*}{\multicolumn{2}{|c|}{ Foreign-born }} & \multicolumn{8}{|c|}{ Foreign-born } \\
\hline & & & & & \multicolumn{2}{|c|}{ Living in U.S. $<10$ yrs } & \multicolumn{2}{|c|}{ Living in U.S. $\geq 10 \mathrm{yrs}$} & \multicolumn{2}{|c|}{ U.S. citizen } & \multicolumn{2}{|c|}{ Non-U.S. citizen } \\
\hline & $\%$ & $(95 \% \mathrm{Cl})$ & $\%$ & $(95 \% \mathrm{Cl})$ & $\%$ & $(95 \% \mathrm{Cl})$ & $\%$ & $(95 \% \mathrm{Cl})$ & $\%$ & $(95 \% \mathrm{Cl})$ & $\%$ & $(95 \% \mathrm{Cl})$ \\
\hline \multicolumn{13}{|c|}{ Herpes zoster (shingles) vaccination, ever ${ }^{+t+\dagger}$} \\
\hline$\geq 60 \mathrm{yrs}$ & 30.0 & $(28.6-31.4)$ & 15.2 & $(13.1-17.6)^{\S}$ & - & - & 15.5 & $(13.3-18.0)$ & 17.1 & $(14.5-19.9)$ & 8.5 & $(5.5-13.0)^{* *}$ \\
\hline \multicolumn{13}{|c|}{ HPV vaccination among females (at least 1 dose), ever ${ }^{\S \S \S \S ~}$} \\
\hline $19-26$ yrs & 43.2 & $(39.0-47.4)$ & 18.6 & $(13.9-24.4)^{\S}$ & 15.7 & $(9.4-25.0)$ & 21.8 & $(14.7-31.2)$ & 25.2 & $(16.1-37.3)$ & 15.2 & $(9.6-23.3)$ \\
\hline \multicolumn{13}{|c|}{ HPV vaccination among males (at least 1 dose), ever ${ }^{\S \S \S \S ~}$} \\
\hline $19-26$ yrs & 8.5 & $(6.7-10.8)$ & 6.8 & $(3.8-11.8)$ & - & - & - & - & - & - & - & - \\
\hline \multicolumn{13}{|c|}{ HPV vaccination among females (at least 1 dose), ever ${ }^{\S \S \S \S}$ who reported first HPV dose at age $19-26$ years } \\
\hline $19-26$ yrs & 13.0 & $(10.6-15.9)$ & 5.2 & $(3.0-9.0)^{\S}$ & - & - & - & - & - & - & - & - \\
\hline \multicolumn{13}{|c|}{ HPV vaccination among males (at least 1 dose), ever ${ }^{\S \S \S \S}$ who reported first HPV dose at age $19-26$ years } \\
\hline $19-26$ yrs & 2.4 & $(1.5-3.7)$ & - & - & - & - & - & - & - & - & - & - \\
\hline
\end{tabular}

Abbreviations: $\mathrm{Cl}=$ confidence interval; $\mathrm{HPV}=$ human papillomavirus; $\mathrm{HR}=$ high risk; $\mathrm{Td}=$ tetanus-diphtheria toxoid; Tdap = tetanus, diphtheria, and acellular pertussis vaccine.

* Adults were considered at high risk for pneumococcal disease if they had ever been told by a doctor or other health professional that they had diabetes, emphysema, chronic obstructive pulmonary disease, coronary heart disease, angina, heart attack, or other heart condition; had a diagnosis of cancer during the previous 12 months (excluding nonmelanoma skin cancer); had ever been told by a doctor or other health professional that they had lymphoma, leukemia, or blood cancer; had been told by a doctor or other health professional that they had chronic bronchitis or weak or failing kidneys during the preceding 12 months; had an asthma episode or attack during the preceding 12 months; or were current smokers. For hepatitis A and hepatitis B vaccination, data were collected on selected respondent characteristics that increase the risk for infection (travel to countries where hepatitis A infections are endemic and having chronic liver disease; having diabetes, travel to countries where hepatitis B infections are endemic, and having chronic liver disease, respectively).

${ }^{\dagger}$ Respondents were asked if they had received an influenza shot or nasal spray in the past 12 months and if so, in which month and year. Missing month and year were imputed (3.1\%), and interviews from August 2013-June 2014 were used to estimate vaccination coverage during July 2013-May 2014 using Kaplan-Meier survival analysis.

$\S p<0.05$ by T test for comparisons between U.S. born and foreign born.

9 $p<0.05$ by $T$ test for comparisons between those living in the U.S. $<10$ years and those living in the United States $\geq 10$ years.

** $p<0.05$ by $T$ test comparing U.S. citizens and non-U.S. citizens.

${ }^{+\dagger} p<0.05$ by $T$ test comparing persons aged $50-64$ years and aged $\geq 65$ years with persons 19-49 years for influenza; persons aged 19-64 years with high-risk conditions with persons aged $\geq 65$ years for pneumococcal; persons aged 50-64 years and aged $\geq 65$ years with persons aged 19-49 years for tetanus; persons aged 19-64 years with persons aged $\geq 65$ years for Tdap; and persons aged 19-59 years with diabetes with persons aged $\geq 60$ years with diabetes for hepatitis B.

$\S \S$ Respondents were asked if they had ever had a pneumonia shot.

กा Respondents were asked if they had received a tetanus shot in the past 10 years. Vaccinated respondents included adults who received Td during the past 10 years or Tdap during 2005-2014.

*** Respondents who had received a tetanus shot in the past 10 years were asked if their most recent shot was given in 2005 or later. Respondents who had received a tetanus shot since 2005 were asked if they were told that their most recent tetanus shot included the pertussis or whooping cough vaccine. Among 36,324 respondents aged $\geq 19$ years, those without a "yes" or "no" classification for tetanus vaccination status within the preceding 10 years ( $n=1,977$ [5.4\%]), for tetanus vaccination status during 2005-2014 ( $n=1,098$ [3.0\%]), or those who reported tetanus vaccination during 2005-2014, but were not told vaccine type by the provider $(n=8,612[23.7 \%])$, did not know vaccine type (Td or Tdap) $(n=1,765[4.9 \%])$, or refused to answer or for whom data were not obtained $(n=5[0.01 \%])$ were excluded, yielding a sample of 22,867 respondents aged $\geq 19$ years for whom Tdap vaccination status could be assessed. In February 2012, ACIP recommended Tdap vaccination for all adults aged $\geq 19$ years, including adults aged $\geq 65$ years.

${ }^{t+\dagger}$ Estimate is not reliable due to small sample size $(\mathrm{n}<30)$ or relative standard error (standard error/estimates) $>0.3$.

$\S \S$ Respondents were asked if they had ever received the hepatitis A vaccine, and if yes, were asked how many doses were received.

ๆ ศ $\mathrm{Had}$ traveled outside the United States to countries other than countries in Europe, Japan, Australia, New Zealand, or Canada since 1995.

**** Respondents were asked if they had ever received the hepatitis B vaccine, and if yes, if they had received at least 3 doses or less than 3 doses.

${ }^{t+t \dagger}$ Respondents were asked if they had ever received a shingles vaccine.

$\S \S \S \S$ Respondents were asked if they had ever received the HPV shot or cervical cancer vaccine, and if yes, age at the first dose.

ๆศศๆ The denominator includes persons aged 19-26 years without HPV vaccination prior to age 19 years, and the numerator includes those in the denominator who reported first HPV dose at age 19-26 years. 

The Morbidity and Mortality Weekly Report (MMWR) Series is prepared by the Centers for Disease Control and Prevention (CDC) and is available free of charge in electronic format. To receive an electronic copy each week, visit MMWR's free subscription page at http://www.cdc.gov/mmwr/mmwrsubscribe.html. Paper copy subscriptions are available through the Superintendent of Documents, U.S. Government Printing Office, Washington, DC 20402; telephone 202-512-1800.

Readers who have difficulty accessing this PDF file may access the HTML file at http://www.cdc.gov/mmwr/volumes/65/ss/ss6501a1.htm?s_cid=ss6501a1_w. Address all inquiries about the $M M W R$ Series, including material to be considered for publication, to Executive Editor, MMWR Series, Mailstop E-90, CDC, 1600 Clifton Rd., N.E., Atlanta, GA 30329-4027 or to mmwrq@cdc.gov.

All material in the MMWR Series is in the public domain and may be used and reprinted without permission; citation as to source, however, is appreciated. Use of trade names and commercial sources is for identification only and does not imply endorsement by the U.S. Department of Health and Human Services.

References to non-CDC sites on the Internet are provided as a service to $M M W R$ readers and do not constitute or imply endorsement of these organizations or their programs by CDC or the U.S. Department of Health and Human Services. CDC is not responsible for the content of these sites. URL addresses listed in $M M W R$ were current as of the date of publication.

ISSN: 1546-0738 (Print) 